\title{
WestVirginiaUniversity
}

THE RESEARCH REPOSITORY @ WVU

Graduate Theses, Dissertations, and Problem Reports

2005

\section{Shared decision-making and its impact on inclusion for special needs students}

Deborah E. Kuhns

West Virginia University

Follow this and additional works at: https://researchrepository.wvu.edu/etd

\section{Recommended Citation}

Kuhns, Deborah E., "Shared decision-making and its impact on inclusion for special needs students" (2005). Graduate Theses, Dissertations, and Problem Reports. 2651.

https://researchrepository.wvu.edu/etd/2651

This Dissertation is protected by copyright and/or related rights. It has been brought to you by the The Research Repository @ WVU with permission from the rights-holder(s). You are free to use this Dissertation in any way that is permitted by the copyright and related rights legislation that applies to your use. For other uses you must obtain permission from the rights-holder(s) directly, unless additional rights are indicated by a Creative Commons license in the record and/ or on the work itself. This Dissertation has been accepted for inclusion in WVU Graduate Theses, Dissertations, and Problem Reports collection by an authorized administrator of The Research Repository @ WVU.

For more information, please contact researchrepository@mail.wvu.edu. 


\title{
Shared Decision-Making and Its Impact on Inclusion for Special Needs Students
}

Deborah E. Kuhns

\author{
Dissertation submitted to the \\ College of Human Resources and Education \\ at West Virginia University \\ in partial fulfillment of the requirements \\ for the degree of
}

\author{
Doctor of Education \\ in \\ Educational Leadership \\ Paul E. Chapman, Chair \\ David L. McCrory \\ John G. Wells \\ Jaci L. Webb-Dempsey \\ Sebastian R. Diaz \\ Department of Advanced Studies
}

Morgantown, West Virginia

2005

Keywords: Shared Decision-Making, Inclusion, Collaboration, Modifications, Disabilities Copyright 2005 Deborah E. Kuhns 


\section{ABSTRACT \\ Shared Decision-Making and Its Impact on Inclusion for Special Needs Students}

Deborah E. Kuhns

Shared decision-making is a style of leadership that affords ownership, empowerment, and being part of a team that can make a difference. When the Individuals with Disabilities Education Act (IDEA) required a committee to develop an Individualized Education Program, inclusion was considered in order to provide the least restrictive environment within which the student could make progress in a school setting. When the regular classroom teachers feel that they help to make decisions for inclusion of children in their classrooms, does it impact their implementation of inclusion? Regular classroom teachers were interviewed for this case study to determine how shared decision-making involves them and resolves barriers of inclusion for special needs students when teachers are involved in the process. 


\section{Dedication}

To my parents, who gave me the desire to learn. To my husband, who is my mentor, my colleague, and my friend. To my children, who are living proof that miracles happen. 


\section{Acknowledgements}

I am thankful to the committee at West Virginia University that supported me through this project and treated me as a colleague rather than a student: Doctors David McCrory, John Wells, Jaci Webb-Dempsey, Sebastian Diaz, and to Doctor William Deaton who began the project with us. I am especially grateful for my Chairman, Doctor Paul Chapman, for his energy and positive attitude that always makes everything seem possible.

I appreciate the cooperation by the county and school staff who entrusted me with their perceptions and knowledge. Their dedication to children is evident in their responses.

I have personally been blessed with children who constantly encourage my abstractions and a husband who supports my convictions, and I am grateful for such sustenance in my life. 
Table of Contents

Page

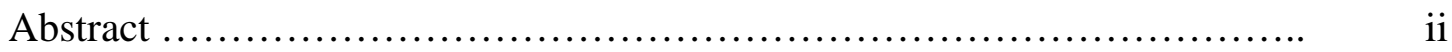

Dedication.......................................................... iii

Acknowledgements.................................................... iv

Table of Contents................................................ $\quad \mathrm{V}$

List of Tables........................................................ xi

List of Figures.................................................. xii

CHAPTER 1 - INTRODUCTION........................................ 1

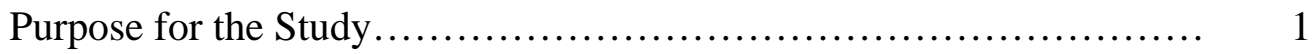

Relevance.................................................... 1

The Research Question........................................... 4

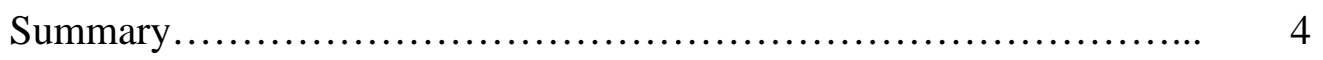

CHAPTER 2 -REVIEW OF RELATED LITERATURE...................... 7

The Meaning of Inclusion...................................... 7

Implementing the Law....................................... 9

Controversy about Inclusion.................................. 10

Barriers to Inclusion................................... 11

One Study Concerning Implementing Testing Modifications...... 13

Implementation of Inclusion for Instruction....................... 17

Leadership................................................. 20

Collaboration........................................... 20

Shared Decision-Making: A Study of Principals’ Beliefs........ 22

Shared Decision-Making and Teamwork.................... 26 


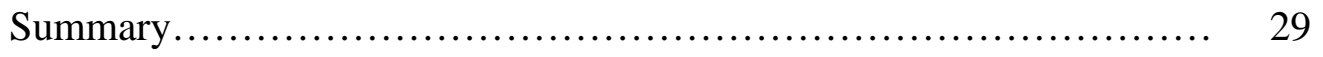

CHAPTER 3 - METHOD ............................................. 31

Participants............................................... 33

Apparatus.................................................... 36

Procedure..................................................... 38

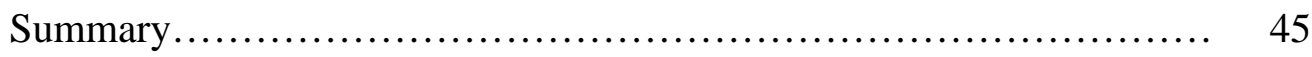

CHAPTER 4 - RESULTS.............................................. 46

Overview of County's Inclusion................................. 46

Overview of School............................................ 48

Opportunities for Shared Decision-Making....................... 50

Description of Teachers and Classrooms.......................... 52

Preschool Teacher.......................................... 52

Kindergarten Teacher..................................... 54

First-Grade Teacher....................................... 55

Second-Grade Teacher................................... 56

Third-Grade Teacher.................................... 58

Fourth-Grade Teacher...................................... 59

Analysis of IEP Modifications.................................. 60

Preschool IEP Modifications............................... 60

Kindergarten IEP Modifications............................ 63

First-Grade IEP Modifications............................ 65

Second-Grade IEP Modifications........................... 67

Third-Grade IEP Modifications............................. 70 
Fourth-Grade IEP Modifications......................... 72

Relationship Between Modifications and Interview Questions.......... 75

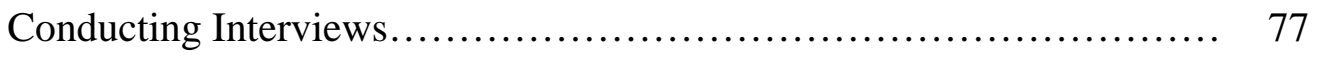

Impact of Shared Decision-Making on Inclusion.................... 77

At SAT and IEP Meetings............................... 78

Through Collaboration..................................... 80

By Services for Students............................... 80

Resolves Barriers...................................... 81

Barriers to Inclusion.......................................... 82

Scheduling............................................. 82

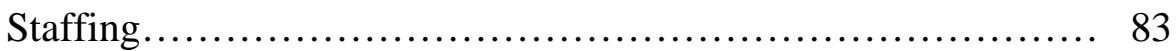

Responsibilities......................................... 83

Environment.......................................... 84

Curriculum............................................. 85

Modifications........................................... 86

Behavior.................................................. 86

Emotional.............................................. 87

Training............................................. 87

Collaboration.......................................... 88

Regular Educators Included in Shared Decision-Making for Inclusion..... 92

Emergent Themes............................................. 94

Positive Shared Decision-Making........................... 94

Positive Inclusion......................................... 94 
Modifications.................................................. 95

Principal.................................................... 95

Ways to Help Students....................................... 95

Lack of Training.......................................... 96

More Time to Collaborate...................................... 96

Attitudes.................................................... 96

Concerns about Students in Classrooms........................ 97

Scheduling................................................ 97

Regular Educators to Collaborate.............................. 97

Need for More Staffing..................................... 98

Physical Environment...................................... 98

CHAPTER 5 - DISCUSSION............................................... 101

Shared Decision-Making Impacting Inclusion......................... 101

Shared Decision-Making Resolving Barriers for Inclusion............... 102

Regular Educators Included in the Decision-Making Process............. 104

Implications for the School........................................ 104

Implications for the County..................................... 106

Implications for the State....................................... 106

Suggestions for Replicating the Study.............................. 107

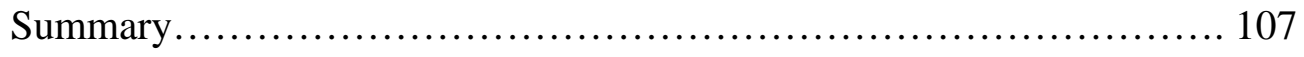

References............................................................. 110

Appendix A: Letter to Superintendent.......................................... 121

Appendix B: One-question Questionnaire to Teachers..........................122 
Appendix C: Informational Letter to Teachers........................... 123

Appendix D: Summary Sheet (Log) for Individualized Education Program........ 124

Appendix E: Letter to Principal...................................... 125

Appendix F: IEP Document Analysis Protocol........................... 126

Appendix G - Table G1: Relationship Between Modifications \& Interview

Questions....................................... 128

Appendix H - Table H1: Preschool - The Impact of Shared Decision-Making on

Inclusion........................................ 131

Appendix H - Table H2: Kindergarten - The Impact of Shared Decision-Making

on Inclusion.................................. 133

Appendix H - Table H3: First Grade - The Impact of Shared Decision-Making

on Inclusion....................................

Appendix H - Table H4: Second Grade - The Impact of Shared Decision-Making

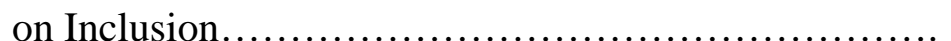

Appendix H - Table H5: Third Grade - The Impact of Shared Decision-Making on Inclusion.

Appendix H - Table H6: Fourth Grade - The Impact of Shared Decision-Making on Inclusion.

Appendix I - Table I1: Barriers to Inclusion by Category......................

Appendix J - Table J1: Regular Educators Included in Shared Decision-Making for Inclusion.

Appendix K - Table K1: Positive Indications of Inclusion and Shared 
Appendix L - Table L1: Emergent Themes in Order by Number of Teachers

Responding to Each Theme......................... 150

Appendix M - Approval ............................................. 153

Appendix N - Vita..................................................... 154 
List of Tables

Page

Table 1. Timetable for Study.......................................... 39

Table 2. Protocol of Interview Questions.................................. 42

Table 3. IEP Document Analysis Protocol - Preschool......................... 62

Table 4. IEP Document Analysis Protocol - Kindergarten....................... 64

Table 5. IEP Document Analysis Protocol - First.............................. 66

Table 6. IEP Document Analysis Protocol - Second........................... 68

Table 7. IEP Document Analysis Protocol - Third........................... 71

Table 8. IEP Document Analysis Protocol - Fourth.......................... 73

Table 9. Common Modifications....................................... 76

Table 10. How Shared Decision-Making Impacts Inclusion..................... 79

Table 11. Examples of How Shared Decision-Making is Resolving These Barriers for Inclusion....................................................... 91 


\section{List of Figures}

Page

Figure 1. Barriers to Inclusion............................................ 90

Figure 2. How Regular Educators are Included in Shared Decision-Making for

Inclusion by Grade Levels.......................................... 93

Figure 3. Emergent Themes.................................................. 99 


\section{CHAPTER 1}

\section{INRODUCTION}

Purpose for the Study

A central component of school improvement is the idea of shared decisionmaking (Glickman, 1993). While shared decision-making goes by many names, such as school-based management, shared governance, site-based management, and collaboration, the rationale is that a group of interested stakeholders will decide, share and reflect together as a team (Sergiovanni, 1994). Special education is one area requiring team decisions. When President Clinton signed the Individuals with Disabilities Education Act (IDEA) in 1997, the goal was to strengthen academic expectations and accountability for children with disabilities. Another purpose for IDEA was to bridge the gap that often exists between the regular curriculum and what special education students learn (Smith, 1999) so that all students could benefit from classroom instruction. Knowing whether there are barriers to shared decision-making and how collaboration is working will help to determine if inclusion is being implemented in a way that benefits special needs students.

\section{Relevance}

Educators have attempted to comply with the mandates in the Education for All Handicapped Children Act (P.L. 94-142) since it was signed into law by President Ford in 1975. The interpretation of the concept of inclusion for a free and appropriate public education in the least restrictive environment has been varied, which has led to inconsistencies for providing beneficial services to students identified as disabled. Renaming the act to Individuals with Disabilities Education Act (IDEA) in 1990 entitled 
students with disabilities to the same access to public education. The addition of amendments in 1997 to IDEA entitled students with disabilities to participation and progress within the general education curriculum.

When P.L. 94-142 was being deliberated, Congress declared that all students can benefit from education (Smith, 1999). With the IDEA amendments, Congress further declared that students with disabilities can learn what non-disabled students learn, and that the outcomes of their learning are to be incorporated with the overall results of a school, county, and state. If the students with disabilities are held to standards consistent with all other students, then the curriculum must be aligned with that instructed to all other students. Although this curriculum may be taught with modifications and accommodations, the special needs students are to be given the same opportunities for participating in this instruction with age-appropriate peers.

Regardless, many of our children are still failing to achieve real participation and progress (Hitchcock, Meyer, Rose \& Jackson, 2002). Hitchcock et al. (2002) explains that equal rights of students with disabilities cannot be guaranteed by merely physically placing students in a classroom beside same-age peers. These researchers suggest that a curriculum designed to be accessible and supportive from the beginning will improve learning opportunities.

Although the term "inclusion" does not appear in the law, the concept of teamwork is part of the requirements by requiring that a committee must make the decision for identifying and initially placing and determining services within the least restrictive environment for a student in special education. P.L. 94-142 emphasizes the importance of the collaborative process through multidisciplinary and Individualized 
Education Program (IEP) teams. Professionals (teachers who are familiar with the general education curriculum, administrators, school psychologists, and counselors), related service providers, parents, family members, and the student are invited to be part of the team. Team members utilize all the resources and knowledge of their colleagues when making recommendations for improving educational outcomes for students with disabilities.

Therefore, the emphasis on teamwork is not only encouraged, it is mandated as part of P.L. 94-142. It takes a team approach to determine the educational needs of a student and how those needs will be addressed on an IEP, and what modifications to the regular classroom are necessary for that child to experience success while being educated for even part of the day with age-appropriate, non-disabled, peers.

Jean Crockett and James Kauffman (1999) believe that for students with disabilities to be served well in inclusive settings the regular education teacher must be supportive of the principles and challenges of teaching them. In a study conducted by Scruggs and Mastropieri (1996), 9,772 teachers were asked about their attitudes toward mainstreaming children with disabilities. The willingness of these educators to include disabled students in their classrooms increased as the amount of classroom assistance required for the students decreased. When asked, among other requests, most teachers wanted personnel support and more time for collaborating with support staff.

Educators collaborating together to discuss possible ways to implement inclusion can generate support for the idea of inclusion. Shared decision-making provides opportunities to work collaboratively, gives participants a sense of ownership (Chernow \& Chernow, 1992), and allows room for changes to occur. Steve Parson (1999) believes 
that people will change when their opinions count. If educators realize that they have a voice in how to implement inclusion, it might be possible that the barriers to integrating special needs students into the regular classroom could be diminished or eliminated. Identifying those barriers in one school could provide insight into whether shared decision-making makes a difference for including special needs students in that school.

\section{The Research Question}

It then becomes important for the benefit of students to answer this question: How can shared decision-making impact the process of inclusion for special needs students? Attempting to find answers to this question leads to two others as subsets to the research question: (a) How can shared decision-making resolve barriers for inclusion?

(b) How are regular educators included in the decision-making process when it comes to inclusion of special needs students in their classrooms?

\section{Summary}

Some of the barriers to inclusion continue to demonstrate that the physical presence of special needs students within the regular classroom is not enough to assure learning. There continues to be time constraints that inhibit special education teachers and general educators from planning instruction together (Martin, 1995). Teachers may have more than five grade levels of instruction represented in their classrooms (Fuchs, Fuchs, Hamlett, Phillips, \& Bentz, 1994). Gottlieb, Alter, Gottlieb, and Wishner (1994) found that only $16 \%$ of teachers in their study indicated that they could be trained with the necessary skills to keep these children in their classes, and only $10 \%$ presented activities that could be considered to be adaptations to the curriculum. While it may appear that teachers are reluctant to have special needs students in their classrooms 
(Scruggs \& Mastropieri,1996), it is actually because teachers feel unprepared to deal with their needs (Roberts \& Mather, 1995).

Gajria, Salend, and Hemrick (1994) suggested that teacher acceptability, or whether a practice is consistent with their teaching style, determines whether a classroom teacher uses a specific strategy. In some cases, the modifications in the student's IEP are not implemented if they are not commensurate with what the teacher wants to utilize in his or her classroom. Adapting regular materials, using alternative materials, modifying grading criteria, and providing individualized instruction were all considered to be less desirable and feasible by general education teachers, as determined by Vaughn and Schumm (1996). They concluded "teachers are willing to make accommodations that demonstrate acceptance of the student . . . but less willing to make adaptations that require planning, instructional, or environmental adaptations” (p. 109). In this same study it was reported that teachers' beliefs about instruction focus on meeting the needs of the class as a whole rather than on implementing specific instructional practices that will meet the needs of target students.

Using shared decision-making places the emphasis on collaboration, consensus surrounding goals, and shared responsibility (Wasley, 1994). By collaborating, teachers can begin to share the responsibility of educating all students within their classrooms that will lead to better learning and more successful inclusion. When a person has participated in decisions, there is a greater personal stake in seeing those decisions succeed (Rothstein, 1990). Providing classroom teachers with opportunities for participating in shared decision-making concerning inclusion could benefit special needs students in 
regular education classes. Determining whether shared decision-making is occurring for inclusion of special needs students in one school is a purpose of this case study. 


\section{CHAPTER 2}

\section{REVIEW OF RELATED LITERATURE}

At the heart of both inclusion and shared decision-making is the idea that people being aware of other people's concerns and feelings can create new possibilities of hope for individuals with disabilities. Both of these educational reforms were initiated by committed people and are representative of changes in the way members of society interact toward each other. Although inclusion and shared decision-making have had various definitions and meanings from their inceptions, they can both generate the capability within us to agree with Richard W. Riley, U.S. Secretary of Education in 1995, when he said in a speech to the National Catholic Educators Association, "The children we are educating are the seeds of greatness for the America we love....They all have potential” (p. 5).

Looking at whether or not students with disabilities have the opportunities to achieve their full potential while being included within regular education classrooms in one rural elementary school is another purpose of this case study. Whether shared decision-making is working to help the implementation of inclusion creates another factor to be determined.

\section{The Meaning of Inclusion}

Arriving at a definition for inclusion that is acceptable for all concerned has presented both controversy and compromise. Crockett and Kauffman (1999) explain inclusion as a term that most often describes the placement of a student, regardless of the level of his or her disability, into an age-appropriate general education classroom in the local community school. A similar definition was proposed by Wang (1994) when she 
described inclusion as bringing children who are disabled out of their special classes and into the regular school environment and reducing special education referrals and labels by strengthening regular school programs. Villa and Thousand (2003) describe inclusion as the principle and practice of considering general education as the placement of first choice for all learners, which encourages educators to bring support and services for the students into the classroom.

Baker and Zigmond (1995) determined that inclusion had different meanings for different people, although a common thread that they observed was that inclusion described a "place" for a child to sit in a general education classroom to participate in the general education instructional program. They further discovered that inclusion also meant bringing the special education teacher into the regular classroom to help make inclusion work. Shepherd and Brown (2003) tend to agree with this definition when defining inclusion as providing the necessary support to promote the learning of every student in the regular education classroom after a special education referral. While the Individuals with Disabilities Education Act (IDEA) does not require inclusion to always be the result of an Individualized Education Program (IEP), it requires an IEP team to determine the least restrictive environment for the child (Setout, 2001).

Although Congress pointed out in the reauthorized IDEA of 1997 that special education should be understood as a service and not a place, common factors that appear to be considered relevant in definitions become location for inclusion and providing necessary support when special education students are within the regular classroom. However, Nolet and McLaughlin (2000) caution implementers of inclusion that access to the general education classroom means more than simply being present. Observations of 
classroom practice have suggested that the education received by many students with disabilities does not take advantage of knowledge that has been determined about effective teaching practices (Kauffman, 1996). There is an opportunity with inclusion to open up general education classrooms to a wider variety of learning modes and styles than has characterized past practices. Such attempts are resisted, however, according to Erickson (1996), because the pressures are still intense toward the direction of teaching to students who achieve above the middle level. Implementing inclusion does not mean that all students must be placed in any specific setting. However, providing individualized instruction means that each student must be looked at as an individual when determining services and modifications. While accommodations matter for students, learning is what counts. All students need to be able to demonstrate mastery, not just exposure. Finding the best way to make this happen in every setting is a challenge still facing educators.

Implementing the Law

The passage of the Education of All Handicapped Children Act in 1975 ensured children with disabilities the right to attend public schools. It granted all children the right to a free appropriate public education. The passage of IDEA in 1990 further granted children with disabilities not just the right to be educated in the public schools, but to have the right to an education in the least restrictive environment (LRE). When IDEA was amended in 1997, it was designed to merge special education with whole-school reform that made schools accountable for the educational outcomes of every student. Whole-school reform is compatible with inclusive practices since both embrace staff collaboration, shared decision-making, and a focus on student outcomes (Wahl \& Hehir, 2000). 
The Amendments to the Individuals with Disabilities Act were "designed to strengthen academic expectations and accountability for our nation's 5.4 million students receiving special education services and to reduce barriers that keep them from receiving most, if not all, of their education in general classes” (Lombardi, 1999, p. 93). Recognizing the complexity of managing the changes necessary for responsible inclusion, Lombardi (1999) wrote the following:

It involves having a vision, skills, incentives, resources, and a plan of action. Without a vision, there is confusion. Without the skills, there is anxiety. Without incentives, the change process will be undermined. Without resources, there will be frustration. And without a plan of action, there will be many false starts. (p. 93)

In the years since the development of IDEA, students have been provided with access to education in a public school setting within the regular classroom. However, making education lead to growth in student achievement for special needs children has proven more difficult. Strategies, accommodations, interventions, and modifications are just a few of the terms that are used to imply that all children will learn in general education. Despite efforts toward inclusion, various problems exist with implementing it, which include lack of training for teachers and lack of administrative support (Crockett \& Kauffman, 1998). Some research (Salend \& Duhaney, 1999) has even shown that students with disabilities do not benefit from inclusion.

Controversy about Inclusion One of the areas of misconception regarding inclusion is, if the interpretation of inclusion is that all students are to be included into the regular classroom, and all students 
can be taught and can learn in the same way, then the implication is that placement of children in general education means that they no longer need to be instructed in individual ways. An oxymoron therefore seems to exist between implementing inclusion and providing special education services.

In a study conducted by Schumm and Vaughn (1992), teachers in the general education classroom rarely used the special education student's individualized educational program (IEP). The IEP provides the guidelines and a means of measuring success of services and academic growth for special education students in the regular classroom. Martin (1995) expressed concerns about inclusion programs that offer less individualized instruction to children and are not determined by objective outcome measures and scientific evidence. As Director of the Federal Bureau of Education for the Handicapped (BEH) at the time that P.L. 94-142 was drafted, Edwin W. Martin encouraged continual measurement of its effectiveness. However, Roberts and Mather (1995) suggested that there is little evidence of a relationship between IEP goals and subsequent instruction within the general education curriculum. P.L. 94-142 mandates that the IEP itself should be a team effort.

\section{Barriers to Inclusion}

Nolet and McLaughlin (2000) recommend that all teachers become skilled at making accommodations in order to be able to demonstrate that all students can make meaningful progress in the general curriculum. However, in a study by Scruggs and Mastropieri (1996), teachers surveyed responded that they lacked the skills or training to modify instruction as well as lacking the time and resources. According to Crockett and Kauffman (1998), educators fear a loss of equity for students with disabilities unless they 
are provided with appropriate curriculum and instruction, supportive peer and teacher interactions, and suitable organization and management of their educational environments. One of the contributing factors to the needs of general educators is that the least restrictive environment (LRE) for learning will vary from student to student and often from time to time for a particular student (Crockett \& Kauffman, 1999). In addition, administrators' skills, knowledge, and understanding are challenged as they attempt to accommodate increasing numbers of students with disabilities into general education classrooms. Administrators must cope with their own and their faculty's lack of preparation for educating students with special needs (Scruggs \& Mastropieri, 1996).

Bateman (1992) explains that there are too few teachers adequately trained in effective teaching strategies and that most curricular materials are inadequately designed for use with low performing children. She also expresses concern that children with disabilities are included in general education with no expectation that they perform at grade level and with nothing near the support that would be essential for increasing their chances of performing near that level.

Despite the continued evolution toward inclusive education, many disparities exist among schools and even states concerning implementation. The U.S. Department of Education (2003) found that the percentage of students with disabilities ages 6-21 who were taught for 80 percent or more of the school day in general education classrooms ranged from 18 percent in Hawaii to 82 percent in Vermont. In some schools the mere physical presence of students with disabilities in regular classrooms is considered inclusion. In other schools inclusion means active modification of content, instruction, and assessment practices so that students can successfully engage in academic 
experiences and learning (Villa \& Thousand, 2003).

\section{One Study Concerning Implementing Testing Modifications}

Gajria, Salend, and Hemrick (1994) conducted a study that examined teachers’ judgements concerning the testing modifications for students identified as learning disabled and included in general educational settings in high schools.

Purpose. The purpose of this study was to assess general education teachers' perceptions concerning the acceptability of testing modifications for included special education students. Prior to their study there was limited data on the acceptability and use of specific testing accommodations for included special education students, although previous studies had indicated that some classroom teachers adapted tests by reading test directions, using oral tests and accepting oral responses, allowing separate testing locations, simplifying response formats, dividing tests into sections, and allowing use of class notes during testing. However, there were no studies that examined regular classroom teachers’ perceptions and use of test design modifications, which is considered critical in the successful inclusion of students with disabilities (Salend, 1994). Gajria, et al. (1994) considered it important to gather information on factors that influence teachers' decisions to make test design adaptations that facilitate the success of included students. This was achieved by assessing teachers’ judgements concerning the acceptability of a variety of testing content and format modifications.

The purpose of their study was to address these research questions:

1. Are general education teachers familiar with testing modifications for included special education students?

2. What are the testing modifications that general education teachers use? 
3. Do the test modifications protect the integrity of the tests?

4. Is there a difference in general education teachers' perceptions of the ease of use and the effectiveness of the testing modifications?

Method. A questionnaire consisting of 32 test design modifications was distributed to general education teachers who taught $7^{\text {th }}$ through $12^{\text {th }}$ grades in two suburban school districts in New York. The 64 teachers who accurately completed the questionnaires had met the criteria of having learning disabled students in their classrooms in which they provided direct instruction and administered teacher-made tests. Part 1 of the questionnaire requested descriptive information from the respondents regarding such data as years of teaching experience in what grades and subjects and college credits completed in special education. Part 2 consisted of questions regarding the respondents' awareness, use, and integrity of the 32 test adaptations that composed the questionnaire, as well as rating the teachers' perceptions of the ease of use and the effectiveness of the test modifications by the use of a 5-point Likert scale.

Procedures and results. To determine awareness of testing modifications, the researchers looked at items on the questionnaire that were selected by $90 \%$ or more of the respondents. Among these were: teachers preparing typewritten rather than handwritten tests, allowing more space for answers, giving shorter more frequent tests, as well as reading test items and directions to the students, allowing more time, and presenting items in a predictable hierarchical sequence. One of the modifications of which teachers were less aware was providing an answer check sheet that lists the components expected on essay questions.

To ascertain what testing modifications were actually used by general education 
teachers, the researchers again looked at those responses selected on the questionnaire by 90\% or more of the teachers. Those modifications selected included typewritten tests, better spacing for responses, placing a blank beside each item rather than having students draw lines for matching, and allowing more time. Test modifications used by $50 \%$ or fewer of the teachers included: giving a sample test in advance, providing a model of a correct response, the use of technological equipment for presentation of test items and student responses, developing alternative scoring procedures, and permitting students to dictate responses. The least used test modification, which goes along with the teachers not being aware of it, was providing an answer check sheet that lists the expected components.

Some of the same responses, which indicated teachers' awareness and use of the modifications, were also selected as maintaining integrity of the tests: typewritten tests and spacing of test items. Monitoring students, limiting number of choices and arranging the answers vertically on multiple-choice tests, and placing blanks beside the items for matching rather than drawing lines indicated high percentages for protecting the integrity of the test, but were not necessarily ranked high for teachers' awareness or use. While all of the responses were selected more than $50 \%$ of the time by the teachers for protecting the integrity of the test, some had lower frequency of selection indicating some concern about integrity. Those included were: giving a sample test, using alternative scoring procedures, and providing an answer check-off sheet for essays.

The differences between ease of use and the effectiveness of the testing modifications indicate that teachers perceive that modifications in test format rather than in administration are the easiest to incorporate. One specific item dealing with adjusting 
the reading level of the test to meet the students' needs was answered in the affirmative by $85 \%$ of the teachers as being aware of the modification, while only $59 \%$ indicated that they used this modification, and 73\% of the teachers considered this modification still protected the integrity of the test.

Discussion. Results of this study suggest that although teachers may be familiar with a variety of testing modifications, they may not implement them because they view them as ineffective, difficult to implement, or as a threat to the academic integrity of their tests. An analysis of teachers' use of testing modifications indicated that teachers were more likely to select modifications that can be used with all students and included changes in test design rather than administration procedures. Results also indicated that teachers are less likely to use modifications that are specific to the needs of individual students, such as permitting students to dictate their responses, taking a test in another setting, and using technological equipment for presentation of test items and student responses. The one exception to this was that $90 \%$ of the teachers in the study allowed more time to the included special education students to complete their tests, which is noted by researchers as the most frequently suggested test accommodation for students with learning disabilities.

Conclusion. This study suggests that teachers are more likely to accept testing modifications that they perceive as maintaining academic integrity, are effective, and that place few demands for individualizing on their time and material resources. For example, although teachers believe that adjusting the reading level of the test, permitting students to dictate responses, and defining unfamiliar words on tests are effective strategies, they do not consider these easy to implement, and do not use them as often. 
This may imply that teachers lack information regarding ways in which testing modifications can be incorporated efficiently for included students.

It was further concluded from this study that teachers should be provided with data on the effectiveness of testing modifications, ease of and resources needed for implementation, ways to adapt the techniques, and the reasons for the test modifications. These researchers believe that teachers are more likely to implement testing modifications if they are provided with training on how to select, implement, and adapt testing modifications to meet the individualized needs of the students in their classrooms, and are given the opportunities to brainstorm solutions to problems that teachers may encounter implementing the modifications. They caution that teacher acceptability needs to be considered when helping regular classroom teachers to implement testing modifications.

This study is included here because it provides evidence of the barriers to inclusion that exist concerning test modifications for special needs students. This is supportive evidence that if teachers are not trained in implementing testing modifications, they are unlikely to use them.

Implementation of Inclusion for Instruction

Vaughn and Schumm (1996) revealed that general educators are unlikely to make extensive, time consuming adaptations that they do not believe to be effective practice. Zigmond (1996) indicates that, despite training at special workshops, teachers revert back to what is comfortable for them regarding instruction with data demonstrating that teachers spent most of their time teaching the whole class and rarely taught small groups or individual students or utilized cooperative learning. Teachers participating in the 
studies confirmed the data with reasoning that included: peer-assisted activities take the right mix of students; specific subjects require whole-class activities; and accommodations for students with special needs just may simply not be a good idea. She found that teachers in her study did not seem concerned about individual achievement, individual progress, or individual learning. The National Association of State Boards of Education's report (1992) confirmed this when they found that most of the goals successfully attained as a result of IDEA fell into the category of increased access, not improved programming with enhanced student outcomes.

Zigmond (1996) further discovered that planning for instruction was not databased on assessments or formal or informal evaluations of success on previous lessons for individual or groups of students. Adaptations to instruction were instead based on stereotypes rather than on individual students’ needs, and were very general; for example, redesigning tests and allowing flexibility for weekly spelling lists. Participants acknowledged the need for more than in-class co-teaching and whole-class accommodations. One of Zigmond's conclusions at the time of this study was that the empirical data indicated that the students did not learn very much in the general education setting. Elrich (1996) concluded from Zigmond's study that in some classrooms the mere presence of the students integrated into the regular education classroom was not enough to provide them with individual accommodations. What is needed is "to provide instruction in a way that allows each individual child to realize his or her maximum potential” (Elrich, 1996, p. 200).

Schulte (1996), based on Zigmond’s findings, asks why teachers did not implement more individualized teaching even when they had the knowledge and support 
for it. She concludes that teacher beliefs regarding ability and assumptions about learning are areas that need to be explored. In the view of Hitchcock, Meyer, Rose, and Jackson (2002), because the conception, design, and implementation of the general curriculum are the most important determinants of whether students with disabilities can access, participate, and progress within it, the most critical step to increase the access, participation, and progress for students with disabilities is to change the curriculum itself. They believe that doing this will create a curriculum that is better, not just for students with disabilities, but for all students. This argument was supported by Lipsky and Gartner (1987) when they determined that changing general education to make it more flexible and responsive and make it special for all students would better educate the full range of students. Yell (1998) suggested that special education must be individually tailored to meet the needs of students with disabilities and to provide meaningful educational benefits for all students.

If we are serious about educational reform and school improvement, then we must be committed not to helping all students achieve a minimum standard but to helping all students learn all they can (Kauffman, Gerber, \& Semmel, 1988). The solutions build on the belief that all students can learn skills that are of value to them, even though these skills will differ from one child to the next (Raynes, Snell, \& Sailor, 1991).

Madeleine Will, while assistant secretary to the Office of Special Education and Rehabilitative Services (OSERS), presented a paper to then Secretary of Education William J. Bennett entitled Educating Students with Learning Problems: A Shared Responsibility (1986) calling for creative responses for improving the education of students with learning problems in the regular education setting. The general solution 
recommended by Will for solving these problems is for general educators to take greater responsibility for students who have learning problems (Carnine \& Kameenui, 1990). However, teachers who were interviewed in school districts in which successful integration into regular classrooms had been found (Janney, Snell, Beers, \& Raynes, 1995) attributed the successful integration to a team approach and support offered by the principals in their schools.

\section{Leadership}

\section{Collaboration}

Friend and Cook (1992) define collaboration in this way: "Interpersonal collaboration is a style for direct interaction between at least two coequal parties voluntarily engaged in shared decision making as they work toward a common goal” (p. 5).

Collaboration is viewed by them as a style or an approach to interaction and can be used to problem-solve, assess, and teach. Cohen (1993) stated that principals have to balance concerns of parents of regular and special education students with teacher training and promoting collaboration. Literature confirms that the principal's support is key to effective inclusionary practice (Rude \& Anderson, 1992). Crockett and Kauffman (1998) advise that how educational leaders interpret the principles of Least Restrictive Environment, as a place or as educational needs, has a significant effect on how schools will be structured and classrooms designed to address the needs of all students.

Based on a survey by the National Center on Educational Restructuring and Inclusion (NCERI, 1994, 1995), several factors for the successful implementation of inclusive education were identified. Among those were a visionary leadership in which 
all stakeholders must take responsibility for the outcome and collaboration between those involved in student evaluation and program development. Villa and Thousand (2003) suggest that school leaders clearly communicate to educators that best practices to facilitate inclusion are identical to best practices for educating all students. They believe that this message will help schools to understand that inclusion is not an add-on. Inclusion is a natural extension of promising research-based education practices that positively affect the teaching and learning of all students and that redefines educators’ and students’ roles and responsibilities as creative and collaborative partners.

Fullan and Miles (1992) suggest that collaborative time for teachers to undertake and sustain school improvement may be more important than equipment or facilities or staff development. According to researchers (Pugach \& Wesson,1990; Johnson \& Pugach,1992), special education's efforts at collaboration appear to be a logical outgrowth of the concept of the least restrictive environment. This idea has led to what is now considered a paradigm shift toward collaboration across all aspects of education for creating instructional environments which support heterogeneous classes that accommodate a diverse student population. Friend and Cook (1990) predicted that efforts to promote site-based management and other forms of participatory management in schools would affect all members of the educational community and involve them in shared decision-making and other collaborative activities.

Wasley (1994) explains that in shared decision-making, the emphasis is on collaboration, consensus surrounding goals, and shared responsibilities. She defines teacher leadership as "the ability to encourage colleagues to change, to do things they wouldn’t ordinarily consider without the influence of the leader” (Wasley, 1991, p. 170). 
Lieberman (1992) emphasizes that teacher participation in leadership may be the most critical component of the process of change. Leadership at the school level fosters collaboration.

Inclusive education cannot be successful without collaboration since inclusion is predicated on professionals working together for the purpose of improving the education of all students in the school (Graden \& Bauer, 1991). As viewed by Graden and Bauer, collaborative problem solving is central to the success of inclusive schools and provides the support by which interventions, adaptations, and accommodations are implemented in inclusive classrooms.

Through collaboration, interventions are not imposed by reformers, but develop with supportive, reflective analyses on data-based information that relate practices and perceptions to procedures and goals (Clift, Veal, Holland, Johnson, \& McCarthy, 1995). Conzemius and O’Neill (2001) state that collaboration represents the compassionate and wise heart of school improvement and that without collaboration our knowledge and data will go unused. Steve Parson (1999) includes shared decision-making as one of the twelve components which he presents when he provides training and technical assistance to communities developing collaborative organizations. Schlechty (1997) relates that advocates of shared decision-making claim it will improve student learning, create teacher satisfaction, and develop new forms of leadership.

Shared Decision-Making: A Study of Principals’ Beliefs and Practices

In a study regarding their views of shared decision-making, 144 school principals were surveyed from an urban county in a Southwestern state along the U.S./Mexico border (Apodaca-Tucker, Slate, \& Brinson, 2001). 
Purpose. The following were the three purposes of this study:

1. to examine the extent to which shared decision-making was being implemented as viewed by school principals at the elementary, middle, and secondary schools within this county

2. to ascertain whether there were differences between the three levels, as viewed by the principals, in shared decision-making practices and beliefs

3. to compare and contrast the findings with those obtained by Livingston, Slate, and Gibbs (1999) in their study of rural school principals in South Georgia Methods and procedures. Using Glickman's model (1993) of shared decision making, 90 elementary, 30 middle, and 24 secondary school principals responded about their shared decision-making beliefs and practices at school. A modified version of the School Beliefs and Practices Survey (Livingston, Slate, \& Gibbs, 1999) was administered to the principals who participated in this study to determine demographic data, responses on a Likert scale concerning beliefs about shared decision-making, and responses to statements about who made decisions in their school concerning practices related to teaching and learning.

Following contacts with administrative personnel at each district, phone calls were made to the principals who were informed of the purpose of the study. If they wished to participate, the items and scoring format for the survey were read aloud over the phone in an interview that took thirty minutes. The researcher offered to send a fax copy if the principal did not wish to respond to the questions by phone.

Results. All of the findings on every question were above the upper quartile showing that principals in this southwest state indicated strong agreement with the belief 
statements related to shared decision-making. These items of agreement between the three levels of principals (elementary, middle, and high school) included: (a) site-based management is preferable to central office management, (b) people closest to the student have the clearest understanding of how to best meet the needs of the student, (c) ownership in a decision enhances the quality of that decision and the likelihood of a successful outcome, (d) all parties must be involved in decision-making, (e) teachers are professionals who possess expertise to make key decisions about schools and schooling. (The middle school principals indicated the lowest level of agreement of this item at $90 \%)$.

Questions concerning daily school activities related to schedules, instructional materials, and rules were used to determine whether differences existed in shared decision-making practices and beliefs between school levels. Principals indicated teacher involvement with administrators in decisions about the daily schedule at all three levels with decreasing participation from high school to middle school to elementary levels. High school principals with committees indicated the least involvement in decisions about instructional materials while elementary principals participating with committees expressed almost twice as much involvement in the selection of instructional materials.

Middle school principals indicated the highest percentage on collaborative decisions made by a committee of administrators and teachers for the following issues: (a) rules or policies that affect the school, (b) new instructional programs, (c) professional development programs, (d) instructional expenditures, and (e) changes in the mission statement. Although the findings concerning who makes decisions at their school indicate that middle school principals are practicing collaboration more than the other 
levels for decisions within their schools, middle school principals had indicated the lowest belief (at $86.6 \%$ ) that site-based management is preferable to central office management.

Without exception, all three levels of principals indicated that personnel evaluation procedures were determined by the principals, with only a small percentage of these decisions being made by a committee of teachers and administrators. Middle school principals reported the least amount of involvement from the central office for decision-making relating to personnel evaluation.

Discussion. In this study, all principals (100\%) at the elementary, middle, and high school levels agreed that ownership in a decision enhances the quality of that decision for schools to be successful. Fewer principals agreed that teachers possess the expertise to make key decisions about schools and schooling. When the results of the southwestern principals were compared with the rural school principals in Georgia, the trend of beliefs and practices varied on some issues. More confidence in teachers' ability to make decisions in the southwestern community appeared to be present than was present among the principals in rural Georgia. The southwestern principals also reported higher confidence in the ability of people closest to the students as having the clearest understanding of how to best meet the needs of the students than the principals in rural Georgia. While both areas of principals reported believing in shared decisionmaking, principals from both areas reflected the same reluctance to release their control of school staffing and personnel issues.

Conclusions. The researchers of this study advised taking the position of Schlechty (1997), who found that having every participant in shared decision-making 
participate in making decisions enhances the effort toward successful schools. They agree with Sergiovanni (1992) in believing that the success of shared decision-making depends on the leadership of the principal and is necessary to increase student learning. Principals’ perceptions of shared governance appeared to represent schools that are moving toward collaborative school governance with teachers and administrators working together for school improvement.

This study demonstrates that decision-making that is shared in schools leads to an improved quality of those decisions and increased opportunities for schools to be successful. Experiencing a sense of ownership in a decision helps to create a vested interest in seeing it succeed, which may lead to greater student achievement. According to Glickman (1993), “Educators cannot teach students how to gain entry into the knowledge and power of the profound discussions of a democracy unless they themselves have gained entry into the knowledge and power of the profound discussions of their schools” (p. 28).

\section{Shared Decision-Making and Teamwork}

Teachers in Vaughn and Schumm’s (1996) study reported that they were more comfortable with considering or accepting teaching techniques and practices that stemmed from their own ranks. Cuban (1990) observed that the reason we see so many school reforms is that the reforms never begin in the classroom where change is most likely to have its greatest impact. Since students learn in classrooms, not board rooms, teachers should be deeply involved in the decision-making process (Lashway, 1996). Sergiovanni (1994) believes that the rationale for shared decision-making is that those who are closest to students are best equipped to make educational decisions to improve 
instructional programs. The purpose of shared decision-making is to improve effectiveness and student learning by increasing staff commitment and ensuring that schools are more responsive to the needs of their students and community (Goodlad, 1984).

Fullan (2001) compares leadership in business with leadership in education, which he believes have increasingly more in common. He states that schools are beginning to find that new ideas, knowledge creation, and sharing are crucial to solving learning problems, but that schools can learn from companies how to be innovative and get results. However, he acknowledges a similarity in that they both must become learning organizations or fail to survive with change. He further believes that while leadership is key to large-scale improvement, it is radically different than it has been.

One of the differences that has evolved concerning leadership is sharing the leadership. It is recommended (Meadows \& Saltzman, 2002) that for shared leadership to be successful, the principal must make sure that teachers have the appropriate skills and opportunities to practice them. The principal can also model shared leadership by practicing and acknowledging effective group participation. A basic goal of shared decision-making is getting everyone involved in school decisions (Chernow \& Chernow, 1992), although participatory management does not mean that everyone decides everything (David, 1996). Those who are informed about and care about the issues and know the context in which the decisions will be carried out are the ones who will make sound decisions (David, 1996). Liontos (1994) believes that change is most likely to be effective and lasting when those who implement it feel a sense of ownership and responsibility for the process. 
West and Idol (1990) explain well how collaboration is used to make school decisions for meeting the educational needs of all students as a process that involves the individuals responsible for implementing decisions as being the ones who actually make those decisions. They further explain that the decisions are made at the level closest to the issue being addressed based on the beliefs that those most closely affected by decisions ought to play a significant role in making those decisions and that educational reform efforts will be more effective and last longer when carried out by people who feel a sense of ownership and responsibility for the decision-making process. Will (1986) expounds on this process for delivering educational services to meet individualized student needs by administrators and teachers collectively contributing skills and resources to carry out appropriate educational plans. With the idea of shared responsibility for serving students with disabilities, Will promoted the concept of the regular education initiative.

Leaders have learned that the best results come from people working creatively and collaboratively rather than from a culture being imposed that is based on command, compliance, and control. The continued success of U.S. businesses and schools is best guaranteed by bringing everyone's talents together to achieve the results we want, states Bonstingl (2001). He further believes that higher student achievement may be reached through better planning and more informed decision-making because when our students fail, it is often because our systems of teaching, learning, and assessment have been inadequate to meet their needs. In a study of successful schools, Newmann and Wehlage (1995) discovered that the staff in these schools shared a common purpose for student learning, created opportunities for teachers to collaborate and help one another achieve 
the purpose, and took collective - not just individual - responsibility for student learning.

Murphy and Beck (1995) suggest that often the necessary supports needed for successful school-based management are absent, but that for this reform to be successful support mechanisms must be in place. Schmoker (1999) recommends that we concentrate more on measurable goals in order for site-based management to thrive. Student learning is measurable and a good reason for collaborating. According to a study conducted by Straus (1996) student achievement in mathematics and teacher morale were significantly higher in the schools in her study that used Total Quality Management, an idea of scientific management developed by William Edwards Deming that is focused on consensual decision-making. Based on evidence such as this, Wheatley (2000) asks why everyone is not working in a self-managed environment right now.

\section{Summary}

The answer to Wheatley's question about why everyone is not working in a selfmanaged environment is possibly fear - fear of letting go of control and fear of failure. However, where student learning is concerned, the risks are worth the possibilities because we can't afford to lose even one child to uncertain teaching instruction or refusal to collaborate. According to Murphy (1995), if the best of inclusion can be coupled with powerful conceptions of learning and teaching and with the traditional strengths of special education, then real improvement remains a possibility. Kauffman (1993) suggests that perhaps the most effective way of improving and evaluating the education of students with disabilities is through experimentation with new programs.

Although the idea of shared decision-making is not new, there remains the possibility that through shared decision-making the barriers to inclusion might be 
resolved. Will (1986) promoted the concept of the regular education initiative with the idea of a deeply shared responsibility and total school involvement in serving persons with disabilities. For this study, this interpretation of shared decision-making will be used while determining to what extent it is being explored as an option to implement inclusion at one elementary school. Interviews with regular educators will give evidence as to whether they are included in decisions for special needs students within their classrooms. 


\section{CHAPTER 3}

\section{METHOD}

This descriptive case study obtained information from the general educator's perspective as to what barriers are influencing the implementation of inclusion within the regular classroom in order to answer the following question: How can shared decisionmaking impact the process of inclusion for special needs students? By determining barriers to inclusion, the general educator will begin to identify ways through shared decision-making to resolve these issues. It is hoped that the data obtained will enable educators to understand how they can better assist students to be successful within inclusive settings.

As a researcher I have an admitted bias toward special education students and issues involving them. This presents a mixture of emotions when it comes to providing beneficial services for students with special needs. Years of experience have demonstrated to me that at times what is needed for a student may not be available within a school system. P.L. 94-142 requires that students' needs be examined in individual ways so that regardless of what is needed for a child it should be provided by counties despite economic and personnel limitations.

It is, therefore, a fine line when addressing student needs in an Individualized Education Program (IEP) meeting between providing what is best for a student and recommending what is available. There is a constant juggling within me of playing the role of advocate and also representing the school system with which I am employed.

My years of being a special educator have contributed to the dilemma within me. Over thirty years ago, working on an undergraduate degree in speech therapy seemed like 
an opportunity for me to help children with special needs. Through the years, I have been a speech therapist and a special education teacher, served on and coordinated Student Assistance Teams (SATs) and completed a program in collaborative consultation, obtained a master’s degree in learning disabilities, a master’s degree in behavioral disorders, and certifications in autism and mental impairment. Along with these experiences came the realization that in order to help special needs students, an educator has to think beyond obvious resources and utilize the obscure reserves within us to truly make a difference. Beginning to think differently and to look at the bigger, overall picture led me to obtain a master’s degree and to pursue a doctorate degree in educational leadership, believing that with knowledge comes power to help make a difference.

The review of literature indicates that successful inclusion is attributed to a team approach. It therefore becomes relevant to determine whether regular educators are included in the decision-making process when it comes to inclusion of special needs students in their classrooms. Analyzing through interviews with regular educators if students with disabilities are experiencing successful inclusion through shared decisionmaking in a rural elementary school is the purpose of this case study.

The case study approach was considered the most appropriate method for this study so that data analysis could be completed by someone who understands inclusion issues because of the need to make analytic judgments throughout the data collection phase. The relevance of this is that without a firm grasp of the issues, important clues would be missed without knowing what deviation on this particular subject was acceptable. The point is that case study data collection is not merely a matter of recording data in a mechanistic fashion, as in some types of research. An investigator 
must also be able to interpret the information as it is being collected and to know immediately if several sources of information contradict one another and lead to a need for additional evidence (Yin, 2003). The outcome of this study is "not the generalization of results, but a deeper understanding of experience from the perspectives of the participants” in the study (Maykut \& Morehouse, 1996, p. 44). Belenky (1992) uses the term interpretive-descriptive research to refer to exploratory studies such as this, which rely on people's words and meanings as data for analysis.

The goal of this descriptive case study is to gather the information directly from six general educators through interviews, informal observations, and by document analysis of IEPs, thereby improving validity through corroboration of the collected data by obtaining the information from multiple sources. The use of multiple sources of evidence in case studies allows an analysis of each source of evidence separately and a comparison of the conclusions from the different analyses (Yin, 2003). In addition, any finding or conclusion in a case study is likely to be much more convincing and accurate if it is based on several different sources of information, thereby developing converging lines of inquiry (Yin, 2003).

\section{Participants}

The subjects for this study were six regular classroom teachers within an elementary school in a rural county located in north central West Virginia. The school contains 480 preschool through fourth-grade students. Consolidation of four smaller schools gathered the teachers and students together under one roof and under the leadership of one principal in August, 2002. Since that time, the principal who was hired from outside of the county has initiated educational reforms, both welcomed and 
controversial. One of the reforms addressed has been inclusion. The implementation of inclusion was varied within the four smaller schools, which led to various interpretations of how it should be implemented within this school.

A wide variety of methods for implementing inclusion of special needs students into the regular classroom continue to exist within this elementary school, which is the only school in this county school system containing elementary-age students. Therefore, what this school does toward including its students with disabilities influences the entire county's elementary student population. What remains of unfavorable inclusion practices could affect these students for years to come. Obtaining data about inclusion in this school benefits not only the current students, but future students. General educators can best provide this information concerning implementing inclusion within the regular education classroom.

There are a variety of exceptionalities represented by the students with disabilities within this school. Students having autism, behavioral disorders, mental impairment, specific learning disabilities, visual impairments, speech and language disorders, preschool special needs, orthopedic or physical disabilities, and other health impairments, such as attention deficit disorder (ADD) and attention deficit hyperactive disorder (ADHD) are identified and are being served through combinations of placements in special and regular education settings.

Within the school there are 22 regular classroom teachers from preschool to fourth grade. One regular classroom teacher having the highest number of identified special education students was selected for each of the six grade levels by using the West Virginia Education Information System (WVEIS), a statewide technology informational 
network that provides a list of the students who are receiving special education services within this school. By comparing these names with class lists, the six teachers were determined. It was believed that the challenges of instructing special needs students could be better identified and expressed by teachers having several students with IEPs in their classes. The six teachers participating had the following number of identified special needs students within their classes during this case study: preschool (3), kindergarten (1), first (3), second (6), third (5), and fourth (6).

Any student in this school identified as having a disability and having an Individualized Education Program (IEP) is considered to be a student with a disability for the purposes of this study with the exception of students who receive only speech or language services and occupational (OT) or physical (PT) therapy for fine and gross motor skills. Students requiring only speech, language, OT, or PT services were not counted as disabled for this study because such disabilities in and of themselves do not present significant instruction or behavior management difficulties with which the teacher must implement inclusion with significant modifications or accommodations to the curriculum or instruction.

Each of the six regular education teachers were given a simple one-question questionnaire explaining briefly the reason for requesting their assistance and their name. These teachers were asked to circle yes or no to answer this question: Would you be willing to assist me with work on my dissertation concerning inclusion? If any of these six teachers preferred not to participate, then the teacher having the next highest number of special education students for that grade level would have been asked until six willing participants were procured. 
After receiving their willingness to participate, a letter explaining the study further was given to the six teachers. The respondents were then identified as grade-level teachers. The description of the study provided to the regular classroom teachers deliberately did not include the term shared decision-making. The reason for this was to be able to obtain willing participants based on the subject of inclusion without those who have strong opinions about leadership styles eliminating themselves. This should not be interpreted as researcher bias. The structure of this study, of asking questions that were recorded and transcribed, lends itself to extracting diverse information from the respondents who participated in this case study.

\section{Apparatus}

The West Virginia Education Information System (WVEIS) was used to identify the students in this school who have IEPs. WVEIS is accessed via assigned passwords. Within this system is a list of all special education students. It was necessary to access each student's file in order to determine what special education services each student was receiving in order to eliminate the students receiving speech, OT, and PT services. The regular classroom teacher who has the student in his or her class was determined by looking at class lists supplied by the school office, which lists teachers' class rosters. The number of special education students within each class was determined by totaling the names of the students, using fictitious first names and last initials.

The one-question questionnaire was given to the six grade-level teachers having the highest number of special education students in their classes. This questionnaire was reviewed to identify the willing participants. Those answering yes to the question were given a letter of further explanation. 
Interviews conducted with each willing participant obtained their opinions and knowledge about inclusion and shared decision-making, as well as the current modifications and accommodations they were making for the identified special education students in their class. A summary sheet from each student's Individualized Education Program (IEP), which lists the modifications developed for every identified special education student, was provided for the researcher by the special educator who served the students within these six classrooms. These are obtained by accessing the IEP Writer computer program, which is used to develop and print each student's IEP.

Examination of the Summary Sheet for each student determined what program modifications were suggested for the students in each of the classrooms. These modifications are used to allow the curriculum and instruction within the regular classroom to be accessible and beneficial to special needs students.

While interviewing the regular classroom teachers, a prepared protocol of questions was used. “A research-question-based set of questions should be worked out in advance, with departures from the protocol limited by design” (Stake, 1995, p. 65). As suggested by Yin (2003), the interviews followed a line of inquiry through questions asked in an unbiased manner that served the needs of the line of inquiry. These focused interviews remained open-ended but followed the protocol. Two or three sessions were necessary with each teacher to cover the twenty-six questions during the interviews. Informal observations were conducted to provide the researcher with information to substantiate data supplied by the informants. These were conducted within the classroom in which the regular educator taught. Confirming provided data assures validity in case studies. 
Procedure

A time-table (see Table 1) has been designed to explain the steps with planned dates for initiating and terminating each step. Adherence to this was maintained throughout the research process.

After approval of the Prospectus, the next step of the research process involved submitting an Institutional Review Board (IRB) request to West Virginia University for approval to conduct the study. Once approved by the IRB, the researcher sent a letter to the Superintendent of Schools at the Board of Education of the county in which the study was conducted seeking his approval (see Appendix A). After receipt of this, the onequestion questionnaire (see Appendix B) and informational letter (see Appendix C) were distributed.

A Summary form (see Appendix D) printed out using the IEP Writer for each student identified as a special education student within the school was reviewed to identify the modifications listed on these students' IEPs to obtain a general idea of modifications being utilized for inclusion. These documents were obtained with permission from the principal (see Appendix E) and, along with the interviews, provided information regarding implementation of modifications contained in the students' IEPs.

An IEP Document Analysis Protocol (see Appendix F) was developed to determine the various modifications being implemented within each classroom. The number of times a specific modification was listed on the IEPs represented within that class was documented. This provided the researcher with a composite list of the modifications that had been recommended for each of the special needs students included successfully within each of the six classrooms and how often the same 
Table 1

Timetable for Study

\begin{tabular}{|c|c|c|c|c|}
\hline 2003 & Week 1 & Week 2 & Week 3 & Week 4 \\
\hline Oct. & & & $\begin{array}{l}\text { Accepted to } \\
\text { Candidacy } \\
(10 / 21 / 03)\end{array}$ & $\begin{array}{l}\text { Determine } \\
\text { topic }\end{array}$ \\
\hline Nov. & $\begin{array}{l}\text { Begin } \\
\text { research }\end{array}$ & $\begin{array}{l}\text { Begin writing } \\
\text { Chapter } 1\end{array}$ & $\begin{array}{l}\text { Gather } \\
\text { research }\end{array}$ & $\begin{array}{l}\text { Rewrite } \\
\text { Chapter } 1\end{array}$ \\
\hline Dec. & $\begin{array}{l}\text { Continue } \\
\text { research }\end{array}$ & $\begin{array}{l}\text { Meet with } \\
\text { Chair (12/9/03); } \\
\text { Discuss Chapter } 1\end{array}$ & $\begin{array}{l}\text { Read research; } \\
\text { Rewrite } \\
\text { Chapter } 1\end{array}$ & $\begin{array}{l}\text { Begin } \\
\text { writing } \\
\text { Chapter } 2\end{array}$ \\
\hline 2004 & Week 1 & Week 2 & Week 3 & Week 4 \\
\hline Jan. & $\begin{array}{l}\text { Meet with } \\
\text { Chair } \\
\text { (1/6/04); } \\
\text { Discuss } \\
\text { Chapters } 1 \text { \& } 2\end{array}$ & $\begin{array}{l}\text { Add two studies } \\
\text { to Chapter } 2\end{array}$ & $\begin{array}{l}\text { Meet with } \\
\text { Chair } \\
\text { (1/19/04); } \\
\text { Discuss } \\
\text { Chapter } 2\end{array}$ & $\begin{array}{l}\text { Write } \\
\text { Chapter 3; } \\
\text { Prepare } \\
\text { References }\end{array}$ \\
\hline Feb. & $\begin{array}{l}\text { Meet with } \\
\text { Chair } \\
\text { (2/2/04); } \\
\text { Discuss } \\
\text { Chapter } 2\end{array}$ & $\begin{array}{l}\text { Send Chapter } 1 \\
\text { electronically } \\
\text { to Committee }\end{array}$ & $\begin{array}{l}\text { Meet with } \\
\text { Chair } \\
\text { (2/23/04); } \\
\text { Discuss } \\
\text { Chapters } 2 \text { \& } 3 \\
\text { and review Ch. } 1\end{array}$ & $\begin{array}{l}\text { Complete } \\
\text { Writing } \\
\text { Chapter } 3\end{array}$ \\
\hline March & $\begin{array}{l}\text { Meet with } \\
\text { Chair (3/8/04); } \\
\text { Discuss } \\
\text { Chapter } 3\end{array}$ & $\begin{array}{l}\text { Send Chapters } \\
2 \& 3 \\
\text { electronically } \\
\text { to Committee }\end{array}$ & $\begin{array}{l}\text { Determine date to } \\
\text { discuss } \\
\text { Prospectus with } \\
\text { Committee }\end{array}$ & $\begin{array}{l}\text { Revise } \\
\text { Chapters } 2 \text { \& } 3 \\
\text { and send to } \\
\text { Chairman }\end{array}$ \\
\hline April & $\begin{array}{l}\text { Make copies of } \\
\text { Chapters, } \\
\text { References and } \\
\text { Appendixes for } \\
\text { Committee }\end{array}$ & $\begin{array}{l}\text { Meet with } \\
\text { Committee for } \\
\text { Prospectus } \\
\text { approval } \\
(4 / 12 / 04)\end{array}$ & $\begin{array}{l}\text { Prepare \& send } \\
\text { application } \\
\text { for IRB } \\
\text { approval }\end{array}$ & $\begin{array}{l}\text { Send letter } \\
\text { of approval to } \\
\text { Superintendent } \\
\text { \& Principal }\end{array}$ \\
\hline May & $\begin{array}{l}\text { Determine } \\
\text { number of } \\
\text { students for } \\
\text { teachers }\end{array}$ & $\begin{array}{l}\text { Distribute } \\
\text { One-question } \\
\text { Questionnaire } \\
\text { to six teachers }\end{array}$ & $\begin{array}{l}\text { Give six teachers } \\
\text { an informational } \\
\text { letter; } \\
\text { Purchase recorder }\end{array}$ & $\begin{array}{l}\text { Obtain IEP } \\
\text { Summary } \\
\text { forms for } \\
\text { students }\end{array}$ \\
\hline June & $\begin{array}{l}\text { Schedule } \\
\text { interviews with } \\
\text { teachers }\end{array}$ & $\begin{array}{l}\text { Conduct } \\
1^{\text {st }} \text { interview } \\
\text { with } 2 \text { teachers }\end{array}$ & $\begin{array}{l}\text { Conduct } \\
1^{\text {st }} \text { interview } \\
\text { with } 2 \text { teachers }\end{array}$ & $\begin{array}{l}\text { Conduct } \\
1^{\text {st }} \text { interview } \\
\text { with } 2 \text { teachers }\end{array}$ \\
\hline July & Transcribe & $\begin{array}{l}\text { Conduct } \\
2^{\text {nd }} \text { interview } \\
\text { with } 2 \text { teachers }\end{array}$ & $\begin{array}{l}\text { Conduct } \\
2^{\text {nd }} \text { interview } \\
\text { with } 2 \text { teachers }\end{array}$ & $\begin{array}{l}\text { Conduct } \\
2^{\text {nd }} \text { interview } \\
\text { with } 2 \text { teachers }\end{array}$ \\
\hline
\end{tabular}


Table 1 (continued)

Timetable for Study

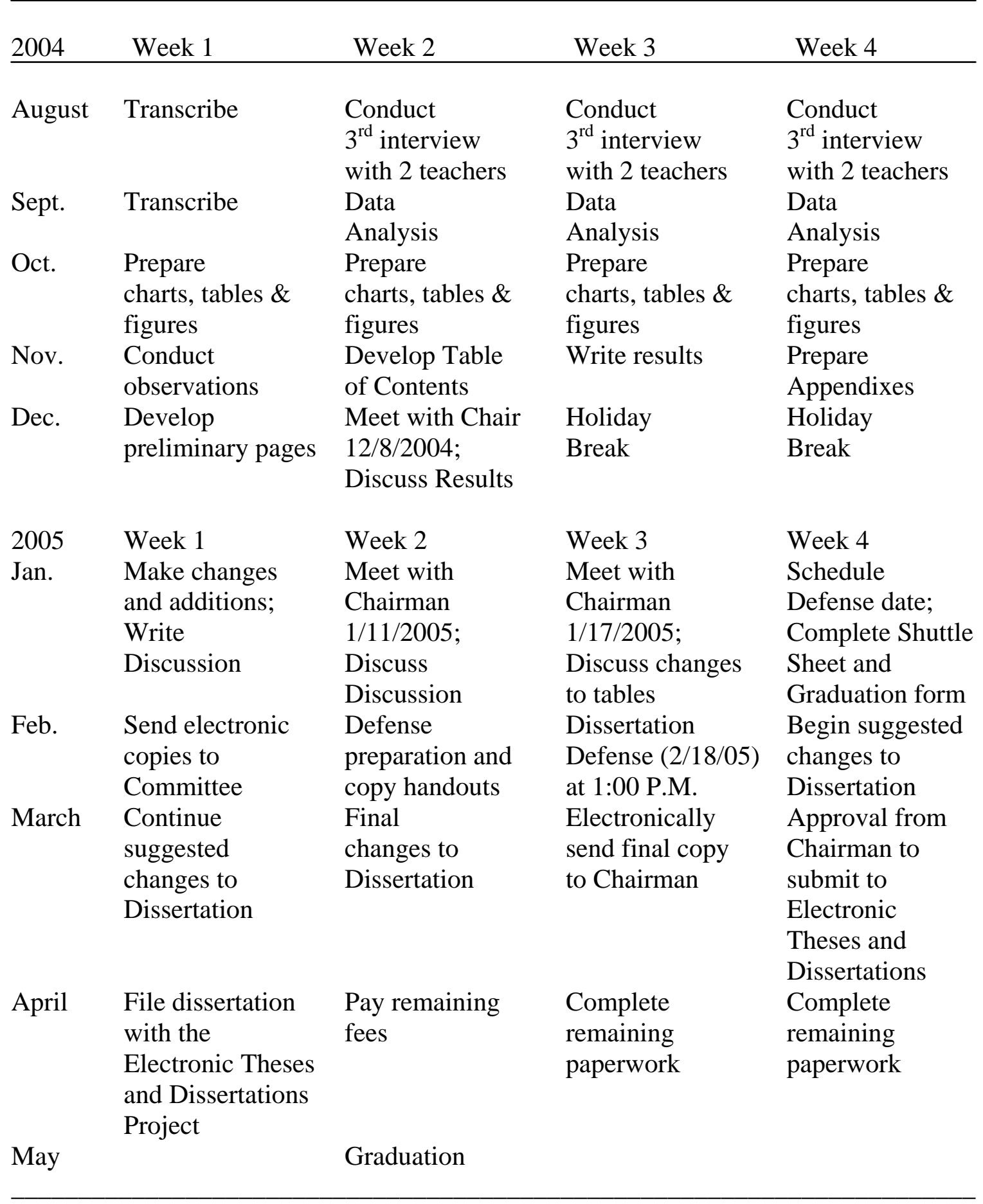


modification appeared in these IEPs from each class. This information was useful for the researcher to be able to discuss modifications and probe for specifics during the interviews.

The interviews were then conducted with the classroom teachers who had met the criteria and had expressed a willingness to participate. During the interviews, the participants responded to questions (see Table 2) regarding inclusion and shared decision-making. Their exact responses were recorded electronically with written notes taken briefly during the interview. During the actual exchange, the interviewer should listen, take notes, and stay in control of the data gathering (Stake, 1995). It is important in this qualitative study to understand people’s experience in context (Maykut \& Morehouse, 1996). Their words, therefore, were recorded electronically with a tape recorder and some notes taken as they verbalized their beliefs and opinions about inclusion and shared decision-making. Their answers were analyzed to determine relationships, to probe issues, and to aggregate categorical data (Stake, 1995). Questions were designed to elicit responses that would identify barriers to inclusion and the benefits of shared decision-making.

The constant comparative method (Maykut \& Morehouse, 1996) was used to analyze the data. This is a nonmathematical procedure that is designed to identify emergent themes and patterns in qualitative data. Transcribed interviews were analyzed using the Ethnograph v5.0 computer software program. This software program was selected because it allows the researcher to search and note segments of interest within the data, mark these with code words, and then runs analyses. 
Table 2

Protocol of Interview Questions

Probe Question

Definition $\quad$ 1. Define inclusion as you understand it.

Description $\quad 2$. In general, how would you describe inclusion in your school?

Purpose $\quad 3$. What do you see as the reason for inclusion?

Learning 4. In your opinion, in what setting do you think special education students learn better?

Concerns $\quad 5$. What concerns or difficulties do you see with inclusion?

Expectations 6. What expectations do you have for students with disabilities in your class?

Environment $\quad$ 7. What effect does the presence of a special education student have on the regular classroom environment?

Implementation 8 . What are some things that might help you to implement inclusion?

Instruction $\quad 9$. How is your instruction different because of special needs students being in your class?

Modifications 10. What modifications do you use in your class?

Lesson plans $\quad 11$. When you design your lesson plans, how do you consider both special and regular education students?

Assistance $\quad 12$. What do you do for special education students in your class that you feel is helpful for the other students? 
Table 2 (continued)

Protocol of Interview Questions

Probe Question

Additional 13. Are there modifications that you know that you aren't doing

modifications now that you think would be helpful for the other students?

Assessment 14. How do you feel that you are best able to assess the achievement of special needs students in your class?

Input $\quad 15$. How is your input at IEP meetings meaningful?

IEP Meetings 16. How could you contribute more at IEP meetings?

Implementation 17. What do you think you could do to change the way inclusion is implemented?

Principal 18. How does the principal help with inclusion?

Definition 19. How would you define shared decision-making?

Improvement 20. Does shared decision-making improve inclusion in your school? Why? or Why not?

Outcomes 21. What are the outcomes of shared decision-making at this school?

Support 22. How does your school environment support shared decisionmaking?

Collaboration 23. What do you think someone needs to know about this school to help teachers collaborate with each other? 
Table 2 (continued)

Protocol of Interview Questions

Probe Question

Opportunities 24. What opportunities do you think there should be for shared decision-making?

Impact 25. How does shared decision-making affect the regular classroom teacher for inclusion?

Process 26. How are you included in the decision-making process when it comes to inclusion? 
The transcript from each interview was reviewed to identify categories within the themes. The major themes were reviewed for similarities and common relationships. Strauss and Corbin (1998) refer to examination and interpretation of data gathered for qualitative research as a microanalysis. "Qualitative analysis involves a radically different way of thinking about data” (Strauss \& Corbin, 1998, p. 59). It requires the researcher to learn to listen and let the data speak to them.

Informal observations were conducted after the completion of the interviews. This assisted in determining substantiation.

\section{Summary}

In this case study, interviewing regular education teachers provided data for finding emergent themes to determine how shared decision-making works when it comes to inclusion for special needs students. Through software analysis determining segments of interest, barriers to inclusion were ascertained from the teachers' responses to questions, as well as whether the regular educators feel included in the decision-making process for implementing inclusion in their school.

It takes support from a school's principal to implement inclusion successfully. Whether and how this support is achieved and demonstrated by the school's educational leader affects the outcome of inclusion. Creating an environment conducive to shared decision-making provides opportunities for participation by general educators in decisions impacting all students.

Lists of what modifications for the students that have been determined to be implemented in the six classrooms will be provided in the next chapter. The relationship between the analysis of these modifications and interview questions will be examined. 


\section{CHAPTER 4}

\section{RESULTS}

\section{Overview of County’s Inclusion}

The county in my study has dealt with inclusion according to available and limited resources. Few business opportunities and high poverty, leading to a low taxbase, have created circumstances that have been challenging and frustrating to both parents and educators. Making do through the years has created some ill-will toward the school system. Recovering from that has been a slow process. However, developing a rapport with parents, while gaining their trust, has created benefits for students.

Lack of funds led to few services for special needs students. The stretches of land between schools caused some services to be available only at certain school sites. Students identified as mentally impaired were bused form whatever school they attended to one central location in the county seat where they were housed in a self-contained classroom somewhat separate from the school itself. Parents were, therefore, reluctant to have their children identified as mentally impaired if they recalled themselves being isolated from other students when they were younger and given that label as a student in this county.

Students identified as learning disabled were kept at their neighborhood school and received services that were sporadic and intermittent by an itinerant special education teacher. There students were, therefore, within the regular classrooms in whatever school they attended with just occasional services provided by the special educator when that person made it back to that school, along with the other schools he or she served in this county. There was little time for collaboration between the provider of services and the 
regular classroom teachers who were, therefore, left to fend for themselves concerning the assistance they could provide with no training about students with learning disabilities.

Few students were identified as having behavior disorders due to a combination of issues. Both parents and teachers were reluctant to refer students for services involving a particular teacher certified to provide them because the services were inadequate and infrequent. Even when there was an obvious need to consider this disability for a student in any of the county schools, the proper evaluations and services rarely occurred.

These various services have been what is available in this county for over twenty years. Adequate training has not been provided about inclusion to special educators nor to regular educators. Each individual school was left to determine how to best serve special needs students in and out of the regular classroom. Collaboration between special educators and regular educators was unheard of with the limited resources. When the special education teacher was in a school, it was to attempt to increase weak areas for students who had been identified as needing special education services.

The challenges of dealing with these experiences brought many frustrations to the newly consolidated school in 2002. Parents were reluctant to have their children even referred for evaluations because of their very real fears of what might happen to them if they qualified. Regular education teachers were unwilling to refer students to the Student Assistance Team (SAT) because they believed that the process didn’t work since students had rarely been identified or received services even if they were identified. Special educators had not experienced implementing inclusion because most of them had been busy traveling from school to school trying to improve students' skills. 
This was all prior to No Child Left Behind. Educators had believed that once a student was labeled as a special education student there was relief because at least that child's scores wouldn't count or pull down the overall scores of the class, school, or county. However, after the enactment of No Child Left Behind, the challenge of truly educating all students to their fullest potential, as well as identifying what students really needed referred for possible special services, combined with the unfunded mandates of the No Child Left Behind Act, all became the responsibility of the educational leader who assumed the position as principal of this brand new consolidated elementary school.

Evidence of this past history is provided through statements made by the teachers. The first-grade teacher said: "Since this school opened, the IEP meetings are better run the teachers have more input." and "This is so much better than busing the students to different schools.” The third-grade teacher shared her opinion with, “IEP meetings have improved tremendously since this school opened.”

\section{Overview of School}

The consolidation of this school housing 480 students from four smaller schools brought out many conflicting opinions of how the new school should conduct business. Three of the four schools represented site-base management simply because of their inaccessibility. Their educational leadership consisted of a teaching principal (General Elementary School with 45 students) and an itinerant principal between two of the schools (Stoneybrook Elementary with 70 students and Clarion Elementary with 35 students). (The real names of the schools have been changed). Only one of the schools, Westinghouse Elementary, which was the largest of the four schools, with 300 students, actually had a full-time principal who was present consistently in the building. This 
principal, however, found less stress for himself by allowing the staff to make their own individual choices regarding parent involvement, curriculum, instruction, schedules, and special education, as well as any other decisions needing to be made at Westinghouse Elementary School.

The challenge of blending the history of the previous way things were done became the responsibility of an educational leader with his own experiences of twentyone years in education not within this school system. The person hired to do this job had his own successes that he brought to this position, which included achieving the Schools of Excellence award in three elementary schools. This National Distinguished Principal has served at the state level on committees and in offices for the principals' association. Along the way while being a teacher, teaching-principal, assistant principal, and principal he facilitated obtaining various grants that affected instruction for science, reading, and technology.

However, regardless of past achievement, he was an outsider to this community and was, therefore, regarded as suspect concerning methods of operation. Parents were offended by locked outside doors to the school in a county in which parents had come and gone directly to their children's classrooms at any time of day to talk to the teachers. Limiting student parties to two a year and not celebrating children's birthdays in classrooms were also points of contention by parents. Eliminating most field trips also met with opposition by parents and teachers alike. They all wanted to see immediately a playground and bulletin boards displaying children's work. They still wanted to see Christmas programs with all of their children participating - all 480 of them. 
It was not initially understood that with a larger school there were necessary safety precautions because of the number of students and because of the school's location on a major highway, not in a remote rural part of the county. The number of students in a combined school limited the amount of flexibility that had been possible in smaller schools. Now 480, not 35 or even 300 , students had to be fed on a schedule within a given amount of time. The combination of these issues and accountability required by the No Child Left Behind Act did not allow for optimum instruction to be an option. It was now a necessity and a priority.

Even teachers in the new building disagreed with some of these issues, as well as a few others. Basically, having come from schools in which they taught what they wanted without regard to Instructional Goals and Objectives or Content Standards, they initially resented new leadership requiring that State guidelines be followed in preparing their instruction. Some of the teachers also resented having duties in the new school and ability-grouping not being used to determine their class lists.

Foremost of their concerns was now having even more students identified as special needs within their classrooms, who would remain in their class for most of the day, but would have IEPs that would need to be followed. Using the same curriculum with all students and following modifications listed on IEPs were also no longer options.

\section{Opportunities for Shared Decision-Making}

Along with bringing a background of educational successes to the position as principal, the educational leader brought a belief in shared decision-making. This was first realized at a week-long symposium the week before the new building opened in which the entire staff participated. During that first week, the staff developed the 
school's Mission and Vision Statements, a school-wide schedule, a school discipline policy, and determined a mascot. Training was provided for collaboration and teamwork. This week was a prime opportunity to tap into the individual strengths and resources and to get to know each other.

Other instances of shared decision-making within that first year included each staff member choosing a committee on which to serve (such as curriculum, discipline, and administrative), and grade-level team meetings, leadership teams across grade levels and special educators, and decisions made at Faculty Senate meetings that affected the school. Beyond requirements for classroom management and instruction of students, most of the decisions were shared by all staff members. During the second year, it was necessary to eliminate grade-level team meetings due to scheduling concerns, but which were again reinstated during the third year of operation by changing school schedules. Reassuring teachers that the process would be followed encouraged classroom teachers to make referrals to the Student Assistance Teams (SATs).

Opinions concerning shared decision-making opportunities at this school were expressed with statements such as these: The preschool teacher commented, "It's more of a team effort here.” The kindergarten teacher agreed with this concept with, "It's more than one person making the decision.” The first-grade teacher reported, "Leadership team meetings make decisions as a team" and "Shared decision-making makes you feel important.” The second-grade teacher expressed, "We all get together to discuss and come up with the best solution.” The third-grade teacher discussed her opinion with her comment, "Shared decision-making is the way to go." "When decisions are made we have discussions and a vote" and "People try to make it work when they were a part of 
the decision” demonstrate her perceptive nature and the appreciation of shared decisionmaking by the fourth-grade teacher.

\section{Description of Teachers and Classrooms}

\section{Preschool Teacher}

The preschool teacher is certified also in preschool handicapped. She, therefore, serves two roles within this school. She has worked 17 years within this county and worked in seven schools in this community as an itinerant preschool special needs teacher before having her class within the current school. She is confident of her abilities and the acceptance she receives in this school, as demonstrated when she stated, "When it comes to shared discussions, my opinion is very valuable here.” She does a good job providing instruction to the twenty children in her program. Depending on the year, there may be several students identified as handicapped in her program. On other years, there may be none. For this particular year, she had one student who was identified as mentally impaired and two as preschool handicapped, which, according to state policy, requires a student to have two areas of concern. In these students' cases, in addition to communication, it involved physical needs that were met with a wheelchair and a walker.

This teacher stays very informed about changing requirements in her program, but remains flexible concerning the curriculum she provides for her students. She also demonstrates a positive attitude toward the changes that made it necessary for her to move her program to this school with the closing of the smaller schools. Her program was somewhat separate from the school in which she had been housed, leaving her to be independent and to make her own decisions. Moving to this school caused her to have a principal who was more involved with her program, which meant that she was not left to 
make her own decisions as much as she had been used to doing. Adapting well to these changes is evident with her comment, "An outsider would feel comfortable in this school because it has a good atmosphere.” She also spoke to the advantages of inclusion even at the preschool level with the statement, “Children serve as role models and teach other students.”

The physical appearance of her classroom is what would be expected in any preschool class. There are tables with tiny chairs to accommodate smaller bodies. Every available space is filled with tables instead of individual student desks, a sand-table, toy kitchen set, Lego blocks table, a reading corner with large pillows, many library books and puppets, a science center table, a child-size wardrobe with a mirror, an easel for student artists, cubbies filled with sleeping mats, computers and a television, as well as many toys for playtime and manipulatives in labeled bins on shelves for hands-on instruction. There is a behavior chart containing pockets and student names with sticks that are removed for inappropriate behavior. The walls are covered with charts and posters for identification of colors, shapes, letters, and numbers. Classroom helpers are named beside a large cutout of Clifford on the bulletin board along with kites and letters spelling out Soaring High in Preschool. A large flag above the teacher's desk proclaims: A Teacher is a Special Friend Whose Love and Kindness Never End. On the wall next to the door where all can see it when they enter is a large cutout tree labeled Our Family Tree, which contains the names of all the students in the preschool class.

During an informal observation, the preschoolers had just completed lunch and were resting with their heads on the tables to settle their stomachs before going out onto the playground. They were quietly waiting for their teacher and aide to give them 
permission to get their jackets on to go outside to play. These students are energetic, but obviously compliant toward authority at a young age. This teacher manages their behavior, instruction, and physical needs in an impressive manner.

\section{Kindergarten Teacher}

This kindergarten teacher has an easy-going manner about her that is appealing to both kindergartners and their parents. After thirty years of experience as an elementary teacher, she has quiet management of her classroom that yields results both academically and behaviorally. She is positive, as indicated by her comment, "The outcome of shared decision-making at this school is to get the best possible situation going for that child.” She also demonstrated a humbleness when she stated, "I just know that there’s probably a lot of things that I don't know that I should know or could know that would be more helpful” and an awareness of student needs with her statement, "Learning styles need to be considered.” Prior to teaching at this school when it opened, she had taught the rest of her career at only one other school in this county, which was close enough to walk to from her home.

Her classroom represents an exciting learning environment for children this age with many learning materials even on the white board: schedules, posters, alphabet cards, shape cards, a word wall, a calendar/sentence poster with student names, number lines, names for line leader and helper, a welcome poster, and manners posters. Above the white board are number posters with objects, color names’ poster, and teacher-made animal letters that go along with a power point of sounds made by this teacher for beginning phonics instruction for the students. Also included in this room are computers and a television, many bins containing toys and activities, cubbies with mats and 
blankets, a reading area with large beanbag chairs, a roller easel with letters and sound pictures, and a large toy kitchen set. Four students sit at each kindergarten-size table within this welcoming environment.

An informal observation indicated a nurturing and academic atmosphere within the kindergarten class. Instruction was being provided by the kindergarten aide, which consisted of morning welcoming activities with the students and singing songs with them as the teacher took roll and prepared the absent-list to be sent to the office.

\section{First-grade Teacher}

The first-grade teacher, even after twenty-nine years of experience, is still enthusiastic and energetic. She came from a well-known family in the community, married into a prominent family, obtained a master's degree, and has remained in the area throughout her marriage and teaching career. She is constantly seeking out new methods of instruction and is always first to volunteer to attend workshops involving curriculum and materials. Although occasionally outspoken regarding school-wide decisions, she continually strives to teach her students effectively. Compassion toward her students is indicated by her comment, “I don’t return F papers,” and her idea that special needs students feel less threatened and not embarrassed within a special education setting when they have questions. On the other hand, she describes some of her own colleagues with, "Some of us are workers and some of us are troublemakers."

The first-grade teacher's classroom is vibrant with color and learning materials. It welcomes students with a large welcome bear poster and wooden apples spelling out welcome. The students' individual desks, grouped in pods of four, lends credence to her statement, "The brighter kids help the lower and they all work together.” Her classroom 
contains many of the usual learning tools: alphabet chart for handwriting, calendar and weather charts, number lines, a word wall, a collection of library books, Saxon Math bins, a globe, puppets, an overhead projector, computers and television, as well as some slightly different materials: a large red apple pocket holder for words or papers, a Student of the Day mini-poster, a behavior pocket chart with green, yellow, red, and blue pockets for students' names, individual plastic drawers with student names containing alphabet letters, and a large white board on rollers with storage bins for manipulatives, a wooden American flag containing the words First Grade Class and Land of the Free, another large pocket poster saying Today’s Centers Are, a hot lunch/cold lunch poster with clothespins, and a monthly pocket chart for birthdays.

Students orally responding as a group, while reviewing a previously presented concept was the method of instruction observed within this class during an informal observation. The first-grade students were found sitting on the floor surrounding the teacher while naming pictures and ending sounds and answering questions as a group during this phonemic awareness activity.

\section{Second-grade Teacher}

The second-grade teacher has taught nineteen years within this county at five different elementary schools. She teaches with some direct instruction, but much of her daily instruction is through small groups with peers assisting peers to learn concepts. This is demonstrated by pods of four student desks grouped together. She is generally vivacious and positive in her association with students and staff members. During the interview, she expressed concern that some people are “... unwilling to try new things.” In a school where a few teachers have a difficult time dealing with necessary changes in 
schedules, this teacher commented, "It bothers other teachers if the special education teacher can't make it into the class when she was scheduled to be, but it doesn't bother me because I just fit them in other groups.” She feels responsible for seeing that all children in her class learn to their potential, indicated by her saying, "When I write my lesson plans I think about how I can design this lesson so that everyone can be successful.” This teacher enjoys technology and sharing her knowledge with others.

Her classroom has many of the traditional instructional aides on the walls, such as calendars, counting lines, the U.S. map, student teaching-clock, 100 number chart, the cursive alphabet on cards above the white board, pockets containing schedules, computers, and a television. In addition, this second-grade classroom contains some different items than other classrooms: a large stoplight with clothespins containing names for classroom management, a sentence handwritten on the board - I will follow directions, and an old style of student desk placed behind the teacher's desk. Also present was a large welcome sign above and reaching from one end to the next of the board, a poster - Sometimes I Feel - containing faces with feelings along with fifteen separate posters with pictured feelings, Small Group Rules written on the board with separate rules listed, vocabulary words written on individual bright paper and attached with magnets to the white board, a counter containing small group materials such as math manipulatives, toy money, a Sentence Building Game, and Leap Pads. One poster indicates her own love of reading - Books are Treasures Waiting to be Discovered.

In this second-grade classroom during an informal observation, the teacher was discussing with her students the disappointment she felt when some of her students were making fun of a special education student. With six students identified with special 
needs within her class, there may be a greater need for this teacher to discuss discipline concerns on a regular basis. This observation and her comment during the interview about “non-medicated ADHD” students being a concern in class indicate her awareness of appropriate classroom behavior.

\section{Third-grade Teacher}

The third-grade teacher is one of those teachers that everyone would want for their children. Her love of teaching is evident in every school setting, which includes meetings, staff developments, and in front of the class. Her positive attitude is infectious to all with whom she comes in contact. Twenty-eight of her thirty years of teaching were spent at one school before the consolidation to the present school. Knowledgeable and informed, this teacher has completed a master's degree plus forty-five hours of graduate education. Her caring nature is evident in the following statements: "I would purposefully go back toward the kids that I know would need it and make sure that they were doing what I'd asked them to do, or if they didn’t quite understand something” and “If they don't pass a test, then we'd go over it and I'd give it to them again or give it to them orally." Accepting all students and nurturing them is obvious when she says, "We are all one family in my class.” Students in her class sit in separate desks.

This third-grade classroom contains the usual computers and television, Saxon Math bins, library books on a cart, multiplication table poster, and student mailboxes. However, some different items observed were laminated vocabulary words on a poster, student work taped on the walls, wooden welcome blocks on the door, and a Happy Birthday poster with student names for each month. On the white board was a hanging pocket holder with the names of various centers posted and containing student names. 
There was a poster laminated and containing one question - How is Your Day? Her desk was organized and her classroom neat and inviting.

During an informal observation in third grade, respect was being discussed with the students as a follow-up from the counselor presenting a lesson on character education. The students were listening intently as the teacher described ways to show respect and kindness toward other people, which is further evidence of the kind of person she is. Fourth-grade Teacher

The fourth-grade teacher has nineteen years of experience and forty-five hours beyond a master's degree, as well as certification at the middle school level. She has taught within this county at three other schools besides this consolidated one. She can be described as well-informed and perceptive regarding educational reforms. She acknowledges that No Child Left Behind causes frustration. She sees the merits of small groups of teachers so that issues can be discussed and it will not be taken personally when “...disagreeing with people.” During the interview, she described the way she designs her lessons so that all students will gain from the instruction. "I usually plan a lesson considering the lower level because I feel like those are the students that we have the ability of making the biggest impact on.” She demonstrated a belief in inclusion with her comments, "Sometimes even the gifted kids learn from special needs students how to do something in a different way" and "The regular students remember something better after teaching it to other students.” This teacher has a quiet influence on other teachers with her knowledge and leadership skills. About implementing inclusion, she stated, "I think everyone has to buy into it and I think people are more willing to do that if they feel like they were in on the decision-making than if someone just says, we're doing it.” 
The fourth-grade teacher's classroom contained many teacher-related knickknacks. Unique to her classroom were mini-posters stating Be in Control, a large stereo with speakers, a Good Manners poster, many shapes on posters above the board, types of writing posters, a poster with capitalization rules, Place Value System posters, The Classroom Rules posted, and a School is Fun large poster with a cutout of a school. There was no visible welcome sign. The students' desks, however, were in pods of four desks for students to work together.

During an informal observation of this class, this fourth-grade teacher was attempting a strategy that she expressed a desire to do, having the students work in small groups. The fourth-grade students were working in groups of four on a spelling assignment while the teacher circulated around the room to assist where necessary.

\section{Analysis of IEP Modifications}

The IEP Document Analysis Protocol for each grade level lists the identified special education students' modifications that are specified on their Individualized Education Programs (IEPs). An analysis follows of these modifications by grade level.

\section{Preschool IEP Modifications}

At the preschool level, the modifications indicate more severe needs. It makes sense that since these children are severe enough to have been identified at such a young age, they are in need of full-time adult assistance. This is in addition to the classroom teacher and aide already present in the room. As evidenced by the type of modifications, mobility for two of the most severe students is a relevant concern since one is in a walker and one is in a wheel chair. One of the three preschool students completes assignments below level and has modifications on her IEP that will assist her with completing 
classroom assignments more successfully (see Table 3). No testing modifications have been determined to be necessary at this time for any of these three students.

Assignment modifications:

- Simplify directions

- Keep materials close

- Modify or use alternate assignments

- Individual help or small group work

Testing Modifications:

None listed
General modifications:

- Vac Pac chair, wedge, standing table

- Adult assistance (full-time)

- Shortened school day

- Limit independent work 
Table 3

IEP Document Analysis Protocol for Preschool

Student Exceptionality Modifications on IEP

Ashley J. Preschool Handicapped

Rhonda M. Mentally Impaired

Tommy M. Preschool Handicapped
Vac Pac Chair

Wedge

Standing Table

Adult Assistance for toiletry needs and mobility

Shortened school day - she will attend school from 8:00 A.M. to 10:00 A.M. 4 days/week

Simplify directions: check for understanding

Keep materials close at hand

Modify or use alternate assignments at her level as needed

Individual help or small group work as much as needed

Limit independent work

Supplementary Aide - he requires a lot of assistance. This is the only way he can be successful with non-handicapped peers 


\section{Kindergarten IEP Modifications}

At the kindergarten level there is only one student identified as special needs within this kindergarten class. Modifications on her IEP (see Table 4) were specific to completing assignments (allowing extra time, directions to be clarified, and modifying assignments to meet performance level) and for testing (in a small group). No general modifications were listed.

Assignment Modifications:

- Extended time

- Clarify directions

- Modify to meet performance level
Testing Modifications:

- In small group

General Modifications:

None listed 
Table 4

IEP Document Analysis Protocol for Kindergarten

Student Exceptionality Modifications on IEP

Linda S. Mentally Impaired $\quad$ Extended time to complete assignments

Clarify directions

Modify assignments to meet performance level

Test in small group if needed 


\section{First-grade IEP Modifications}

All three identified special need first-graders had modifications on their IEPs (see Table 5) for completion of assignments (e.g., shorten or allow extra time) and for testing (test in small group if needed). In addition, modifications were listed for general success within the regular classroom environment, such as no grade being given below $65 \%$ if task is attempted.

Assignment Modifications:

- Shorten or allow extra time

- $\quad$ Extended time

- Clarify directions

- Modify to meet ability level

\section{Testing Modifications:}

- Read test orally and/or accept oral answers

- Test in small group if needed

- If test score is below $65 \%$, retest orally and average both test scores
General Modifications:

- Include class participation in grades

- If non-successful, redo assignment in special ed.

- No grade below 65\% if assignment is attempted 
Table 5

IEP Document Analysis Protocol for First Grade

Student

Michael M. Mentally Impaired

Sandra P. Mentally Impaired
Modifications on IEP

Shorten or allow extra time to complete assignments

Clarify directions and check for understanding

Modify classroom assignments to meet ability levels

Include class participation as part of grade

Read tests orally and/or accept oral answers

Test in small group if needed

Jason M. Other Health Impaired (ADHD) Extended time to complete assignments

Clarify directions and check for understanding

Modify assignments to meet performance level in the academic areas of phonics, reading, spelling, and grammar

If classroom test score is below $65 \%$, retest orally and average both test scores

Non-successful academic achievement on written tasks will be redone with special education staff

Shorten or allow extra time to complete assignments

Clarify directions and check for understanding

Modify classroom assignments to meet ability levels

Include class participation as part of grade

Read tests orally and/or accept oral answers

Test in small group if needed.

No grade below $65 \%$ as long as assignment is attempted 


\section{Second-grade IEP Modifications}

At the second-grade level, all six students had some modification to classroom assignments and various testing accommodations (see Table 6). In addition, each of the six students had at least one general modification on their IEPs that would allow for the student to experience some success, such as: no failing grade if attempted, including class participation as part of the grade, preferential seating, and checking for on-task.

Assignment Modifications:

- Extended time

- Clarify directions

- Modify to meet performance level

- Use mathematical tables, charts, and calculators

\section{Testing Modifications:}

- Retest orally as needed/if score is below $65 \%$

- Accept oral answers

- Extra breaks, extra time, \& flexible scheduling

- Test in small group
General Modifications:

- No grade below $60 \%$ or $65 \%$ if attempted

- Include class participation as part of grade

- Preferential seating

- Check for on-task and redirect 
Table 6

IEP Document Analysis Protocol for Second Grade

Student $\quad$ Exceptionality $\quad$ Modifications on IEP

Susie C. Learning Disability

Sasha D. Mentally Impaired

Jonie D. Mentally Impaired

Zane M. Learning Disability
Extended time to complete assignments

Clarify directions and check for understanding

Modify assignments to meet performance level

If test score is below 65\%, retest orally

Testing will include more breaks, extra time for timed testing, and flexible scheduling

Allow extra time to complete assignments

Clarify directions and check for understanding

Read tests orally as needed

Modify classroom assignments to meet ability levels

No grade below $60 \%$ will be given as long as work is attempted

Use mathematical tables and charts as needed

Shorten or allow extra time to complete assignments as needed except reading tests

Test in small group if needed

Modify classroom assignments to meet ability levels

Include class participation as part of grade

Preferential seating away from distractions

Use mathematical charts, calculator, and tables as needed

Check for on-task behavior; redirect as needed

Extended time to complete assignments

Clarify directions and check for understanding

Modify assignments to meet performance level

No grade below $65 \%$ as long as the assignment is attempted

More breaks, extra time for timed testing, and flexible scheduling 
Table 6 (continued)

IEP Document Analysis Protocol for Second Grade

Student Exceptionality

Modifications on IEP

Ritchie R. Mentally Impaired

Shorten or allow extra time to complete assignments

Clarify directions and check for understanding

Modify classroom assignments to meet ability levels

Include class participation as part of grade

Read tests orally and/or accept oral answers

Test in small group if needed

No grade below $60 \%$ as long as assignment is attempted

Tyrone W. Learning Disability

Clarify directions and check for understanding

If test score is below $64 \%$, retest orally 


\section{Third-grade IEP Modifications}

Each of the five third-graders had at least one modification (See Table 7) for assignment completion (e.g., modify to ability level) and for test-taking (e.g., retest orally if obtaining score below 65\%). Three of the five third-grade students had general modifications on their IEPs that would assist with successful inclusion, such as: pointing out spelling and punctuation errors without penalizing for grades, dictating lengthy written responses to a scribe, and assignment reduction in all academic areas.

Assignment Modifications:

- Clarify directions

- Modify to ability

- Extended time

Testing Modifications:

- Retest orally if score below $64 \%$

- Extended time
General Modifications:

- $\quad$ Preferential seating

- Point out spelling and punctuation errors but do not penalize for grading purposes

- Dictate lengthy written responses to scribe

- Assignment reduction in all academic areas 


\section{Table 7}

IEP Document Analysis Protocol for Third Grade

\begin{tabular}{|c|c|c|}
\hline Student & Exceptionality & Modifications on IEP \\
\hline \multirow[t]{4}{*}{ Jarrod B. } & Behavior Disorder & Preferential seating \\
\hline & & Clarify directions \\
\hline & & $\begin{array}{l}\text { Modify classroom assignments to match } \\
\text { ability levels }\end{array}$ \\
\hline & & $\begin{array}{l}\text { May retake orally tests which have a score } \\
\text { below } 65 \%\end{array}$ \\
\hline \multirow[t]{5}{*}{ Kenny B. } & Learning Disability & $\begin{array}{l}\text { Extended time to complete assignments and } \\
\text { written tests as need }\end{array}$ \\
\hline & & $\begin{array}{l}\text { Clarify directions and check for } \\
\text { understanding }\end{array}$ \\
\hline & & Modify assignments to performance \\
\hline & & $\begin{array}{l}\text { Point out spelling and punctuation errors, } \\
\text { but do not penalize for grading purposes }\end{array}$ \\
\hline & & $\begin{array}{l}\text { Dictate lengthy written responses to a scribe } \\
\text { as needed }\end{array}$ \\
\hline \multirow[t]{4}{*}{ Evan D. } & Learning Disability/Behavior & Extended time to complete assignments \\
\hline & & $\begin{array}{l}\text { Clarify directions and check for } \\
\text { understanding }\end{array}$ \\
\hline & & Modify assignments to performance level \\
\hline & & $\begin{array}{l}\text { If classroom test score is below 65\%, may } \\
\text { retest orally }\end{array}$ \\
\hline \multirow[t]{6}{*}{ Brianna P. } & Learning Disability & Extended time to complete assignments \\
\hline & & Modify to performance level \\
\hline & & $\begin{array}{l}\text { Clarify directions and check for } \\
\text { understanding }\end{array}$ \\
\hline & & Test scores below 64\%, may retest orally \\
\hline & & The two test scores will be averaged \\
\hline & & $\begin{array}{l}\text { Assignment reduction in all academic areas } \\
\text { to performance level }\end{array}$ \\
\hline \multirow[t]{3}{*}{ Charity R. } & Learning Disability & Extended time to complete assignments \\
\hline & & $\begin{array}{l}\text { Clarify directions and check for } \\
\text { understanding }\end{array}$ \\
\hline & & $\begin{array}{l}\text { If test grades are below } 64 \% \text {, may retest } \\
\text { orally }\end{array}$ \\
\hline
\end{tabular}




\section{Fourth-grade IEP Modifications}

Five fourth graders’ IEPs contained a modification (see Table 8) concerning classroom assignment completion (e.g., clarify directions) and five out of six IEPs contained a test modification, such as read tests orally in content area subjects.

Four of the six students' IEPs allowed for general modifications, such as providing a scribe, grades to be determined by regular and special educator together, reduced workload, and one-on-one tutoring.

Assignment Modifications:

- Shorten or allow extra time

- Clarify directions

- Modify to ability level

Test Modifications:

- Read orally and/or accept oral answers

- Test in small group

- Retest orally if score below $64 \%$

- Read tests orally in content area subjects
General Modifications:

- Include class participation as part of grade

- Provide a scribe for larger written expression answers

- No grade below $65 \%$ if attempted

- Grades will be determined together by classroom and special ed. teacher

- Reduced work load

- One-on-one tutoring 
Table 8

IEP Document Analysis Protocol for Fourth Grade

Student $\quad$ Exceptionality $\quad$ Modifications on IEP

Edwin D. Mentally Impaired

Jasper M. Learning Disability

Taylor M. Learning Disability

Chester P. Mentally Impaired

Robin S. Learning Disability
Shorten or allow extra time to complete assignments

Clarify directions and check for understanding

Modify classroom assignments to meet ability levels

Include class participation as part of grade

Read tests orally and/or accept oral answers

Test in small group if needed

Allow extra time to complete math assignments

Clarify directions and check for understanding

Extended time to complete assignments

Clarify directions and check for understanding

Test scores below 64\%, may retest orally

Modify assignments to meet performance level

Tests will be read orally for content area subjects

A scribe will be provided for larger written expression answers

Extended time to complete assignments

Clarify directions and check for understanding

Modify directions to performance level

If classroom test score is below 65\%, may retest orally

Extended time to complete assignments

Clarify directions and check for understanding

Modify assignments to performance level

If classroom test score is below 65\%, may retest orally

No grade below $65 \%$ given as long as assignment is attempted

Grades will be determined together by the classroom and special education teacher 
Table 8 (continued)

IEP Document Analysis Protocol for Fourth Grade

\begin{tabular}{ll} 
Student & Exceptionality \\
\hline
\end{tabular}

CalebY. $\quad$ Mentally Impaired $\quad$ Reduced work load

One-on-one tutoring

Oral testing

Extended time as needed 


\section{Relationship Between Modifications and Interview Questions}

Within the six interviewed regular education classrooms (see Table G1 - Appendix G), there was a total of fifty-four separate modifications listed on the students’ IEPs. However, when asked questions about what modifications they were using in class and what they might be doing for special education students that will enhance instruction for all students, the teachers indicated thirty additional modifications that they were currently implementing that were not listed on their students' IEPs. Of the fifty-four separate modifications, only ten that were listed on their students’ IEPs were reportedly being used by these six teachers in their classrooms. This indicates that only $18 \%$ of the modifications listed on the students’ Individualized Education Program (IEP) were mentioned by the teacher when asked what modifications they use in class.

In three of the six interviews, the teachers indicated that they could not think of any modifications that would help all students that they weren’t already doing. While one teacher specified that she would like to do more writing activities to assess individual writing ability, this might not be considered a modification. Of the remaining teachers, two indicated that they would like to do more small-group activities that might help all the students in their classes.

Table 9 presents the different modifications listed for all of the twenty-four students within these six regular education classrooms. Of the twenty-five different modifications, eleven were common to more than one classroom for students, and three were specified to be implemented in all six classrooms, according to the students' IEPs. However, during the interviews, none of the six teachers mentioned simplifying directions, modifying assignments to student's level, or extended time as modifications 


\section{Table 9}

Common Modifications

Modification

Frequency

Simplify/clarify directions; check for understanding 6

Modify or use alternate assignments at student's level 6

Extended time or shortened assignments; allow extra breaks 6

Test in small group if needed $\quad 4$

Retest orally \& average test scores if score is below 65\% 4

Include class participation in grades 3

No grade below 65\% if assignment is attempted 3

Read test orally 2

Preferential seating $\quad 2$

Dictate lengthy written responses to scribe $\quad 2$

Assignment reduction in all academic areas; reduced workload $\quad 2$

Keep materials close $\quad 1$

Individual help or small group work as much as possible $\quad 1$

Vac Pac chair, wedge, standing table $\quad 1$

Adult assistance (full-time) 1

Shortened school day 1

Limit independent work $\quad 1$

If unsuccessful, redo assignment in special education 1

Use mathematical tables, charts, and calculators 1

Accept oral answers $\quad 1$

Check for on-task and redirect $\quad 1$

Point out spelling \& punctuation errors but do not penalize for grading purposes 1

One-on-one tutoring $\quad 1$

Read tests orally in content area subjects 1

Grades will be determined together by classroom \& special education teacher 1 
that they were implementing within the classrooms in which these modifications are listed on IEPs for students in their class.

\section{Conducting Interviews}

The individual interviews with the six regular classroom teachers were conducted within the school building itself during the summer when there were no distractions. The speech room, which houses two speech therapists, was the location for discussing the questions on the Interview Protocol. Although the computers, shelves, and bookcases were covered for the summer, the tables and chairs were available and were all that was needed to conduct the interviews. The participants were each dressed casually in shorts and short sleeves for the season.

Each interviewee sat across from the researcher at the table with the cassette recorder between them. Each of the regular classroom teachers was cooperative throughout the interviewing process with no discussions before or after concerning what was said. The interviewee was addressed at the beginning of the taping as the grade-level teacher for the students they teach, rather than by their name, which further validated the anonymity that they were assured.

Furthermore, there were no objections to my tape recording the interviews. The teachers were candid and verbally communicative while expressing their opinions, suggestions, and perceptions.

\section{Impact of Shared Decision-Making on Inclusion}

The question of how shared decision-making can impact the process of inclusion is indicated in Tables H1 through H6 - Appendix H, which contain the interviewed teachers' perceptions and opinions about inclusion and shared decision-making within 
this school setting. What they had to say regarding inclusion and the implementation of it and how shared decision-making is carried out merges into the impact of shared decisionmaking on inclusion in each of these six tables. All of the grade levels are individually depicted with documentation of the teachers' comments.

Within these individual tables are reported ways that are currently in existence in this setting of how students' needs are being met through inclusion. Evidence from the interviews of meeting students’ needs while implementing inclusion consisted of teachers formally and informally collaborating to discuss techniques to assist students, examining the provided services, and resolving barriers on a regular basis.

The information reported by the teachers on the six individual grade charts yields Table 10 in which four common trends can be identified from the interviews of how shared decision-making impacts inclusion. It can be seen that the teachers' comments indicate that within these four areas of impacting inclusion there are many examples of shared decision-making being effectuated in this educational environment.

\section{At SAT and IEP Meetings}

At SAT and IEP meetings all of the individuals in attendance have the opportunity to verbalize what suggestions they would like to make for the instruction of that child. This would be through modifications to the curriculum and accommodations that will help the child be successful in a classroom with students his or her same age who learn in different ways. The kindergarten teacher said that it is at these meetings that, "We discuss strategies that you would use with that child" and that "You get to verbalize at SAT and IEP meetings the academic and social progress the child has made in the regular classroom.” The first-grade teacher reflects that she shares this 
Table 10

How Shared Decision-Making Impacts Inclusion

Trends

Examples

At SAT \& IEP meetings

Through Collaboration

By Services for Students

Resolves Barriers
Look at samples of student's work

Discuss what has and hasn't worked for the student

Work as a team to make decisions

Discuss academic and social progress

Discuss student's needs with all the people involved

Get input from other people

Scheduling the students

Everybody has different opinions \& sees a child differently

Modifications

Strategies \& techniques

Curriculum

Talking \& sharing \& coming up with a good plan that is best for the student

Regular ed. and special ed. sharing weekly lesson plans The best way for special students to learn

Special educators sharing ideas with classroom teachers

Placement for student's benefit

Programs students should be in

Trying to make transitions smoother

Regular educators sharing with special educators what is needed for them to help students in regular classroom

Getting the best possible situation going for the child Special educators going into regular classrooms to work to help students with regular educator

Shared decision-making has an impact on how teachers feel about inclusion

Work harder to achieve the goal by being a part of it 
opinion when she says, "We work as a team and make decisions about kids in IEP meetings.” The second-grade teacher sums up the purpose of IEP meetings when she says, “At IEP meetings I give input and tell them the student's needs and what I think needs to be done and what we've done so far that's worked and what hasn't worked." The third-grade teacher expressed the sentiment that she feels, “...open and comfortable in the IEP meetings.” She added, “In IEP meetings you can come right out and say exactly how the student is doing.” Getting to “...communicate with the special education teacher at the IEP meetings” seemed important to the fourth-grade teacher.

\section{Through Collaboration}

Through collaboration is another trend reflected in how shared decision-making impacts inclusion. The preschool teacher indicates that "Everybody here listens and collaborates to make a student's setting better.” The first-grade teacher offers her sentiment toward collaboration in this school with this statement, "Shared decisionmaking improves inclusion because everybody has a different opinion and everybody sees a child differently." The second-grade teacher says that "Shared decision-making improves inclusion because you have input from other people” and it provides “...time to get together and discuss to get input from other people to come up with the best solution.” This statement represents collaboration as it is viewed by the interviewed teachers.

\section{By Services for Students}

Services are provided, as reported by the preschool teacher, through the "Placement of students in regular classrooms with specific teachers for the benefit of the child who wants the child and can work with them.” The kindergarten teacher 
acknowledges the importance of determining what services will ensure success for special needs students with her statement, "At IEP meetings we decide what programs we think the child should be in.”

A key to improvement and to providing continual beneficial services comes not only by way of direct instruction in the classroom, but also by the organization of the services provided, as agreed to by the first-grade teacher when she said that we need to “...work to try to make the transition smoother between the regular classroom and special education.” The reason for this is so that when the special needs students return from being with the special education teacher they can blend easily back into the regular classroom and work on whatever assignment or activity the other students are doing.

\section{Resolves Barriers}

Resolving barriers for students is also a trend concerning how shared decisionmaking impacts inclusion. It can be seen from comments such as the following how these teachers view the impact of shared decision-making on inclusion: "You work harder to achieve the goal because you were a part of it," according to the first-grade teacher. The fourth-grade teacher remarked, "Shared decision-making has an impact on how teachers feel about inclusion - and that's half the battle.”

Resolving barriers can be achieved in many different ways. One of the solutions to implementing inclusion is to provide a means of better instruction within the regular classroom so that all students can benefit from instruction. One of the ways to achieve better instruction is to obtain good curriculum materials. The second-grade teacher acknowledged how this was achieved in this setting when she said, "The grants we received are outcomes of teamwork that turned out well for the whole school.” 


\section{Barriers to Inclusion}

While examples of shared decision-making are apparent, as reported by these teachers, barriers to inclusion were expressed within their discourses, as indicated in Table I1 - Appendix I. The barriers mentioned by the teachers fall into ten categories: Scheduling, Staffing, Responsibilities, Environment, Curriculum, Modifications, Behavior, Emotional, Training, and Collaboration. In the setting for this case study, the principal encouraging shared decision-making leads to teachers resolving barriers to inclusion on their own.

\section{Scheduling}

Issues involving scheduling were expressed by the preschool teacher because of her concerns about having more special needs students in her preschool class than were in the other preschool class. While believing that inclusion helps "children serve as role models and teach other students," she also sees the merits of a "combination of pull-out and with peers” to provide beneficial services. The second-grade teacher also noted the benefits of inclusion with, "Kids learn well from other students in regular classrooms." However, she too acknowledged the benefits of "combination of pre-teach and pull-out and regular education” as services that should be offered. Two different teachers suggested that a solution to providing better services for special needs students through inclusion is at each grade level to put all the identified special needs students into one regular education classroom. This becomes a scheduling issue. The fourth-grade teacher recognized the dilemma of scheduling for special needs students with her comment, "Scheduling can be done only so many ways." At this school, there is an appreciation of 
the principal's involvement with this statement by the second-grade teacher, “The principal is conscious of needs regarding scheduling.”

\section{Staffing}

One of the staffing issues involves a need for more aides for students requiring adult individual assistance throughout the school day. While not acknowledging that this need would lead to being a barrier for these students for inclusion purposes, the preschool teacher appreciated the principal getting involved and solving this problem for two of the more severe students who were in her preschool class. She said of this situation, “The principal was right there and got something done.” Although finding a solution to this concern, there are other issues regarding staffing that require more effort, and some that may not be resolved even within a given school year. Such is the case concerning the fact that most of the special education teachers have full rosters, as recognized by the fourth-grade teacher, who also acknowledges that there is a need "to hire more teachers to come in the regular class to help with special education students on non-core subjects” in order to make inclusion be more successful. Being spread too thin is a dilemma facing special educators trying to provide services to help students benefit from inclusion. This concern is also reflected in the kindergarten teacher’s comment about needing a “...oneon-one in class to focus attention” for some of the students who have a difficult time staying on task.

\section{Responsibilities}

The more special needs students that a regular classroom teacher has within his or her class, the more responsibilities there are for that teacher to be able to successfully implement inclusion. Some of the concerns expressed by the preschool teacher on behalf 
of the regular educators who have older students is that those teachers are "overworked, such as with reading tests orally” and that the classroom teachers may not be “...reading IEPs” of students in their classes. The first-grade teacher admitted to needing to “...study IEPs.” Both are concerns that could interfere with and be a barrier to inclusion. The kindergarten teacher explained that there are "demands on regular teachers' time” and that the "demands decrease accomplishments" within her class and that it takes "a lot of preparation for individual students,” as well as requiring time to consider “...learning styles." The second-grade teacher suggested that she needed to "keep files and be organized” as part of her own responsibility.

\section{Environment}

Issues involving the environment are varied and range from "lack of space for small groupings," as reported by the fourth-grade teacher, to "special students interfere with the regular classroom,” as expressed by the kindergarten teacher. The discussion about environmental issues indicated a problem for the special needs students with the kindergarten teacher's comments, “special education students needs quiet," but also suggested that the students themselves may on occasion interfere with the regular classroom when noting that "special education students can cause chaos.” In addition, specific disabilities were mentioned by the second-grade teacher as possibly causing problems within the regular classroom: non-medicated ADHD, autistic children, and children with severe speech, while also acknowledging that it "depends on the severity of disability." The "lack of physical space,” as reported by the preschool teacher, reflects her concern that with one student in a wheelchair and one student using a walker having enough space for them to get around is difficult in a preschool class. 


\section{Curriculum}

The opinions concerning the curriculum were varied depending on the circumstances of the teacher reporting the information. The first-grade teacher sees the advantages of both regular education and special education students using the same reading series, so that when the special needs students are out of the regular classroom receiving help on skills related to the reading textbook, they will be able to return to the classroom and blend right in with the other students reading the same story and covering the same vocabulary words. The first-grade teacher says this about how she handles modifying the curriculum, “I adapt my lesson plans when I’m teaching the lesson.”

On the other hand, the preschool teacher recognizes the need for students, who are identified at even a young age as being severely and profoundly handicapped, to have a different curriculum that is individualized for their specific needs. The fourth-grade teacher remarked that some of the curriculum being required for special needs students is "not useable information” if their needs are more severe, and that it is "unjust to give them books they can’t read.” She further explained that by the fourth grade if the students were reading at a much lower reading level, or were even non-readers, it becomes much more difficult to present content-area subjects like science and social studies in which the vocabulary is much more difficult. While the fourth-grade teacher shared the idea that "it takes longer to do a concept because you pull it apart," she acknowledged, “Students don’t seem to notice any difference between students.” However, when planning for the special needs students in her classroom, the fourth-grade teacher commented, "I target the lesson plans toward them and then adapt it for the other two ends of the spectrum.” 


\section{Modifications}

Even the preschool teacher acknowledged, “Having to teach below level leaves out higher kids.” She also stated that there needs to be “...more hands-on in the regular classrooms” for students to be more successful. Surprisingly, the kindergarten teacher sees even at this young level that some students are "bored by moving too slowly," and that this presents "challenges of high and low" students being taught together. The firstgrade teacher confirmed this with the sentiment, "You have to gear the work down and slow it down," while also believing that the "work is too hard for some” students. Although the fourth-grade teacher believes that there are "unrealistic goals for really low students,” the second-grade teacher says regarding modifications, “The instruction is the same - just different levels on same activity” and that it is necessary to “...design each lesson so everyone can be successful.” The ongoing challenges facing regular education teachers making modifications to the curriculum for special needs students is evident from these discussions. The third-grade teacher summed up how she handles this challenge by saying that she modifies work but makes sure "all students get the same basics.”

Behavior

"Behavior problems are a concern when students get frustrated,” according to the first-grade teacher, and that "behavior affects the class.” The fourth-grade teacher acknowledges, "Behavior problems cause difficulty.” The kindergarten teacher has this aspiration concerning behavior, "I expect them to not interfere.” While the preschool teacher expressed, “Sometimes B.D. [Behavioral Disorders] children are uncontrollable,” 
in general the topic of behavior concerns in the classroom did not evoke a great deal of comment.

\section{Emotional}

There were emotional issues identified within this setting that involve shared decision-making and inclusion, as well as attitudes and feelings in general. The comments recognized as being emotional concerns ranged from the preschool teacher's comment, "Special education students are unwanted by some teachers" to the fourthgrade teacher’s concern, “No child Left Behind causes frustration.” There were comments that emerged about some staff members possibly not being open to suggestions and being unwilling to try new things. Taking this a step further was the explanation that getting together in smaller groups affords fewer opportunities for discussions and comments to be misinterpreted. Of greater concern regarding the topic of special needs students is the fourth-grade teacher's comment that "we are setting students up for failure with the same expectations as other students,” and a recognized emotion of having "mixed feelings about slow students.” This perceptive expression of her feelings is coupled with the first-grade teacher saying about special needs students, “They feel less threatened in a special education setting.” Resolving emotional issues regarding both how the students and the teachers feel about the inclusion of all students in the regular classroom is an area that is sensitive, but still necessary, by an educational leader.

\section{Training}

There were many expressed ideas about training, and the need for it and the lack of it, interspersed throughout the teachers' discussions during the interviews. The kindergarten teacher said that she would like "ideas about what needs to be done” with 
the special needs students in her class, and "more knowledge of" and "characteristics of special needs children." She further explained that it is "hard to know what to do with them.” The first-grade teacher commiserated with this by her own comments that she did not have "much training about special education in college" and that she needs "training about disabilities and how to teach them” and "different techniques to work with...” the special needs students. Regarding inclusion, she would like to know "what is expected of teachers." The second-grade teacher feels that she does not "know what modifications are out there,” because, as she says, “I don't have a background knowledge of special education.” Both the third-grade and fourth-grade teachers acknowledged that they would like to know more about how to do small-group activities.

\section{Collaboration}

A barrier to inclusion that was generally acknowledged by the regular education teachers interviewed was a need for time together between the special education teachers and the regular classroom teachers to coordinate, plan, and discuss various aspects of including and instructing special needs students. The fourth-grade teacher expressed this by saying, "We need time together to discuss students having difficulties.” The secondgrade teacher said, “We need time together for regular and special education teachers.”

The first-grade teacher's comment, "Regular educators and special educators need time to coordinate” was similar to the third-grade teacher saying that there is a need for a "shared planning period for special and regular educators.” The kindergarten teacher expressed it this way: "We need time together for suggestions and strategies.” Only the preschool teacher did not ask for time to collaborate. An explanation for this is that a teacher of preschool handicaps is both a regular educator and a special educator with training in 
special needs who would not, therefore, have a need to coordinate her services, nor need further training concerning special needs. However, there was a consensus by the other five regular classroom teachers that there needs to be a common time for them to meet on a regular basis in order to help students to be successful in an inclusive setting. This is obviously an area for educational leaders to be concerned about and to address in order to help inclusion be implemented successfully.

Taking this a step further, Figure 1 discloses the barriers to inclusion by the number of reports within the interviews. As can be seen, modifications was the most frequently reported barrier to inclusion within these six classrooms with lack of training being the next highest reported barrier, followed by a need for more collaboration. Curriculum was indicated as the least concern regarding inclusion for students. Table 11 demonstrates examples of how shared decision-making is helping to resolve these barriers within these same ten categories. While barriers to inclusion exist within this school setting, there are definite examples of solving these issues that were corroborated by the teachers. For example, while teachers indicated that there are additional responsibilities for them to instruct special needs students within their classrooms, an example given was the issue being resolved by special education teachers going into the regular classrooms to assist with instruction. The issue of the same reading series being used by both regular and special educators was resolved by the teachers being involved with the selection process of a new reading series that would meet the needs of all students and that could be used within special education and regular classroom settings. Special educators and regular educators getting together at the beginning of the year assists in determining what will help special needs students. 
Figure 1

\section{Barriers to Inclusion}

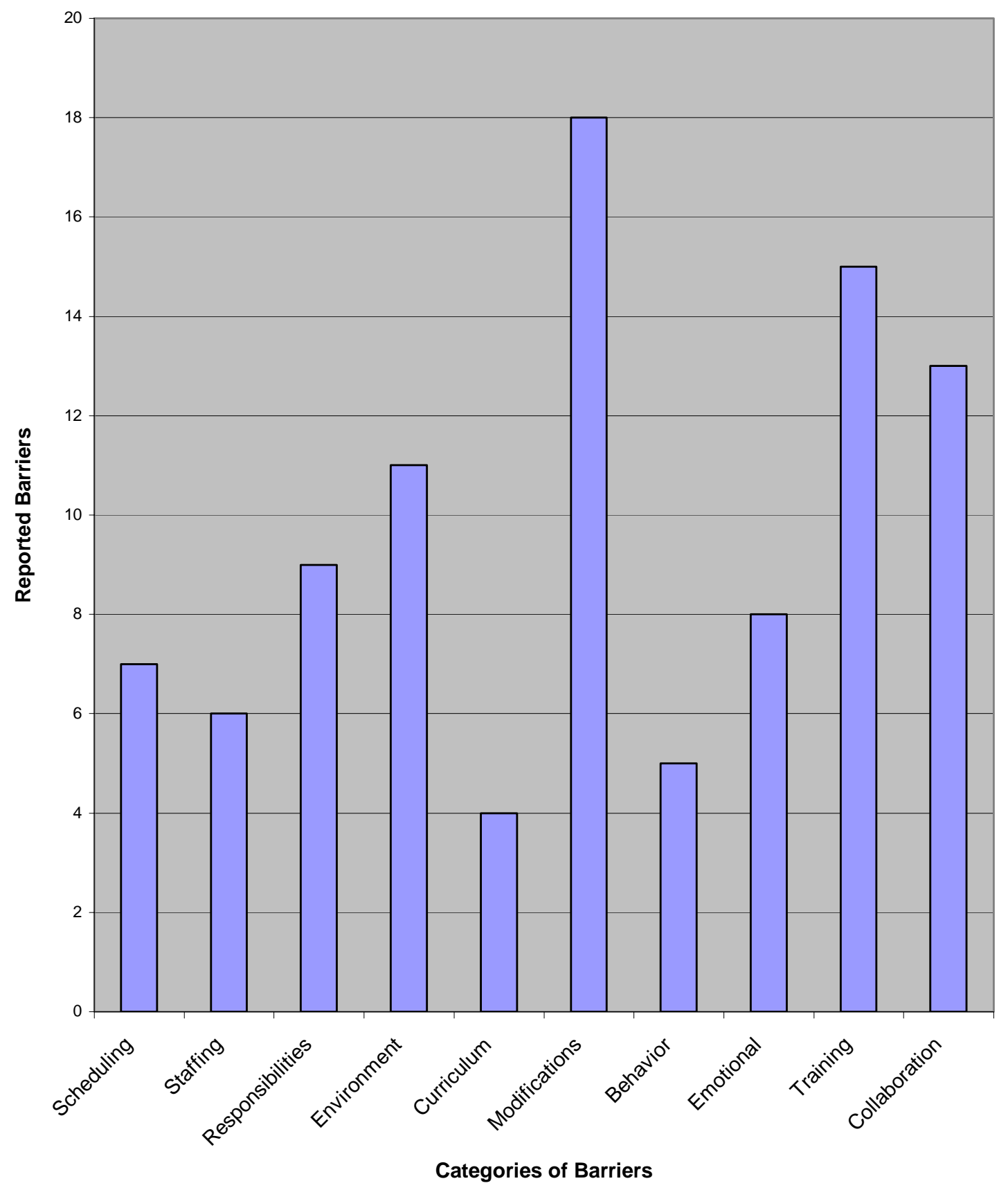

Figure 1. Separate barriers to inclusion reported by the teachers interviewed (left axis) and barriers divided into separate categories (right axis) yield the number of reported barriers to inclusion for each category. 
Table 11

Examples of How Shared Decision-Making is Resolving these Barriers for Inclusion

Barrier Possible Solution to Barrier

Scheduling Through decisions about scheduling and inclusion by special educators Placement in specific regular classroom

Staffing Principal adding staff after problem was discussed about preschool student

Responsibilities Special ed. teachers going into regular classes to provide assistance

Environment Special educator suggests strategies to use with children

Curriculum $\quad$ Requested same reading series for both special and regular ed.

Modifications Deciding on modifications as a team at SAT and IEP meetings

Behavior Having somebody else right there to help focus the students' attention

Emotional Everybody having a voice

Working harder to achieve a goal when you are a part of it

Feeling important and worthwhile

Impacts teachers’ feeling about inclusion

Training Being given hand-outs by special educators

Regular ed. and special ed. working together

Collaboration At SAT and IEP meetings

Through planning together at the beginning of the year

Discussing strategies, techniques, modifications, schedules, curriculum

Classroom teachers getting ideas from special educators for students 


\section{Regular Educators Included in Shared Decision-Making for Inclusion}

There were many reported ways by those interviewed of how this school implements shared decision-making into various aspects of the school, as well as for decisions that affect inclusion for special needs students in the regular classroom. These regular educators indicated ways that they are included in decisions that enhance the implementation of inclusion in this school (see Table J1 - Appendix J). There are indications within these statements that demonstrate that sharing in decisions makes teachers feel important and worthwhile.

There are further indications within the teachers' statements of the importance of ownership of decisions when it comes to accomplishing and fulfilling what has been decided (see Table K1 - Appendix K). These comments also contain positive sentiments about the benefits of inclusion, not only for special needs students, but for students within the regular classroom who are their peers.

The information from the interviews provided nine categories of ways that the teachers are included in making decisions affecting inclusion. A statement such as, "You work harder to achieve the goal because you were a part of it,” is viewed as one way - by taking ownership - that regular educators are included in shared decision-making for inclusion. "Shared decision-making helps with including students and doing lessons and modifications” expresses another way that regular educators are included in the decisions for inclusion of special needs students. Breaking this type of information down into grade levels (see Figure 2) demonstrates further how teachers within this school make decisions that yield positive results toward implementing inclusion. Six of the nine ways were verbalized by all of the teachers interviewed. 
Figure 2

How Regular Educators are Included in Shared Decision-Making for Inclusion by Grade Level

\begin{tabular}{|c|c|c|c|c|c|c|}
\hline & $\mathrm{P}$ & $\mathrm{K}$ & $1^{\text {st }}$ & $2^{\text {nd }}$ & $3^{\text {rd }}$ & $4^{\text {th }}$ \\
\hline At SATs \& IEPs & $\mathrm{X}$ & $\mathrm{X}$ & $\mathrm{X}$ & $\mathrm{X}$ & $\mathrm{X}$ & $\mathrm{X}$ \\
\hline By planning for students (placement, scheduling, etc.) & $\mathrm{X}$ & $\mathrm{X}$ & $\mathrm{X}$ & $\mathrm{X}$ & $\mathrm{X}$ & $\mathrm{X}$ \\
\hline By planning for curriculum \& modifications & & $\mathrm{X}$ & & $\mathrm{X}$ & $\mathrm{X}$ & $\mathrm{X}$ \\
\hline By determining what's best for students & $\mathrm{X}$ & $\mathrm{X}$ & $\mathrm{X}$ & $\mathrm{X}$ & $\mathrm{X}$ & $\mathrm{X}$ \\
\hline Through collaboration & $\mathrm{X}$ & $\mathrm{X}$ & $\mathrm{X}$ & $\mathrm{X}$ & $\mathrm{X}$ & $\mathrm{X}$ \\
\hline With positive feelings about inclusion & $\mathrm{X}$ & $\mathrm{X}$ & $\mathrm{X}$ & $\mathrm{X}$ & $\mathrm{X}$ & $\mathrm{X}$ \\
\hline With positive feelings about shared decision-making & $\mathrm{X}$ & $\mathrm{X}$ & $\mathrm{X}$ & $\mathrm{X}$ & $\mathrm{X}$ & $\mathrm{X}$ \\
\hline By taking ownership & & & $\mathrm{X}$ & & & $\mathrm{X}$ \\
\hline By working as a team & $\mathrm{X}$ & & $\mathrm{X}$ & & & \\
\hline
\end{tabular}

Figure 2. Nine different ways emerged of how regular education teachers share in decisions that assist in implementing inclusion within this school. 


\section{Emergent Themes}

Examination of the information provided by the teachers during the interviews leads to thirteen different themes being identified (see Table L1 - Appendix L). The data supports the notion of needs, such as more training and more extensive collaboration. There are also affirmative statements regarding the role of the principal and the advantages of inclusion.

Positive Shared Decision-Making

Statements concerning regular educators and special educators working together, and that shared decision-making helps with doing lessons and modifications, were viewed as samples of the emergent theme, Positive Shared Decision-Making. A few examples expressed by teachers appreciating their opportunities for giving input include: “It’s a committee decision with almost everything we do,” and “Working together lets classroom teachers know what works.”

Positive Inclusion

The statement, “Students get to spend time with their peers and don’t feel different," was determined to fall under the theme of Positive Inclusion. One of the best reasons for implementing inclusion is manifested in the following comment: "Inclusion shows all the kids that everybody can learn.” A teacher's perception that inclusion is so much better than busing the kids to different schools, that with inclusion all the kids get some attention, and that students enjoy being part of the whole class, are further indications of positive inclusion. "Inclusion is good and it's working” and "The good thing about inclusion is that nobody is pointed out” sum up inclusion viewed in a positive way. 


\section{Modifications}

Comments about modifications were as varied as modifications are that are listed on students' IEPs. These included: “I modify grades according to the IEP and grade on oral work" and "I provide more severe students the same concept but below level,” which indicate the teachers' attempts to help students be successful through their attempts at making modifications and adaptations to the curriculum in the regular classroom.

\section{Principal}

There are many responsibilities of the principal that were mentioned within the interviews by these classroom teachers. Appreciation for his involvement was indicated with remarks such as, “The principal works well in meetings to help place students;” “The principal is conscious of needs regarding scheduling;” and "The principal helps when we go to him about any of our students." Within this building, indications are that the involvement by the principal helps to improve the inclusion process. The shared decision-making, evidenced by the various teams and committees, is in place due to the style of educational leadership within this school.

\section{Ways to Help Students}

Within this group of teachers, there were many ways reported in which students receive help. A few examples are: positioning the student close to the teacher if they are distractible, testing the student separately and using flashcards, guiding students' hands individually for writing, designing each lesson so that everyone can be successful, putting students in groups “so no one looks like they’re getting help,” and helping individual students to get started so that they can then work independently. The nurturing nature of these teachers was demonstrated during the interviews. 


\section{Lack of Training}

The interviewed teachers were quite communicative about wanting further training in order to help special needs students within their classes. They are seeking more information about disabilities, strategies, techniques, modifications, and what is expected of teachers implementing inclusion. It is perceptive of them to realize these needs. It then becomes the responsibility of the administrator in a school to seek out resources and to make the knowledge available to those individuals who are working with students with special needs.

\section{More Time to Collaborate}

The participants interviewed are also searching for a shared time for regular educators and special educators to be able to discuss "problems and strategies” and “necessary changes,” to have time to coordinate, share, and talk together, and even to have "more time at IEP meetings to discuss what needs to be done" for the special needs student. It was communicated by several of the teachers that they sometimes discuss ways to help students as they walk to their cars in the parking lot at the end of the day or during a few minutes in the morning before school starts. While the teachers expressed the need for special and regular educators to have time together, a few acknowledged that they weren't sure how it would be feasible. This becomes the responsibility of the building principal to analyze the need for this collaborative time and to develop a plan that would create these opportunities.

\section{Attitudes}

There were viewpoints expressed by some of the teachers that attitude needed to be worked on among adults in some cases in order to become more open to suggestions 
and to be willing to try new things. Recommendations were made to find all the details before voicing an opinion and to not take it personally if someone disagrees with you. Reports from these interviews indicate that despite some occasional disagreement between professionals, something is working for the benefit of the students in this school. Concerns about Students in Classrooms

There were expressed concerns that sometimes students who are diagnosed with attention deficit hyperactive disorder (ADHD) do not always take their medication, which causes a problem in class if they aren't focused. One teacher, who had several students in her class diagnosed with ADHD, confessed that sometimes she felt there was just “chaos.” It was verbalized by another teacher that sometimes behavior problems cause difficulty in class. The principal's support becomes relevant for these types of situations. Scheduling

It was generally acknowledged by the interviewed teachers of the involvement by the principal regarding the placement of special needs students in specific classrooms for the benefit of the students. Comments indicating this included: placement of students was "for inclusion purposes;" "Placement in specific regular education classes is for students' benefit;” and “Scheduling can be done only so many ways.”

\section{Regular Educators to Collaborate}

The teachers reported that due to scheduling changes in the school, during the second year that the building was opened, grade-level team planning for regular educators had to be eliminated. During the interviews, they expressed reasons that this needed to be put back in place: the need for team planning to get everybody's opinions, grade-level teams helped to coordinate it all, and team planning helped teachers to share 
ideas. The indications were that their input concerning this had made an impact, which led to changes in the school schedule that would allow the team planning to again be put back in place during the third year of the school being in operation. This is an example of shared decision-making contributing to decisions being made in the school that lead to better services for students and that create opportunities for collegiality among teachers. Need for More Staffing

Needing more special education teachers to help implement inclusion within the regular classroom was expressed by one of the participants. It was also suggested that more aides within the regular classrooms would help to implement inclusion better for students in those classes, and that having somebody right there one-on-one would help to keep the distractible student focused in class. The principal had listened to the concerns communicated by a teacher on the behalf of one child, whom she felt could only function successfully in school by having continuous adult supervision, and "he got something done” by being instrumental in the hiring of a one-on-one aide for that particular student.

\section{Physical Environment}

It was conveyed that more space for students with wheelchairs and walkers would be nice and that more space in the regular classrooms would make it easier for having groups of students working on different activities to allow space between groups. Space in this school seems to be a valuable commodity after only being in existence for two years. Solving this issue requires real resourcefulness on the part of the principal. Further analysis of the information from Table L1 - Appendix L yields Figure 3, which is a numerical representation demonstrating how many of the six teachers interviewed made comments falling into these categories. An awareness by the teachers 
Figure 3

\section{Emergent Themes}

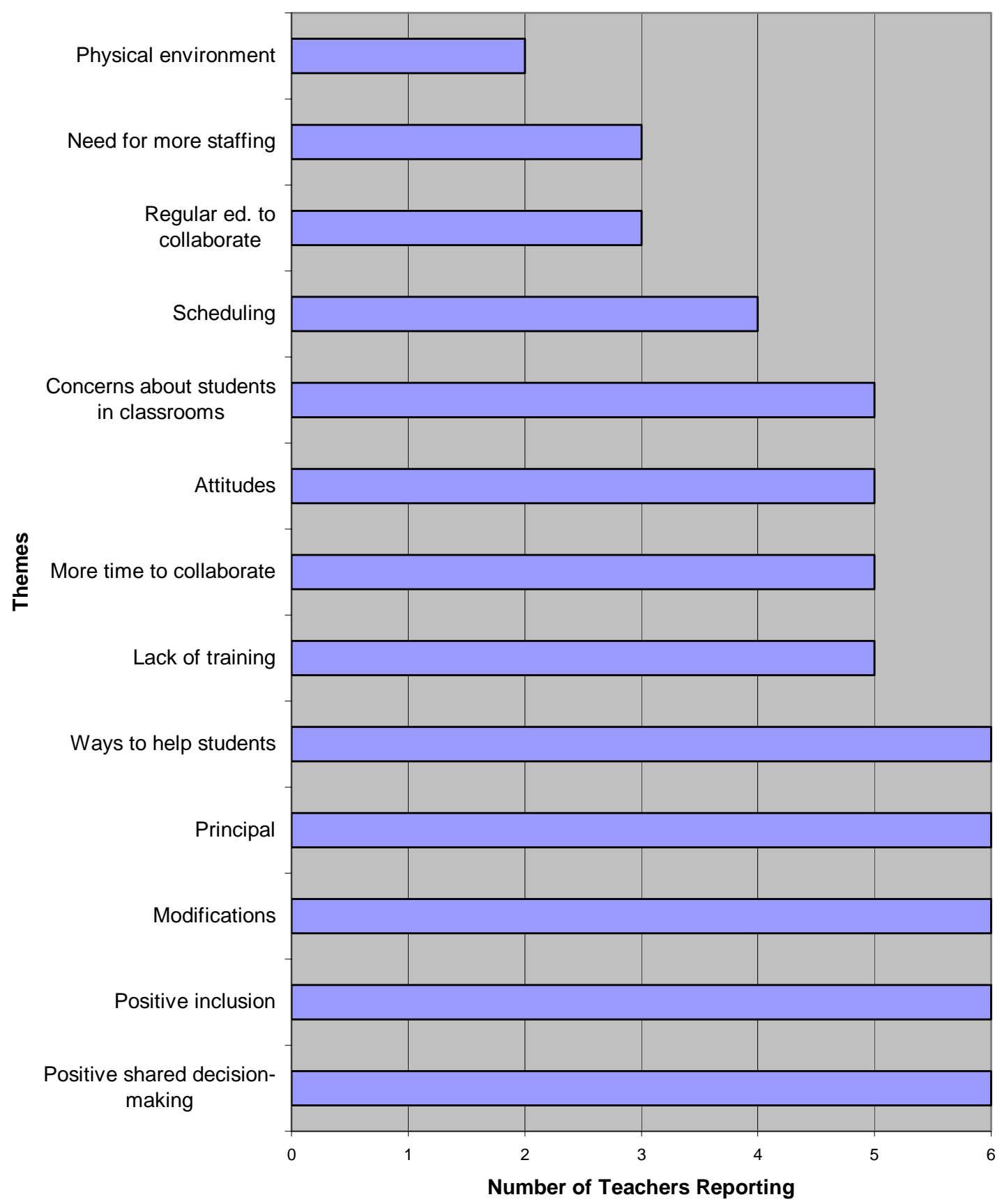

Figure 3. The themes (left axis) that emerged from the six teachers' comments is indicated. The frequency of the comments is demonstrated by the number of teachers (right axis) making statements that fall into each of these thirteen themes. 
is exhibited within this figure of seeking out more knowledge that will benefit the students during the implementation of inclusion. Although the teachers reported some concerns over attitudes within the school environment, a need for more staff to help, and better ways of scheduling special needs students, their overall concerns reflected the ways that they utilize the resources available and view attributes within the building. This is indicated by comments regarding the manner in which they help students in their classrooms. Five of the emergent themes (Positive shared decision-making, Positive inclusion, Modifications, Principal, and Ways to help students) were referred to by all six of the teachers. Four other emergent themes were identified by five of the six regular classroom teachers. 


\section{CHAPTER 5}

\section{DISCUSSION}

How can shared decision-making impact the process of inclusion for special needs students? The current case study was conducted to answer this question plus two additional questions: (a) How can shared decision-making resolve barriers for inclusion? (b) How are regular educators included in the decision-making process when it comes to inclusion of special needs students in their classrooms?

Shared Decision-Making Impacting Inclusion

The results of this case study strongly suggest that shared decision-making can impact the process and resolve barriers to inclusion for special needs students. Given the fact that the most reported barrier to inclusion was concerns with modifications, it becomes more relevant that deciding on modifications as a team at SAT (Student Assistance Team) and IEP (Individualized Education Program) meetings is viewed by teachers as a way to resolve inclusion barriers, and provides teachers opportunities to participate in decisions. Setout (2001) reminds us that while inclusion is not required, it is necessary to utilize a team to determine the least restrictive environment for the child.

“It’s important for inclusion to have shared decision-making,” according to a regular classroom teacher in this study. She further stated, "I think everyone has to buy into it and I think people are more willing to do that if they feel like they were in on the decision-making than if someone just says, we're doing it.” It was recommended by Will (1986) that to improve the education of students with learning problems in the regular education setting, general educators should take greater responsibility for students who have learning problems. Janney, Snell, Beers, and Raynes (1995) attributed successful 
integration of special needs students into regular classrooms to a team approach and support offered by their principals. A team approach and principal support were both substantiated by the teachers' comments in this case study. As one teacher said, “The outcome of shared decision-making at this school is to get the best possible situation going for that child.” Another teacher commented, "Regular classroom teachers are included by giving input into scheduling the student.”

\section{Shared Decision-Making Resolving Barriers for Inclusion}

A testimony to the benefits of inclusion for all students is revealed with the report, "Sometimes even the gifted kids learn from special needs students how to do something in a different way." A confirmation of the purpose for inclusion is indicated by a regular education teacher saying that the reason for inclusion is wanting special needs students “...to have a whole and well-rounded education instead of being separated and feeling different.”

Problems exist with the implementation of inclusion because of lack of training for teachers and lack of administrative support, according to Crockett and Kauffman (1998). This study confirms the teachers' feelings of inadequacy concerning training and knowledge by teachers wanting to know more about disabilities, with lack of training being identified by five of the six teachers as a barrier to inclusion. However, support by the principal in this case study is indicated with statements such as, "The principal was right there and got something done” and "Our principal is involved with the IEP meetings and in the process.” Literature confirms that the principal's support is key to effective inclusionary practice (Rude \& Anderson, 1992).

While Nolet and McLaughlin (2000) recommend that all teachers become skilled 
at making accommodations in order to be able to demonstrate that all students can make meaningful progress in the general curriculum, a study by Scruggs and Mastropieri (1996) indicated that teachers surveyed responded that they lacked the skills or training to modify instruction, much like the teachers in the current study when they requested more strategies and techniques. Bateman (1992) agrees that there are too few teachers adequately trained in effective teaching practices.

The analysis of the IEP (Individualized Education Program) modifications indicates that only $18 \%$ of the fifty-four modifications listed were recalled by the interviewed teachers. This lends support to the study by Schumm and Vaughn (1992) in which it was determined that teachers in the general education classroom rarely used the special education student's IEPs. In this current study, three of the six interviewed teachers indicated that they could not think of any modifications that would help students that they weren't already doing. However, they recalled very few of the modifications that were listed on IEPs for students in their class.

Lack of time to collaborate with special and regular educators together was indicated by comments about teachers needing “...time for special educators and regular educators to talk together.” Graden and Bauer (1991) emphasize that inclusive education cannot be successful without collaboration since inclusion is predicated on professionals working together for the purpose of improving the education of all students in the school. Collaborative time for teachers to undertake and sustain school improvement may be more important than equipment or facilities or staff development, according to Fullan and Miles (1992). As one of the teachers in this study said, "We need more training about disabilities and how to teach them.” 


\section{Regular Educators Included in the Decision-Making Process}

One teacher specifically expressed the sentiment, "There needs to be time when the regular classroom and special education teachers can spend together.” Wasley (1994) explains that in shared decision-making, the emphasis is on collaboration, consensus surrounding goals, and shared responsibilities. The interviewed teachers indicate this with the following statements: “Team planning allowed time to discuss necessary changes.”; “...need more time that we can just sit and share with one another - that would be ideal”; "We need team planning back to have time to share ideas.”; and, "We need shared time together to discuss students so special education teacher can make suggestions if classroom teacher is having problems and to share strategies that work for that child."

A teacher reporting, “The teacher has input about what’s going on and we sit down as a team to decide what's best for the student” supports the idea of shared decision-making. As one teacher reported, "Shared decision-making improves inclusion because everybody has a different opinion and everybody sees a child differently.” Getting together and discussing those differences to provide the best services benefits the child. Regular educators share in decisions that assist in implementing inclusion within this school at SAT and IEP meetings by scheduling and planning for curriculum, with modifications through collaboration, and by determining what's best for the students.

Implications for the School

Teachers are requesting training and knowledge about characteristics of disabilities, strategies, and techniques to better instruct special needs students, as well as asking for methods to implement inclusion practices in their classrooms. The means 
to provide inclusion training could be obtainable through funding with grants. Pursuing this in the spring preceding the next school year will allow for staff development at the outset of the school year as the teachers are beginning to schedule students and plan the new year.

While teachers are being resourceful in developing ways to help students be successful in classrooms, the actual modifications on students' IEPs are possibly not being followed. Instead of interpreting this as little correlation between what teachers should be doing and what they are doing, an alternative explanation could be that the regular classroom teachers do know the students better, as they suggest. Therefore, more collaboration within SAT and IEP meetings could lead to further modifications being placed on the IEPs as recommended by the regular classroom teachers since they have many suggested modifications that would benefit students. By communicating at the IEP meetings what the students' needs are and ways to help the student in the classroom, the regular education teachers will help to create more beneficial IEPs for students. Collaboration and team-building are prerequisites to meaningful change in service provision.

Finding time for regular and special educators to collaborate becomes the responsibility of the principal. Although this will be a challenge, indications are that this would be a worthwhile endeavor that would increase opportunities for shared decisionmaking, which would help to resolve barriers to inclusion and improve inclusion practices within this school. The benefits of this have been demonstrated within this case study and substantiated by research. 


\section{Implications for the County}

While education providers can’t get away from accountability and the standardsmovement, using available information to improve education for all students should remain the goal for county school systems. Given the fact that schools are mandated to decrease the number of students in the bottom quartile, it becomes more relevant when teachers are asking for training to better instruct students. Continuous assessment yields scores that are measurable and can be improved through providing relevant information to classroom teachers on how to instruct required content material by using modifications that make important information available to students with and without disabilities. Students learning better makes it worthwhile for the county to provide for increased teacher training within the county budget. Supporting the school in finding creative ways to provide time for teachers to collaborate to utilize shared decision-making will improve the practice of inclusion within individual schools. According to Conzemius and O'Neill (2001), without collaboration our knowledge and data will go unused.

\section{Implications for the State}

It is important for policy-makers at the state level to understand the relevance of providing better instruction for all students. Besides increasing test scores, the Five-Year Strategic Plan contains goals and objectives toward decreasing the number of students referred for testing for possible placement in special education. Implementing relevant modifications within a classroom and improving curriculum within a school and county can increase success for students prior to referrals. Counties cannot be expected to accomplish their goals for students without additional resources being made available to provide schools with the capability to impart time for shared decision-making and 
collaboration for inclusion purposes.

\section{Suggestions for Replicating the Study}

The purposes for this study, to determine how shared decision-making can impact inclusion and how regular educators are included in the decision-making process, as well as how shared decision-making resolves barriers for inclusion, can be analyzed in a setting in which inclusion is in place. The design of this case study is not to make inclusion work, nor to determine if inclusion by itself is effective. This descriptive case study was used to determine how much of an effect, according to these regular educators, shared decision-making has on the implementation of inclusion in this school.

A further study could determine if actual progress was being made by the special needs students within their inclusive settings or to determine what might help the implementation of inclusion beyond shared decision-making. Therefore, for the purposes of this study, having inclusion in place would be necessary before attempting replication of this study. This study was to determine if shared decision-making is impacting inclusion, not to determine if shared decision-making is part of the school or if inclusion is occurring within federal guidelines. Further studies could assist in determining these issues. However, knowing how shared decision-making impacts inclusion is relevant from an educational leader's perspective because, as previous research indicates, people are more likely to practice what they have participated in deciding. While it is important to know if inclusion is working, it was more relevant for this study to determine the impact that shared decision-making is having on inclusion in this setting.

\section{Summary}

The supporting data from this case study indicates that while teachers feel positive 
about shared decision-making, they want more time for collaboration and sharing ideas. Positive feelings about inclusion are indicated by teachers despite continued concerns about modifications and ways to help special needs students. The six teachers interviewed for this case study had a combined 144 years of experience with a range of 17 to 30 years, yielding an average of 24 years of experience. This might lend itself to a further study of a comparison between experienced teachers, such as these, to teachers newer to the field of education. Does it take experience to recognize a need for collaboration and for providing for all students? This would require a broader study than the current one, but would lead to possible implications for further educational training in undergraduate programs.

The current study was limited only by the grade-level range of the teachers interviewed. A more extensive study including a regular classroom teacher from each grade level through middle school and high school might yield different information and results concerning shared decision-making and inclusion. Do teachers at the secondary level acknowledge a need for more time for collegiality, or is this need satisfied by the dynamics of high schools, such as through department meetings?

However, the current study conducted in one rural elementary school supports what researchers have recognized, how educational leaders interpret the principles of Least Restrictive Environment has a significant effect on how schools are structured and classrooms designed to address the needs of all students (Crockett and Kauffman, 1998). Further, this case study provides in-depth information that was made available through interviewing teachers with whom the interviewer had established rapport by serving on committees, being in IEP meetings, and being present in team meetings. This rapport 
could not have been easily established by an outsider interviewing teachers with whom she or he had not worked. The comfort level of being interviewed by a familiar person who had been at the school with them when it opened two years ago lent itself to candid and honest opinions and perceptions that yielded the unitized data.

The primary recommendation that might be suggested to this school is to find time in the schedule for regular and special educators to meet on a regular and on-going basis. This could lead to sharing suggestions that would potentially further benefit special needs students during the implementation of inclusion. While time is a valuable commodity, Fullan and Miles (1992) suggest that collaborative time for teachers to undertake and sustain school improvement may be more important than equipment or facilities or staff development.

There is a continuing need to understand the importance of shared decisionmaking and the beneficial implementation of inclusion for students with disabilities. Further investigation of these topics will improve theory, research, and practice for instruction that will benefit all students. 


\section{REFERENCES}

American Psychological Association. (2001). Publication manual of the American Psychological Association (5 ${ }^{\text {th }}$ ed.). Washington, DC.

Apodaca-Tucker, M. T., Slate, J. R., \& Brinson, K. H. (2001, May). Shared decisionmaking: Beliefs and practices of principals at the U.S./Mexico border. International Electronic Journal for Leadership in Learning 5 (7). Retrieved 1/7/2004 from http://www.ucalgary.ca/ iejll/volume5/slate.html

Baker, J. M., \& Zigmond, N. (1995). The meaning and practice of inclusion for students with learning disabilities: Themes and implications from the five cases. The Journal of Special Education, 29 (2), 163-180.

Bateman, B. (1992, January). Learning disabilities: The changing landscape. Journal of Learning Disabilities, 25 (1), 29-36.

Belenky, M. F. (1992, October). Bringing balance to the classroom or workplace, paper presented at the Wisconsin Women’s Studies Conference, Preconference Workshop, Green Bay, WI. In P. Maykut \& R. Morehouse, 1996, Beginning qualitative research: A philosophic and practical guide (p. 44). Bristol, PA: The Falmer Press.

Bonstingl, J. J. (2001, January). Are the stakes too high? Principal Leadership, 1 (5), 1-8. Carnine, D. W., \& Kameenui, E. J. (1990, March). The general education initiative and children with special needs: A false dilemma in the face of true problems. Journal of Learning Disabilities, 23 (3), 141-148.

Chernow, F. B., \& Chernow, C. (1992). Elementary principal’s complete handbook: Practical techniques \& materials for inservice administrators. Englewood Cliffs, NJ: Prentice Hall. 
Clift, R. T., Veal, M. L., Holland, P., Johnson, M., \& McCarthy, J. (1995). Collaborative leadership and shared decision making: Teachers, principals, and university professors. New York, NY: Teachers College Press.

Cohen, M. (1993). The politics of special ed. The Special Educator, 8, 266.

Conzemius, A., \& O’Neill, J. (2001). Building shared responsibility for student learning. Alexandria, VA: Association for Supervision and Curriculum Development.

Crockett, J. B., \& Kauffman, J. M. (1998). Classrooms for students with learning disabilities: Realities, dilemmas, and recommendations for service delivery. In B. Y. L. Wong (Ed.), Learning about Learning Disabilities ( $2^{\text {nd }}$ ed.) 489-525. San Diego, CA: Academic Press.

Crockett, J. B., \& Kauffman, J. M. (1999). The least restrictive environment. Mahwah, NJ: Lawrence Erlbaum Associates, Publishers.

Cuban, L. (1990). Reforming again, again, and again. Educational Researcher, 19 (1), 3-13.

David, J. L. (1996, January). The who, what, and why of site-based management. Educational Leadership, 53 (4), 4-9.

Elrich, M. (1996). Order and learning, individuals and groups: A regular education teacher’s response. In D. Speece \& B. Keogh (Eds.), Research on classroom ecologies: Implications for inclusion of children with learning disabilities, 191202. Mahwah, NJ: Lawrence Erlbaum Associates.

Erickson, F. (1996). Inclusion into what? Thoughts on the construction of learning, identity, and affiliation in the general education classroom. In D. Speece \& B. Keogh (Eds.), Research on classroom ecologies: Implications for inclusion of children with 
learning disabilities (pp. 91-10). Mahwah, N. J.: Lawrence Erlbaum Associates.

Friend, M., \& Cook, L. (1990). Collaboration as a predictor for success in school reform. Journal of Educational and Psychological Consultation, 1 (1), 69-86.

Friend, M., \& Cook, L. (1992). Interactions: Collaboration skills for school professionals. White Plains, NY: Longman.

Fuchs, L. S., Fuchs, D., Hamlett, C. L., Phillips, N. B., \& Bentz, J. (1994). Classwide curriculum-based measurement: Helping general educators meet the challenge of student diversity. Exceptional Children, 60, 518-537.

Fullan, M. (2001). Leading in a culture of change. San Francisco, CA: Jossey-Bass.

Fullan, M. G., \& Miles, M. B. (1992). Getting reform right: What works and what doesn't. Phi Delt Kappan 73 (10), 745-752.

Gajria, M., Salend, S. J., \& Hemrick, M. A. (1994). Teacher acceptability of testing modifications for mainstreamed students. Learning Disabilities Research and Practice, 9 (4), 236-243.

Glickman, C. D. (1993). Renewing America's schools: A guide for school-based action. San Francisco, CA: Jossey-Bass.

Goodlad, G. I. (1984). A place called school: Prospects for the future. New York, NY: McGraw-Hill.

Gottlieb, J., Alter, M., Gottlieb, B. W., \& Wishner, J. (1994). Special education in urban America: It's not justifiable for many. Journal of Special Education, 27, 453-465.

Graden, J. L., \& Bauer, A. M. (1991). Using a collaborative approach to support students and teachers in inclusive classrooms. In St. Stainback \& W. Stainback, Curriculum considerations in inclusive classrooms: Facilitating learning for all 
students (pp. 85-100). Baltimore, MD: Paul Brookes Publishing Company.

Hitchcock, C., Meyer, A., Rose D., \& Jackson, R. (2002, November/December).

Providing access to the general education curriculum: Universal design for learning.

Teaching Exceptional Children, 35 (2), 8-17.

Janney, R., Snell, M., Beers, M., \& Raynes, M. (1995). Integrating students with severe disabilities into general education classes. Exceptional Children, 16, 425-439.

Johnson, L. J., \& Pugach, M. C. (1992). Continuing the dialogue: Embracing a more expansive understanding of collaborative relationships. In W. Stainback \& S. Stainback, Controversial issues confronting special education (pp. 215-222). Needham Heights, MA: Allyn and Bacon.

Kauffman, J. M. (1993, September). How we might achieve the radical reform of special education. Exceptional children, 60 (1), 6-16.

Kauffman, J. M. (1996). Research to practice issues. Behavioral Disorders, 22 (1), $55-60$.

Kauffman, J. M., Gerber, M. M., \& Semmel, M. I. (1988). Arguable assumptions underlying the regular education initiative. Journal of Learning Disabilities, 21, $6-12$.

Lashaway, L. (1996). The limits of shared decision-making. Eugene, OR: ERIC Clearinghouse on Educational Management. (ERIC Document Reproduction Service No. ED397467.

Lieberman, A. (1992). School/university collaboration: A view from the inside. Phi Delta Kappan, 74, 147-155.

Liontos, L. B. (1994, March). Shared decision-making. Eugene, OR: ERIC 
Clearinghouse on Educational Management. (ERIC Document Reproduction Service No. ED368034)

Lipsky, D. K., \& Gartner, A. (1987, September). Capable of achievement and worthy of respect: Education for handicapped students as if they were full-fledged human beings. Exceptional Children, 54 (1), 69-74.

Livingston, M. J., Slate, J. R., \& Gibbs, A. (1999). Shared decision-making and practices of rural school principals, Rural Educator, 21 (1), 20-26.

Lombardi, T. P. (Ed.). (1999). Inclusion: Policy and Practice. Bloomington, IN: Phi Delta Kappa Educational Foundation.

Martin, E. W. (1995). Case studies on inclusion: Worst fears realized. Journal of Special Education, 29 (2), 192-199.

Maykut, P., \& Morehouse, R. (1996). Beginning qualitative research: A philosophic and practical guide. Bristol, PA: The Falmer Press.

Meadows, B. J., \& Saltzman, M. (2002, March). Shared decision-making: An uneasy collaboration. Principal, 81, (4), 41-48.

Murphy, J. (1995, Summer). Insights on the context of full inclusion from a non-special educator. Journal of Special Education, 29 (2), 209-211.

Murphy, J., \& Beck, L. G. (1995). School-based management as school reform: Taking stock. Thousand Oaks, CA: Corwin Press, Inc.

National Association of State Boards of Education. (1992). Winners all: A call for inclusive schools. Alexandria, VA.

National Center on Educational Restructuring and Inclusion. (1994, 1995). National study of inclusive education. In D. K. Lipsky \& A. Gartner, (1998, October), 
Taking inclusion into the future. Educational Leadership, 56 (2).

Newmann, F., \& Wehlage, G. (1995). Successful school restructuring: A report to the public and educators by the center on organization and restructuring of schools. Washington, D.C.: American Federation of Teachers. (ERIC Document Reproduction Service No. ED387925.

Nolet, V., \& McLaughlin, M. J. (2000). Accessing the general curriculum: Including students with disabilities in standards-based reform. Thousand Oaks, California: Corwin Press, Inc.

Parson, S. R. (1999). Transforming schools into community learning centers. Blacksburg, VA: Eye on Education, Inc.

Pugach, M. C., \& Wesson, C. (1990). Supporting the participation of exceptional students in today’s classrooms. In E. L. Meyer (Ed.), Exceptional children in today's schools ( $2^{\text {nd }}$ ed.), (pp. 75-105). Denver, CO: Love.

Raynes, M., Snell, M., \& Sailor, W. (1991, December). A fresh look at categorical programs for children with special needs. Phi Delta Kappan, 73, 326-331.

Riley, R. (1995, April). Statement by U. S. Secretary of Education, R. W. Riley to National Catholic Educators Association, Cincinnati, Ohio. Retrieved November 9, 2003, from http://www.ed.gov/Speeches/04-1995/catholic.html

Roberts, R., \& Mather, N. (1995). The return of students with learning disabilities to regular classrooms: A sellout? Learning Disabilities Research and Practice, 10 (1), 46-58.

Rothstein, R. (1990, November). Shared decision making - the first year. Los Angeles: Los Angeles Unified School District, Independent Analysis Unit. 
Rude, H. A., \& Anderson, R. E. (1992). Administrator effectiveness in support of inclusive schools. CASE in POINT, 7 (1), 31-37.

Salend, S. J. (1994). Effective mainstreaming: Creating inclusive classrooms ( ${ }^{\text {nd }}$ ed.). New York: Macmillan.

Salend, S. J., \& Duhaney, L. M. G. (1999). The impact of inclusion on students with and without disabilities and their educators. Remedial and Special Education, 20, 114-126.

Schlechty, P. C. (1997). Inventing better schools: An action plan for educational reform. San Francisco, CA: Jossey-Bass.

Schulte, A. C. (1996). Remediation and inclusion: Can we have it all? In D. Speece \& B. Keogh (Eds.), Research on classroom ecologies: Implications for inclusion of children with learning disabilities (pp. 203-210). Mahwah, NJ: Lawrence Erlbaum Associates.

Schumm, J. S., \& Vaughn, S. (1992). Planning for mainstreamed special education students. Exceptionality, 3, 81-90.

Schmoker, M. (1999). Results: The key to continuous school improvement. Alexandria, VA: Association for Supervision and Curriculum Development.

Scruggs, T. E., \& Mastropieri, M. A. (1996). Teacher perceptions of mainstreaming/ inclusion, 1958-1995: A research synthesis. Exceptional Children, 63, 59-74.

Sergiovanni, T. J. (1992). Moral leadership: Getting to the heart of school improvement. San Francisco, CA., Jossey-Bass.

Sergiovanni, T. J. (1994). Building community in schools. San Francisco, CA: Jossey-Bass. 
Setout, K. S. (2001, November). Does federal law require inclusion? In T. Waddle, Inclusive education. Retrieved January 1, 2004, from http://homepages.wmich.edu/ t1waddle/ed310.htm

Shepherd, T. L., \& Brown, R. D. (2003). Preclusion: The solution to the inclusion confusion. Retrieved November 15, 2003, from http://www.ed.wright.edu/ prenick/article_sheperd.htm

Smith, A. (1999). Systemic education reform and school inclusion. In T. P. Lombardi (ed.), Inclusion policy and practice (pp. 27-34). Bloomington, IN: Phi Delta Kappa Educational Foundation.

Stake, R. E. (1995). The art of case study research. Thousand Oaks, CA: Sage Publications, Inc.

Straus, J. A. (1996). The impact of total quality management on student achievement and school improvements team performance in an urban elementary setting. Ph.D. Dissertation, Old Dominion University. In P. E. Snowden \& R. A. Gorton, 1998, School leadership \& administration: Important concepts, case studies \& simulations (p. 5). Boston, MA: McGraw-Hill.

Strauss, A., \& Corbin, J. (1998). Basics of qualitative research: Techniques and procedures for developing grounded theory. Thousand Oaks, CA: Sage Publications. U. S. Congress House of Representatives, Committee on Education and Labor. (1975, June 26). $94^{\text {th }}$ Congress, $1^{\text {st }}$ Session. House Report N. 94-332, pp. 132-133. In U. S. Senate, Committee on Labor and Public Welfare, Subcommittee on the Handicapped. (1976). Education of the Handicapped Act as amended through December, 31, 1975. (Report No. 72-611). Washington, DC: U. S. Government Printing Office. 
U. S. Department of Education. (1980). To assure the free appropriate public education of all handicapped children. Second Annual Report to Congress. Education of the Handicapped Act. Washington, DC.

U. S. Department of Education. (1996). Eighteenth annual report to congress on the Implementation of the Individuals with Disabilities Education Act. Washington, DC: Office of Special Education Programs, U. S. Government Printing Office.

U. S. Department of Education. (1997). The Individuals with Disabilities Education Act amendments curriculum. Washington, DC.

U. S. Department of Education. (2003). Twenty-third annual report to Congress on the implementation of the Individuals with Disabilities Education Act. Washington, D.C.

Vaughn, S., \& Schumm, J. S. (1996). Classroom ecologies: Classroom interactions and implications for inclusion of students with learning disabilities. In D. Speece \& B. Keogh (Eds.), Research on classroom ecologies: Implications for inclusion of children with learning disabilities (pp. 107-124). Mahwah, NJ: Lawrence Erlbaum Associates.

Villa, R. A., \& Thousand, J. S. (2003, October). Making inclusive education work. Educational Leadership, 61, 2, 19-23.

Wahl, E., \& Hehir, T. (2000, Summer). Inclusive practices: What special education has to offer whole-school reform. MOSAIC - An EDC Report Series, 2 (3). Retrieved November 9, 2003, from http://main.edc.org/mosaic

Wang, M. C. (1994, June). Access to the curriculum presentation given at the World Conference on Special Needs Education: Access and Quality, Salamanca, Spain. In M. C. Wang \& M. C. Reynolds, 1997, Progressive Inclusion: Meeting New 
Challenges in Special Education, Laboratory for Student Success (LSS) Publication Series No. 3.

Wang, M.C., \& Reynolds, M. C. (1997). Progressive inclusion: Meeting new challenges in special education. Laboratory for Student Success (LSS) Publication Series No. 3. Retrieved October 12, 2000, from http://www.temple.edu/LSS/L97-3.htm

Wasley, P. A. (1991). Teachers who lead: The rhetoric of reform and the realities of practice. New York: Teachers College Press.

Wasley, P. A. (1994). Stirring the chalkdust: Tales of teachers changing classroom practice. New York: Teachers College Press.

West, J. F., \& Idol, L. (1990, January/February). Collaborative consultation in the education of mildly handicapped and at-risk students. Remedial and Special Education, 11 (1), 22-31.

Will, M. C. (1986). Educating children with learning problems: A shared responsibility. Exceptional Children, 52 (5), 411-416.

Wheatley, M. (2000). Good-bye, command and control. In The Jossey-Bass reader on educational leadership (pp. 339-347). San Francisco, CA: Jossey-Bass.

Yell, M. L. (1998). The law and special education. Englewood Cliffs, NJ: Prentice-Hall. Yin, R. K. (2003). Case study research: Design and Methods. Thousand Oaks, CA: Sage Publications, Inc.

Zigmond, N. (1996). Organization and management of general education classrooms. In D. Speece \& B. Keogh (Eds.), Research on classroom ecologies: Implications for inclusion of children with learning disabilities (pp. 163-190). Mahwah, NJ: Lawrence Erlbaum Associates. 
APPENDIXES 


\title{
Appendix A
}

Letter to the Superintendent

April 13, 2004

\author{
Deborah Kuhns \\ 106 Glenwood Street \\ Fairmont, WV 26554
}

Dear

I am writing this letter to obtain permission from the County Board of Education to conduct a research project on inclusion and shared decision-making for my doctoral degree in Educational Leadership at West Virginia University.

Research has indicated a need to resolve the barriers to inclusion of special needs students within the regular classroom. Shared decision-making offers a possible solution for implementing inclusion in public schools. With that need in mind, I would like to interview several elementary classroom teachers with identified special education students to analyze the teachers' needs and determine if shared decision-making would offer assistance to them.

I would like to use the WVEIS system, which lists the identified special education students in the school, to determine the classroom teacher at each grade level who, having the most identified special education students in his or her class, will be interviewed. I will also seek to obtain permission from the principal of Elementary School to work with the special education teachers to obtain summaries from the IEP Writer for the special education students in the school to obtain a general idea of modifications being utilized for inclusion.

I have made application for Exemption to West Virginia University’s Institutional Review Board to conduct this case study. I will explain to the teachers that their participation in my study is entirely voluntary and that although their responses during the interviews will be tape recorded for data analysis purposes, they will not be evaluated as part of the evaluation process for professionals by expressing their opinions about inclusion. The design of the study is to extract the teachers' opinions about shared decision-making and inclusion.

Thank you for your consideration and anticipated consent regarding this research study.

Professionally, 


\section{Appendix B}

One-Question Questionnaire

Teacher:

Would you be willing to assist me with work on my doctoral dissertation

concerning inclusion? Yes or No

- This will involve several interviews during the summer. (The time and place will be at your convenience).

- Your evaluation as professionals will not be affected if you choose not to participate.

- You will not be judged or evaluated because of your opinions about inclusion.

- A letter of further explanation will be given to you if you are willing to participate.

Please return this to me by tomorrow.

\section{Thank you!}




\section{Appendix C}

Informational Letter

Teacher of Grade Level

I am attempting to obtain volunteers who are willing to assist me with a study concerning inclusion for my doctoral dissertation at West Virginia University. I have determined the classroom teacher from each grade level who has the most identified special education students in his or her class. You are one of those. However, you are free to participate or to decline to participate. Your participation is entirely voluntary and you may withdraw without any obligation or consequence at any time.

Participation in this study does not reflect your current ideas or opinions about inclusion. Nor does not participating affect any professional evaluation. Your responses will be kept confidential except as is necessary to discuss the responses anonymously within my dissertation. You will be referred to as a "grade-level teacher" and not by your given name.

I plan to meet with you during the summer, at your convenience, for interviews. I will need to tape record your responses during the interviews to help my own memory. In the fall I would like to briefly observe in your classroom.

While your participation is entirely voluntary, I appreciate your assistance.

Thank you in advance for your help with my case study.

Respectfully, 


\section{Appendix D}

\section{SUMMARY SHEET (LOG)}

Student:

DOB:

WVEIS:

School code:

School:_ Age: $\_$Meeting Type:

School:__ Age: $\_$Grade:

IEP Date:

Case Manager:

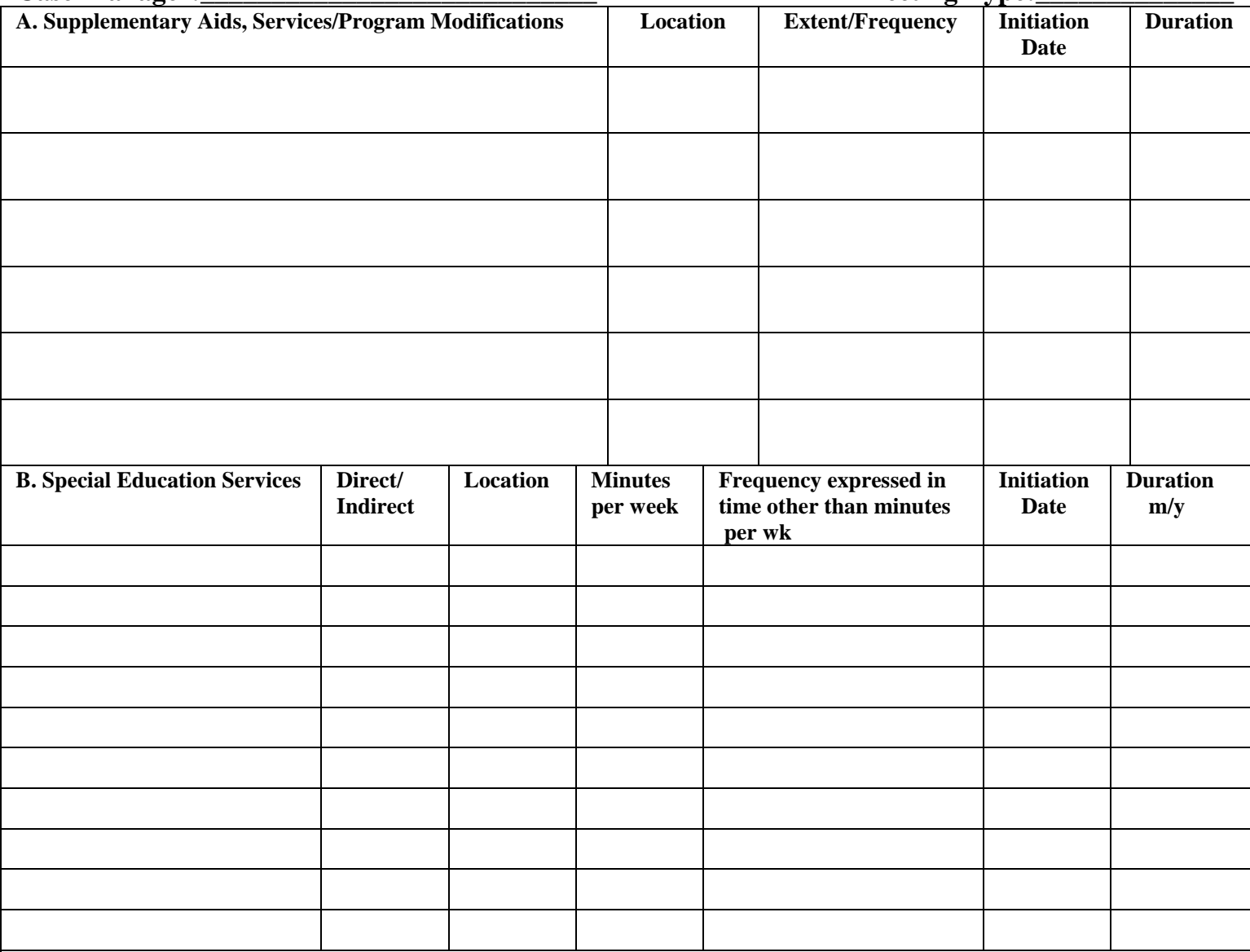

C. Related Services

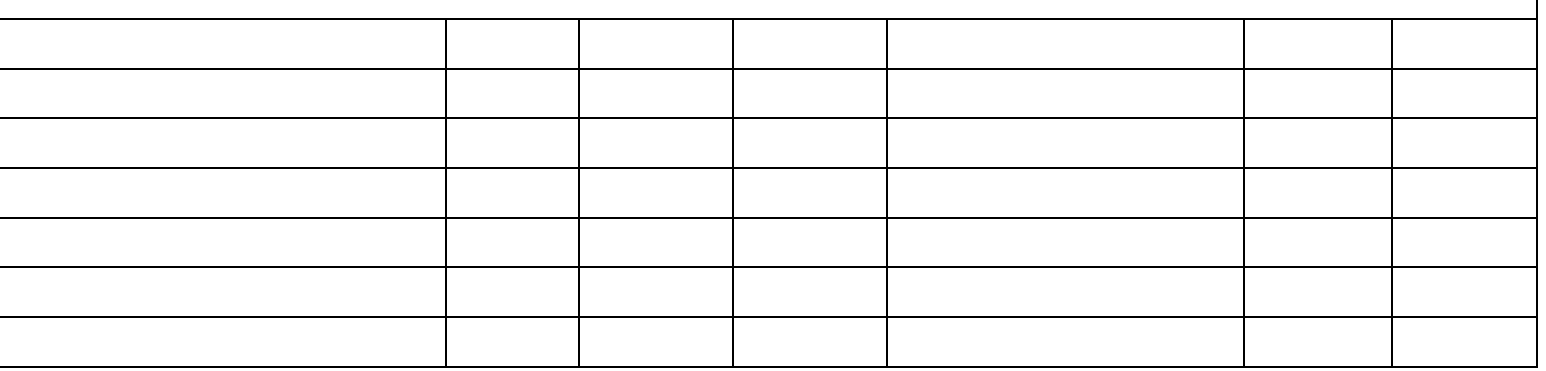

\section{Minutes Per Week in School}

Minutes Per Week in REE

Minutes Per Week in SEE

Minutes Per Week Other

Percentage of time in: Regular Education Environment Special Education Environment Other

\section{PLACEMENT:}

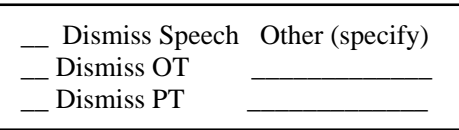

State/County Testing

Standard (no accommodations) _ Yes _ No

Standard w/ accommodations _ Yes No

Non-Standard w/ modifications__ Yes__No

Alternate assessment _ Yes__ No
Extended School Year: __ Yes _ No

ESY hours per week

_ standard diploma

__modified diploma 
Appendix E

Permission from the Principal

April 13, 2004

Deborah Kuhns

106 Glenwood Street

Fairmont, WV 26554

Dear

I am writing this letter to obtain your permission to conduct a research project on inclusion and shared decision-making for my doctoral degree in Educational Leadership at West Virginia University.

Research has indicated a need to resolve the barriers to inclusion of special needs students within the regular classroom. Shared decision-making offers a possible solution for implementing inclusion in public schools. With that need in mind, I would like to interview several elementary classroom teachers with identified special education students to analyze the teachers' needs and determine if shared decision-making would offer assistance to them. I would also like to conduct informal observations in each of the six classrooms.

I would like to use the WVEIS system with its list of identified special education students in the school to determine the classroom teachers at each grade level who has the most identified special education students within his or her class. I plan to then interview those individuals. I would also appreciate having your permission to work with the special education teachers to obtain summary forms from the IEP Writer for the special education students in the school to obtain a general idea of modifications being utilized for inclusion.

I have made application for Exemption to West Virginia University’s Institutional Review Board to conduct this case study. I will explain to the teachers that their participation in my study is entirely voluntary and that although their responses during the interviews will be tape recorded for data analysis purposes, they will not be evaluated as professionals by expressing their inclusions about inclusion.

Thank you for your consideration and anticipated consent regarding this research study.

Professionally, 
Appendix F

IEP Document Analysis Protocol

Teacher of GradeLeve:

Student 1:

First name

Last initial
Exceptionality:

Modifications on this student's IEP:
Student 2:

First name

Last initial

Exceptionality:

Modifications on this student's IEP:

Student 3:

First name

Last initial

Exceptionality:

Modifications on this student's IEP:

Student 4:

First name

Last initial

Exceptionality:

Modifications on this student's IEP:

Student 5:

First name

Last initial

Exceptionality:

Modifications on this student's IEP: 
Appendix F continued

Student 6:

First name
Exceptionality:

Last initial Modifications on this student's IEP:
Student 7:

First name
Last initial
Exceptionality:

Modifications on this student's IEP:

Composite modifications from IEPs

Frequency of of students in this class: modification:

\begin{tabular}{|l|l|}
\hline & \\
\hline & \\
\hline & \\
\hline & \\
\hline & \\
\hline & \\
\hline & \\
\hline & \\
\hline & \\
\hline & \\
\hline & \\
\hline & \\
\hline
\end{tabular}


Appendix G

Table G1

$\underline{\text { Relationship Between Modifications and Interview Questions }}$

Grade: $\quad$ Modifications listed on IEPs: Modifications $\quad$ Modifications

being used in class: not being used:

\begin{tabular}{|c|c|c|c|}
\hline \multirow[t]{9}{*}{ Preschool } & Simplify directions & *Extended time & \multirow[t]{9}{*}{ None } \\
\hline & Keep materials close & \multirow{2}{*}{ *Hand-over-hand } & \\
\hline & Modify or use alternate & & \\
\hline & assignments & *Hands-on & \\
\hline & $\begin{array}{l}\text { Individual help or small group } \\
\text { work }\end{array}$ & \multirow[t]{5}{*}{ *Peer helpers } & \\
\hline & $\begin{array}{l}\text { Vac Pac chair, wedge, standing } \\
\text { table }\end{array}$ & & \\
\hline & Adult assistance (full-time) & & \\
\hline & Shortened school day & & \\
\hline & Limit independent work & & \\
\hline \multirow[t]{7}{*}{ Kindergarten } & Extended time & *Alternative testing & \multirow[t]{7}{*}{ None } \\
\hline & Clarify directions & *Preferential seating & \\
\hline & $\begin{array}{l}\text { Modify to meet performance } \\
\text { level }\end{array}$ & \multirow{5}{*}{$\begin{array}{l}\text { *Closeness to } \\
\text { instructor } \\
\text { *Hands-on } \\
\text { *Use manipulatives } \\
\text { *Pre-preparing work } \\
\text { *Individual work }\end{array}$} & \\
\hline & Test in small group & & \\
\hline & & & \\
\hline & & & \\
\hline & & & \\
\hline \multirow[t]{12}{*}{ First } & Shorten assignments or & \multirow{12}{*}{$\begin{array}{l}\text { Reduced work } \\
\text { *Pair with a peer } \\
\text { *More praise }\end{array}$} & \multirow[t]{12}{*}{ None } \\
\hline & allow extra time & & \\
\hline & Clarify directions & & \\
\hline & Modify to meet ability level & & \\
\hline & $\begin{array}{l}\text { Read test orally and/or accept } \\
\text { oral answers }\end{array}$ & & \\
\hline & Test in small group if needed & & \\
\hline & If test score is below $65 \%$, retest & & \\
\hline & Include class participation in & & \\
\hline & grades & & \\
\hline & $\begin{array}{l}\text { If non-successful, redo } \\
\text { assignment in special ed. }\end{array}$ & & \\
\hline & No grade below $65 \%$ if & & \\
\hline & assignment is attempted & & \\
\hline
\end{tabular}




\section{Appendix G}

Table G1 (continued)

Relationship Between Modifications and Interview Questions

Grade: Modifications listed on IEPs: Modifications Modifications

being used in class: not being used:

\begin{tabular}{|c|c|c|c|}
\hline Second & $\begin{array}{l}\text { Extended time } \\
\text { Clarify directions } \\
\text { Modify to meet performance level } \\
\text { Use mathematical tables, charts, } \\
\text { and calculators } \\
\text { Retest orally as needed/if score is } \\
\text { below } 65 \% \\
\text { Accept oral answers } \\
\text { Extra breaks, extra time, \& } \\
\text { flexible scheduling } \\
\text { Test in small group } \\
\text { No grade below } 60 \% \text { or } 65 \% \text { if } \\
\text { attempted } \\
\text { Include class participation as part } \\
\text { of grade } \\
\text { Preferential seating } \\
\text { Check for on-task \& redirect }\end{array}$ & $\begin{array}{l}\text { Grade on oral } \\
\text { work } \\
\text { Small group work } \\
\text { *Hands-on } \\
\text { activities } \\
\text { *Technology } \\
\text { *Peer tutoring } \\
\text { *Modify grades } \\
\text { *Average oral \& } \\
\text { written grades } \\
\text { Charts in room } \\
\text { *Orally test one- } \\
\text { on-one } \\
\text { *Assess progress } \\
\text { in work stations }\end{array}$ & $\begin{array}{l}\text { Do more } \\
\text { writing } \\
\text { activities and } \\
\text { individually } \\
\text { assess writing }\end{array}$ \\
\hline Third & $\begin{array}{l}\text { Clarify directions } \\
\text { Modify to ability } \\
\text { Retest orally if score below } 64 \% \\
\text { Extended time } \\
\text { Preferential seating } \\
\text { Point out spelling and punctuation } \\
\text { errors but do not penalize for } \\
\text { grading purposes } \\
\text { Dictate lengthy written responses } \\
\text { to scribe } \\
\text { Assignment reduction in all } \\
\text { academic areas }\end{array}$ & $\begin{array}{l}\text { Retest if failure } \\
\text { Reduced work } \\
\text { *Individual help } \\
\text { * Redo } \\
\text { assignments } \\
\text { *Orally test when } \\
\text { needed } \\
\text { * Play games with } \\
\text { entire class } \\
\text { *Hands-on } \\
\text { activities } \\
\text { *Pre-teach } \\
\text { *Use review } \\
\text { sheets }\end{array}$ & Small groups \\
\hline
\end{tabular}




\section{Appendix G}

Table G1 (continued)

$\underline{\text { Relationship Between Modifications and Interview Questions }}$

Grade: Modifications listed on IEPs: Modifications Modifications

being used in class: not being used:

\begin{tabular}{|c|c|c|c|}
\hline Fourth & $\begin{array}{l}\text { Shorten or allow extra time } \\
\text { Clarify directions } \\
\text { Modify to ability level } \\
\text { Read orally and/or accept oral } \\
\text { answers } \\
\text { Test in small group } \\
\text { Retest orally if score below 64\% } \\
\text { Read tests orally in content area } \\
\text { subjects } \\
\text { Include class participation as part of } \\
\text { grade } \\
\text { Provide a scribe for larger written } \\
\text { expression answers } \\
\text { No grade below 65\% if attempted } \\
\text { Grades will be determined together } \\
\text { by classroom and special ed. teacher } \\
\text { Reduced work load } \\
\text { One-on-one tutoring }\end{array}$ & $\begin{array}{l}\text { Read tests orally } \\
\text { Reduced work } \\
\text { *Peer tutoring } \\
\text { Small group } \\
\text { Read assignments } \\
\text { orally } \\
\text { *Individual oral } \\
\text { testing on info. }\end{array}$ & $\begin{array}{l}\text { More small- } \\
\text { group activities }\end{array}$ \\
\hline
\end{tabular}

Note. Additional modifications were stated by the teachers to be what they were using in their classes.

* = a modification named by the teacher that was not listed on their students’ IEPs. 


\section{Appendix $\mathrm{H}$}

Table H1

Preschool - The Impact of Shared Decision-Making on Inclusion

Inclusion

Shared Decision-Making

Impact

Teach included students at a
lower level
Children serve as role-
models and teach other
students
To learn to function in
society

Need a combination of pull-

out and with peers

Need more hands-on in

regular classroom

Learn to the best of their

ability

Sometimes B.D. children

are uncontrollable in a

classroom

Severe \& profound have a

different curriculum

Set up whole environment

for everybody to learn

Use teacher-made tests to

assess

Allow more time, more hands-on and role-modeling
They listened to me and did what I felt was necessary

It's more of a team effort here

Everybody works together

Everybody's opinion is valued

The principal was right

there and got something

done

It's all based on everybody

and we come to a

conclusion

Everybody has a voice and everybody has an opinion

If a problem's brought up,

it's dealt with right there

Talked in leadership

meetings about classrooms

sharing learning

People listen because they

actually respect my opinion

They support me in my

decisions

Our opinion is very

important to everybody

It's a committee decision

with almost everything we do
SAT meetings and IEP meetings are done well never had any problem This school has a good atmosphere - an outsider would feel comfortable in this school

Everybody here listens and collaborates to make a student's setting better The teacher has input about what's going on and we sit down as a team to decide what's best for the student There's no problem as long as everyone continues what they're doing They try to help me if I have a problem Everybody listens so it's just not a one-person thing here

When it comes to the children, it's everybody's decision Place students in classrooms not for the convenience of special education schedules Placement of students in regular classrooms with specific teachers for the benefit of the child who wants the child and can work with them 


\section{Appendix $\mathrm{H}$}

Table H1 (continued)

Preschool - The Impact of Shared Decision-Making on Inclusion

Inclusion Shared Decision-Making

Impact

It's like a table of all educators and we all down and discuss things

If I have a concern or something, everybody listens

When it comes to shared discussions, my opinion is very valuable here The whole environment is set up for everybody to learn Our children with special needs get a very good program here 


\section{Appendix $\mathrm{H}$}

Table H2

Kindergarten - The Impact of Shared Decision-Making on Inclusion

Inclusion

Shared Decision-Making

Impact

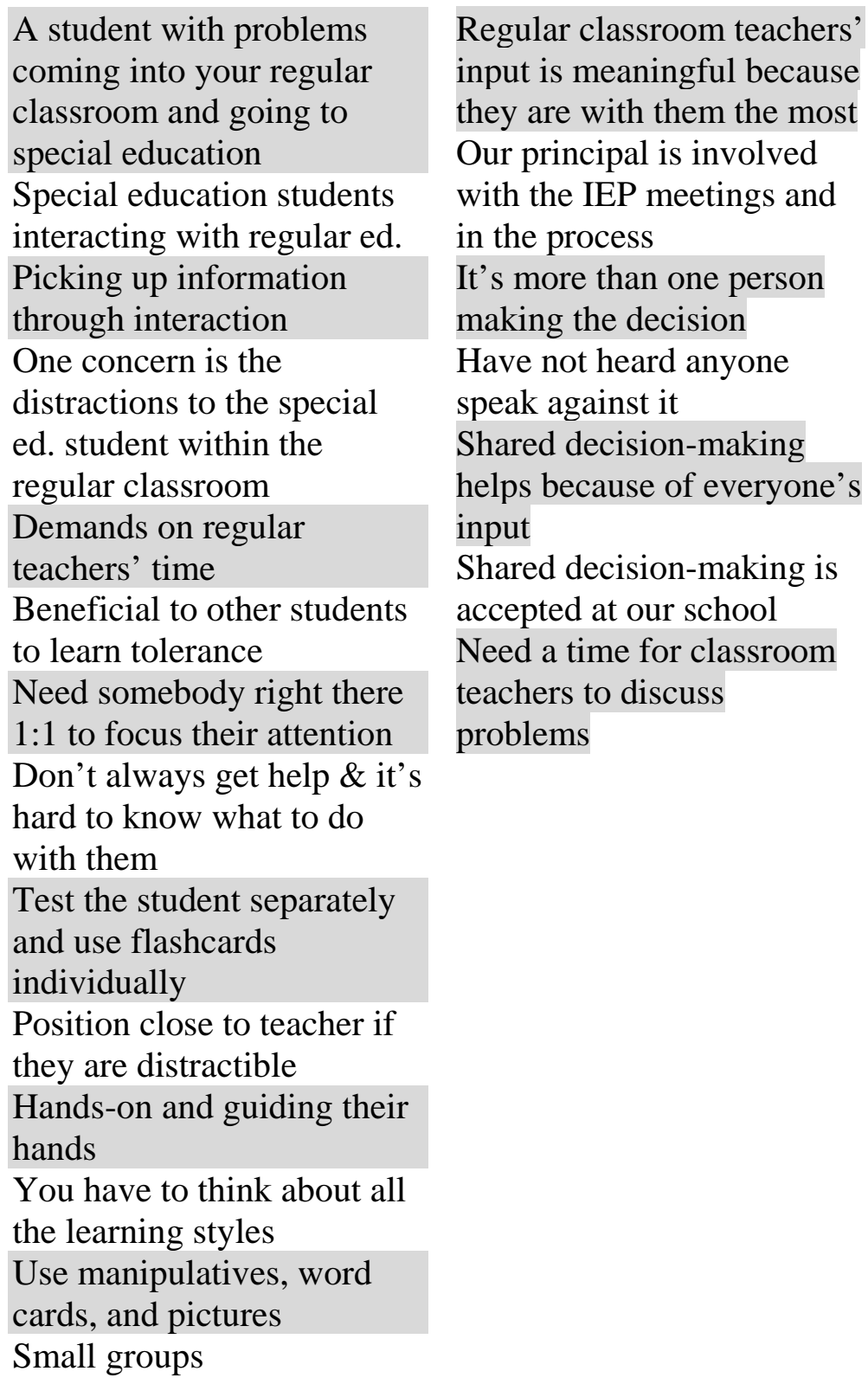

Improve on knowledge of special education children and obtain more information about disabilities The outcome of shared decision-making at this school is to get the best possible situation going for that child Need shared time together to discuss students so special education teacher can make suggestions if classroom teacher is having problems and to share strategies that work for that child

At SAT meetings and IEP meetings we discuss strategies that you would use with that child Get to verbalize at SAT and IEP meetings the academic and social progress the child has made in the regular classroom

All the people that are involved with that student make the decisions At IEP meetings we decide what programs we think the child should be in 


\section{Appendix $\mathrm{H}$}

Table H3

First Grade - The Impact of Shared Decision-Making on Inclusion

Inclusion

Shared Decision-Making

Impact

Kids with special problems included in the regular classroom

Special education teachers help out and coordinate with regular education Inclusion is good and it's working

Students enjoy being part of the whole class

Students with special problems feel a part of the whole school

Special students not being different from the other kids Wanting them to have a whole well-rounded education Special students do not feel separated and different Some benefits to the small groups in special education Students with disabilities sometimes feel less threatened when in special classroom

Behavior problems are a concern when students get frustrated

You have to gear the work down and slow it down

Special students need to try their best and do what they can do

The kids adapt
I have the students more and I know them better Since this school opened, the IEP meetings are better run - the teachers have more input

You feel like a part of it Principal tries to not put all included students in one class

Principal works on schedules so students get phys. ed, music, etc.

Principal works well in meetings to help place students

Leadership team meetings make decisions as a team Worked as a team when writing our reading grant Faculty Senate works as a team to decide on things \& share opinions Need more grade-level team meetings so that we can work as a group to make decisions

You learn to give a little bit Shared decision-making makes you feel important You are worthwhile and you have an opinion
Everybody puts their input in and tries to do best for the child in the situation by coming up with the best decision Shared decision-making improves inclusion because everybody has a different opinion \& everybody sees a child differently

Work as a team and make decisions about kids in IEP meetings

Inclusion allows the classroom teacher to give input into making decisions and to feel important You work harder to achieve the goal because you were a part of it

Work to try to make the transition smoother between the regular classroom and special education Regular ed. and special ed. teachers coordinate, but more time is needed Need more training about disabilities and how to teach them

Need to learn how to use different techniques and work with them Need to schedule so students won't be lost when included 


\section{Appendix $\mathrm{H}$}

Table H3 (continued)

First - The Impact of Shared Decision-Making on Inclusion

Inclusion

Shared Decision-Making

Impact

The brighter kids help the

lower and they all work

together

Inclusion shows all the kids

that everybody can learn

Regular teachers need more

training on inclusion - what

we need \& what is expected

of us

This is so much better than

busing the kids to different

schools

When I see that something's

clicked, I know they've

learned it

I adapt my lesson plans

when I'm teaching the

lesson

Use: special seating

arrangements, eye contact

for attention, reduce and/or

adapt work, pair with a

better reader, and give

praise
Regular classroom teachers are included by giving input into scheduling the student 


\section{Appendix $\mathrm{H}$}

Table H4

Second Grade - The Impact of Shared Decision-Making on Inclusion

Inclusion

Shared Decision-Making

Impact

The kids that would be pulled out are in the regular classroom

Team-teach with special education teachers

Make sure the child accomplishes all they can accomplish

All the kids get some attention - not just the low ones

Special education teacher sometimes pre-teaches During small groups special ed. students are pulled out Kids learn well from other students in regular classrooms

Combination of pre-teach \& pullout \& regular education Special students fit in with other groups when not in special education

Students form good character traits

Students try to improve and work to the best of their ability Autistic kids could cause a problem in the regular classroom

Severe speech is a problem if other kids can't understand them Not-medicated ADHD is a problem if they aren't focused
Regular classroom teacher knows the child best

Can give input about their academic needs Can say what needs to be done and what has or has not worked

Principal is conscious of needs regarding scheduling Principal is fair about placement of children in regular classroom We all get together to discuss and come up with best solution

The more minds the better to think of other things It's one of the best ways to make decisions

Have committees and round-table discussions We need team-planning back to have time to share ideas

Leadership teams were

effective for shared decision-making Helps all the different points of view come together

Attitude is better
Need time when regular education and special education teacher can spend time to talk together Shared decision-making improves inclusion because you have input from other people, which reminds us to look at the other side Shared decision-making has a big effect on inclusion time to get together and discuss to get input from other people to come up with the best solution The grants we received are outcomes of teamwork that turned out well for the whole school

At IEP meetings we have time to talk to the inclusion teacher

Both inclusion and shared decision-making are positive things we do You learn to be understanding of other people because they don't always see the same picture you see

At IEP meetings I give input \& tell them the student's needs and what I think needs to be done and what we've done so far that's worked and what hasn't worked 


\title{
Appendix $\mathrm{H}$
}

Table H4 (continued)

Second - The Impact of Shared Decision-Making on Inclusion

Inclusion

Shared Decision-Making

Impact

\author{
Instruction is the same - \\ just different levels on same \\ activity \\ Use hands-on, peer tutoring, \\ technology, and charts \\ Modify grades according to \\ IEP and grade on oral work \\ Design each lesson so \\ everyone can be successful \\ Peer tutoring is good even \\ for the advanced student \\ Need more writing \\ activities, but that takes a \\ lot of class time \\ Use individual math and \\ reading assessments \\ In stations, look at the \\ progress of their work \\ Provide for the normal and \\ then adapt
}




\section{Appendix $\mathrm{H}$}

Table H5

Third Grade - The Impact of Shared Decision-Making on Inclusion

Inclusion

Shared Decision-Making

Impact

Where all the students are in regular education classes

Special education teachers come in to help them

understand

If student is at a lower level, special ed. pulls them out Special ed. teachers can help regular ed. students also in the class

All students need on-level materials sometimes

All students can hear everything at the same time Can get one-on-one help from special ed. right in the class

Special education helps so that I don't have to water down my stuff

Special students understand so that they can pass tests

Students help other students Modify work but make sure all students get the same basics

Other students don't classify students as special education The good thing about inclusion is that nobody is pointed out Special ed. kids feel like they're included in the class We are all one family in my class
Principal helps when we go to him about any of our students

A group of people make decisions - not me by

myself

Working together lets classroom teachers know what works Special ed. teachers learn how regular ed. teachers teach

I know I can learn everyday

Working together and sharing ideas Shared decision-making is the way to go
Take samples of the students' work to IEP meetings I feel open and comfortable in the IEP meetings In IEP meetings you can come right out and say exactly how the student is doing The IEP meetings are really excellent - they're really good In IEP meetings we accomplish what needs to be accomplished. All that needs to be done is being done now

IEP meetings have improved tremendously since this school opened. It's come a long way Talking and sharing and coming up with a good plan that is best for the student Regular ed. and special ed. working together on what's the best way for the special students to learn Classroom teachers get ideas from special ed. teachers all the time about how to help certain students Shared decision-making is the best thing for the students 


\section{Appendix $\mathrm{H}$}

Table H5 (continued)

Third - The Impact of Shared Decision-Making on Inclusion

Inclusion Shared Decision-Making

Impact

I go around and check on students as they work Everybody's different and no one is the same in my class

Have students repeat

directions and clarify for understanding

Reducing the workload can

still show mastery

Work one-on-one with struggling students

Redo assignments if they

didn't understand

For test failure, redo orally

Give a copy of lesson plans

to special ed. teacher for

pre-teach

Review sheets, games, hands-on, play with the kids, small groups

Can't see any other way to handle inclusion any better
What we're here for is the benefit of the students and to get our students taught Special ed. and regular ed. teachers need time to sit together for a planning period, but now we find a few minutes to discuss if the student's not learning in the regular classroom Special ed. and regular ed. teachers get together at the beginning of the year to determine what is needed for special education teachers to be able to help 


\section{Appendix $\mathrm{H}$}

Table H6

Fourth Grade - The Impact of Shared Decision-Making on Inclusion

Inclusion

Shared Decision-Making

Impact

Students with IEPs being included in the regular ed. program

Students getting special attention by other means \& other teachers

More severe students are pulled out for core subjects Students get to spend time with their peers \& don't feel different

Provide more severe students the same concept but below level Only require them to do what they are capable of doing Read all tests orally for all students

Limit the number of choices on tests

Don't give homework to students who are working below level Students don't seem to notice any difference between students Behavior problems cause difficulty

Does not have any effect on other students' learning

Takes longer to do a concept because you pull it apart

Put students in groups so no one looks like they're getting help
My input is important

because I've had that child and I know what's worked

with that child

Principal tries to schedule

kids so they get as much

help as possible

Placement of students in regular classroom is for students' benefit

People share in making the decisions

The decisions don't rest just on one person

When decisions are made we have discussions and a vote

See more possibilities if more than one person

decides it

More likely to buy into it and it works well and is more effective

People try to make it work when they were a part of the decision

Get a better picture of all of the alternatives By listening to everybody, you have an idea of what might or might not happen You can figure out how to solve any problems together We get together at Faculty Senate and vote and have comments
Need time to spend with special education teachers to know what special ed. does that regular education can try with those kids that are having difficulty learning Need to do more smallgroup activities It would be nice if both this year's and next year's teachers were at the IEP meetings for each child so that we can discuss what works with that child Get to communicate with special education teacher at the IEP meetings

Need more time at the IEP meetings to discuss what you think needs to be done Need to hire more teachers to come in the regular class to help with special education students on noncore subjects

People are more open and willing to work at inclusion and feel good about what comes out of it if they have a say in it

Shared decision-making has an impact on how teachers feel about inclusion - and that's half the battle 


\section{Appendix $\mathrm{H}$}

Table H6 (continued)

Fourth - The Impact of Shared Decision-Making on Inclusion

Inclusion Shared Decision-Making

Impact

Reduce the workload by half

Read tests orally

Peer tutoring helps even the helpers learn different ways of doing things

Do work orally and write answers for them

Help individual students get started to then work independently

As long as they're attempting, reducing the amount of work is not a problem

Consider the lower level when I plan a lesson
Team planning was good for getting everybody's comments

Team planning allowed time for discussing necessary changes

At leadership team meetings you can voice your opinions Leadership team meetings allow input and knowledge about what's going on When Faculty Senate was once a month we had more shared decisions

\section{Shared decision-making} helps with including students and doing lessons and modifications When the regular ed. teacher buys into it, you're three-fourths of the way there because they're willing to do whatever it takes to help that student If they meet each other halfway, they'll be more willing to have a good outlook on the success that they feel that child can get in the regular classroom Scheduling can be done only so many ways Need more realistic goals for really low students We're setting them up for failure if we expect them to do the same things in a classroom with 25 of their peers 


\section{Appendix I}

Table I1

Barriers to Inclusion by Category

Category Grade Barrier

Scheduling Preschool Uneven class distribution of number of special students Need a combination of programs

Kindergarten

First Schedule differently for transition back to class

Second Put all special education students in one classroom

Third

Fourth Scheduling can be done only so many ways

Put all special needs in one classroom

Aren't many choices for scheduling for $4^{\text {th }}$ grade

Staffing Preschool Need more aides

Need smaller caseload

Kindergarten Need 1:1 in class to focus attention

First Inconsistent school psychologists' results

Second

Third

Fourth Rosters are full

Need more teachers to help with inclusion

Responsibilities Preschool Overworked, such as with reading tests orally

Classroom teachers not reading IEPs

Severe students needing more assistance in the class

Kindergarten Demands decrease accomplishments

A lot of preparation for individual students

Time demands

Learning styles need to be considered

First Need to study IEPs

Second Keep files and be organized

Third

Fourth

Environment Preschool Lack of physical space

Kindergarten Distractions

Special education students can cause chaos

Special education students need quiet

Special students interfere with the regular classroom

First Used to be bussed to a different school 


\section{Appendix I}

Table I1 (continued)

Barriers to Inclusion by Category

Category Grade Barrier

\begin{tabular}{|c|c|c|}
\hline \multirow[t]{3}{*}{$\begin{array}{l}\text { Environment } \\
\text { (cont.) }\end{array}$} & Second & $\begin{array}{l}\text { Depends on severity of disability } \\
\text { Non-medicated ADHD don't experience success } \\
\text { Autistic children could cause a problem } \\
\text { Severe speech for communication with other students }\end{array}$ \\
\hline & Third & \\
\hline & Fourth & Lack of space for small groupings \\
\hline \multirow[t]{7}{*}{ Curriculum } & Preschool & Severe and profound need a different curriculum \\
\hline & Kindergarten & \\
\hline & First & Need same reading series in regular and special ed. \\
\hline & Second & \\
\hline & Third & \\
\hline & Fourth & Unjust to give them books they can't read \\
\hline & & Not useable information for some students \\
\hline \multirow[t]{20}{*}{ Modifications } & Preschool & Difficult for non-readers in upper grades \\
\hline & & Having to teach below level leaves out higher kids \\
\hline & & Need more hands-on in regular classrooms \\
\hline & & All modifications are being done \\
\hline & Kindergarten & All modifications are being done \\
\hline & & Some students being bored by moving too slowly \\
\hline & & Challenges of high and low together \\
\hline & First & Try to gear down work \\
\hline & & Work is too hard for some \\
\hline & & I don’t return F papers \\
\hline & Second & \\
\hline & Third & \\
\hline & Fourth & Have to slow down \\
\hline & & Have to teach at a lower level \\
\hline & & Need strategies \\
\hline & & Nonreaders in class are a problem \\
\hline & & Have to read to them \\
\hline & & Need to cover same concepts \\
\hline & & Pulling apart concepts makes them take longer to cover \\
\hline & & Unrealistic goals for really low students \\
\hline \multirow[t]{2}{*}{ Behavior } & Preschool & Sometimes B.D. children are uncontrollable \\
\hline & Kindergarten & I expect them to not interfere \\
\hline
\end{tabular}




\section{Appendix I}

Table I1 (continued)

Barriers to Inclusion by Category

Category Grade Barrier

\begin{tabular}{|c|c|c|}
\hline \multirow[t]{4}{*}{$\begin{array}{l}\text { Behavior } \\
\text { (cont.) }\end{array}$} & First & $\begin{array}{l}\text { Behavior affects class } \\
\text { Students get frustrated }\end{array}$ \\
\hline & Second & \\
\hline & Third & \\
\hline & Fourth & Behavior problems cause difficulty \\
\hline \multirow[t]{10}{*}{ Emotional } & Preschool & Special education students unwanted by some teachers \\
\hline & Kindergarten & \\
\hline & First & Less threatened in special education setting \\
\hline & Second & Attitudes - not open to suggestions \\
\hline & & Unwilling to try new things \\
\hline & Third & \\
\hline & Fourth & Disagreeing with people needs to not be personal \\
\hline & & Mixed feelings about slow students \\
\hline & & Setting students up for failure with same expectations \\
\hline & & No Child Left Behind causes frustration \\
\hline \multirow[t]{15}{*}{ Training } & Preschool & \\
\hline & Kindergarten & Need ideas about what needs to be done \\
\hline & & More knowledge of disabilities \\
\hline & & Characteristics of special needs children \\
\hline & & Hard to know what to do with them \\
\hline & First & Not much training about special ed. in college \\
\hline & & Don't know what other modifications to do \\
\hline & & Didn’t know sign language when I had a deaf boy \\
\hline & & On inclusion - what is expected of teachers \\
\hline & & Need training about disabilities and how to teach them \\
\hline & & Need different techniques to work with them \\
\hline & Second & Don't know what modifications are out there \\
\hline & & Don't have background knowledge of special ed. \\
\hline & Third & Haven’t done small groups as a modification \\
\hline & Fourth & Don't know how to get students to work independently \\
\hline
\end{tabular}




\section{Appendix I}

Table I1 (continued)

Barriers to Inclusion by Category

Category Grade Barrier

\begin{tabular}{|c|c|c|}
\hline ollaboration & $\begin{array}{l}\text { Preschool } \\
\text { Kindergarten } \\
\text { First } \\
\text { Second } \\
\text { Third } \\
\text { Fourth }\end{array}$ & $\begin{array}{l}\text { Need time together for suggestions and strategies } \\
\text { Grade-level teams would help coordinate it all } \\
\text { Regular ed. and special ed. need time to coordinate } \\
\text { Need time together for regular and special ed. teachers } \\
\text { Need team planning to share ideas } \\
\text { Time to sit and share } \\
\text { Need shared planning period for special and regular ed. } \\
\text { Need current, previous, and next teachers at IEPs } \\
\text { Lack of communication } \\
\text { Need team planning for getting everybody's opinions } \\
\text { Time to discuss necessary changes } \\
\text { Time together to discuss students having difficulties } \\
\text { Need more time at IEP meetings }\end{array}$ \\
\hline
\end{tabular}




\section{Appendix J}

Table J1

Regular Educators Included in Shared Decision-Making for Inclusion

Grade Ways Teachers are Included in Decisions

Preschool SAT meetings and IEP meetings are done well - never had any problem The teacher has input about what's going on and we sit down as a team to decide what's best for the student

When it comes to the children, it's everybody's decision

Students are placed in classrooms not for the convenience of special education schedules

Placement of students in classrooms for the benefit of the child It's like a table of all educators and we all sit down and discuss it If I have a concern or something, everybody listens When it comes to shared discussions, my opinion is very valuable here

Kindergarten At SAT meetings and IEP meetings we discuss strategies that you would use with that child

Get to verbalize at SAT and IEP meetings the academic and social progress the child has made in the regular classroom

At meetings we decide what programs we think the child should be in The outcome of shared decision-making at this school is to get the best possible situation going for that child

First Shared decision-making makes you feel important

You are worthwhile and you have an opinion

Everybody puts their input in and tries to do best for the child in the situation by coming up with the best decision

Shared decision-making improves inclusion because everybody has a different opinion and everybody sees a child differently

We work as a team and make decisions about kids in IEP meetings Inclusion allows the classroom teacher to give input into making decisions and to feel important

You work harder to achieve the goal because you were a part of it Work to try to make the transition smoother between the regular classroom and special education

Regular classroom teachers are included by giving input into scheduling the students

Second At IEP meetings we have time to talk to the inclusion teacher

At IEP meetings I give input and tell them their needs and what needs to be done and what we've done so far that's worked and what hasn't worked 


\section{Appendix J}

Table J1 (continued)

$\underline{\text { Regular Educators Included in Shared Decision-Making for Inclusion }}$

Grade Ways Teachers are Included in Decisions

Second Shared decision-making has a big effect on inclusion - time to get

(cont.) together and discuss to get input from other people to come up with the best solution

Third I take samples of the students' work to IEP meetings

In IEP meetings you can come right out and say exactly how the student is doing

Talking and sharing and coming up with a good plan that is best for the student

Regular education and special education working together on what's the best way for the special students to learn

Classroom teachers get ideas from special ed. all the time about how to

help certain students

Special education and regular education teachers get together at the beginning of the year to determine what is needed for special education teachers to be able to help

Fourth Get to communicate with special education teacher at the IEP meetings Shared decision-making has an impact on how teachers feel about inclusion - and that's half the battle

Shared decision-making helps with including students and doing lessons and modifications

Placement of students in regular classroom is for students' benefit 


\section{Appendix K}

Table K1

Positive Indications of Inclusion and Shared Decision-Making

Teacher Comment

Preschool An outsider would feel comfortable in this school because it has a good atmosphere.

Individually assessing students showed me weak areas in my instruction

Kinder. I can't think of any ways to change the way inclusion is implemented. I just know that there's probably a lot of things that I don't know that I should know or could know that would be more helpful.

First The reason for inclusion is wanting them to have a whole and well-rounded education instead of being separated and feeling different. My own daughter learned better and felt more at ease when she had a classroom full of all kids with learning disabilities. She didn't feel threatened and she didn't feel embarrassed if she missed a question. Students think it's neat to help other students.

Second This year when I had special ed. kids in my classroom, I really liked what we did for inclusion. I thought it worked really well.

I think there needs to be a combination of both settings for special ed. students to learn - pulled out for pre-teach and then back into the regular class.

It bothers other teachers if the special ed. teacher can't make it into the class when she was scheduled to be, but it doesn't really bother me because I just fit them in other groups.

When I write my lesson plans I think about how I can design this lesson so that everyone can be successful.

I don't think I know enough about special ed. to know what all modifications are out there. I don't have much special ed. background. I didn't study it.

I think we need to provide for the normal and then adapt what we need to do to help those kids adapt to the normal.

I think there are ways to make inclusion and shared decision-making work positively for the benefits of all.

Third I had a positive experience with inclusion.

A good thing about inclusion is that those special kids feel like they're included in that regular education classroom.

I give the test first to the whole class, \& then one-on-one for some students. I would purposefully go back toward the kids that I know would need it and make sure that they were doing what I'd asked them to do, or if they didn't quite understand something.

If they don't pass a test, then we'd go over it and I'd give it to them again or give it to them orally. 


\section{Appendix K}

Table K1 (continued)

Positive Indications of Inclusion and Shared Decision-Making

Teacher

Comment

Fourth I usually plan a lesson considering the lower level because I feel like those are the students that we have the ability of making the biggest impact on. Those kids that are a little below level have the greatest possibility if we can just get it out of them. These are the kids that I feel like need it the most and are sitting on the fence and can go either way. I target the lesson plans toward them and then adapt it for the other two ends of the spectrum. I think everyone has to buy into it and I think people are more willing to do that if they feel like they were in on the decision-making than if someone just says, we're doing it.

As far as including students and actually doing the lessons and doing the modifications and deciding, I think those sort of things you can do shared decision-making with.

Sometimes even the gifted kids learn from special needs students how to do something in a different way.

The regular students remember something better after teaching it to other students.

When people feel like they had a part in it and they helped make this decision they will try to make it work.

It's important for inclusion to have shared decision-making. 


\section{Appendix L}

Table L1

Emergent Themes In Order by Number of Teachers Responding to Each Theme

\begin{tabular}{|c|c|c|c|}
\hline Theme & $\begin{array}{c}\text { Number of } \\
\text { Teachers } \\
\end{array}$ & $\begin{array}{l}\text { Grade } \\
\text { Level } \\
\end{array}$ & Samples of Comments \\
\hline $\begin{array}{l}\text { Positive } \\
\text { shared } \\
\text { decision- } \\
\text { making }\end{array}$ & 6 & $\begin{array}{l}\mathrm{P} \\
\mathrm{K} \\
1 \\
2 \\
3 \\
4\end{array}$ & $\begin{array}{l}\text { SAT \& IEP meetings are good } \\
\text { Gets best possible situation for students } \\
\text { Work harder to achieve the goal } \\
\text { Have input from other people } \\
\text { Regular ed. \& special ed. working together } \\
\text { Helps with doing lessons and modifications }\end{array}$ \\
\hline $\begin{array}{l}\text { Positive } \\
\text { inclusion }\end{array}$ & 6 & $\begin{array}{l}\mathrm{P} \\
\mathrm{K} \\
1 \\
2 \\
3 \\
4\end{array}$ & $\begin{array}{l}\text { Children serve as role models } \\
\text { Students gain information through interactions } \\
\text { Students enjoy being part of the whole class } \\
\text { All the kids get attention } \\
\text { All students hear everything at the same time } \\
\text { Students spend time with peers and feel the same }\end{array}$ \\
\hline Modifications & 6 & $\begin{array}{l}\mathrm{P} \\
\mathrm{K} \\
1 \\
2 \\
3 \\
4\end{array}$ & $\begin{array}{l}\text { Need more hands-on } \\
\text { Other students being bored } \\
\text { Have to gear work down } \\
\text { Modify grades according to IEP } \\
\text { Modify but make sure all students get the basics } \\
\text { Provide same concept, but below level }\end{array}$ \\
\hline Principal & 6 & $\begin{array}{l}\mathrm{P} \\
\mathrm{K} \\
1 \\
2 \\
3 \\
4\end{array}$ & $\begin{array}{l}\text { Was right there and got something done } \\
\text { Involved with the IEPs } \\
\text { Works on schedules } \\
\text { Conscious of student needs } \\
\text { Helps when we go to him about students } \\
\text { Tries to schedule so kids get as much help as possible }\end{array}$ \\
\hline $\begin{array}{l}\text { Ways to help } \\
\text { students }\end{array}$ & 6 & $\begin{array}{l}\mathrm{P} \\
\mathrm{K} \\
1 \\
2 \\
3 \\
4\end{array}$ & $\begin{array}{l}\text { Individually assessing students } \\
\text { Guiding students' hands } \\
\text { Adapting lessons as I teach } \\
\text { Designing lessons for everyone to be successful } \\
\text { Checking individual students for understanding } \\
\text { Targeting lessons to students a little below level }\end{array}$ \\
\hline
\end{tabular}




\section{Appendix L}

Table L1 (continued)

Emergent Themes In Order by Number of Teachers Responding to Each Theme

Number of Grade

Theme Teachers Level

Samples of Comments

\begin{tabular}{|c|c|c|c|}
\hline $\begin{array}{l}\text { Lack of } \\
\text { training or } \\
\text { knowledge }\end{array}$ & 5 & $\begin{array}{c}\mathrm{K} \\
1 \\
2 \\
3 \\
4\end{array}$ & $\begin{array}{l}\text { About disabilities } \\
\text { About techniques } \\
\text { Need to know more modifications } \\
\text { How to get small groups going } \\
\text { How to get students working independently }\end{array}$ \\
\hline $\begin{array}{l}\text { Need for } \\
\text { more time to } \\
\text { collaborate } \\
\text { between } \\
\text { regular ed.\& } \\
\text { special ed. }\end{array}$ & 5 & $\begin{array}{l}\mathrm{K} \\
1 \\
2 \\
3 \\
4\end{array}$ & $\begin{array}{l}\text { To discuss problems and strategies } \\
\text { For regular and special ed. to coordinate } \\
\text { Time for special ed. and regular ed. to talk toge } \\
\text { Special ed. and regular ed. need time to sit toge } \\
\text { More time at IEP meetings to discuss what nee } \\
\text { be done }\end{array}$ \\
\hline Attitudes & 5 & $\begin{array}{l}P \\
1 \\
2 \\
3 \\
4\end{array}$ & $\begin{array}{l}\text { Find all the details before voicing an opinion } \\
\text { Why some have such an attitude } \\
\text { We need to work on attitude } \\
\text { The problem is adults, not students } \\
\text { Sometimes people are closed }\end{array}$ \\
\hline $\begin{array}{l}\text { Concerns } \\
\text { about } \\
\text { students }\end{array}$ & 5 & $\begin{array}{l}\mathrm{P} \\
\mathrm{K} \\
1 \\
2 \\
4\end{array}$ & $\begin{array}{l}\text { 1:1 aide being territorial } \\
\text { Sometimes chaos } \\
\text { Need smoother transitions } \\
\text { Non-medicated ADHD } \\
\text { Behavior problems cause difficulty }\end{array}$ \\
\hline cheduling & 4 & $\begin{array}{l}\mathrm{P} \\
1 \\
2\end{array}$ & $\begin{array}{l}\text { Uneven distribution } \\
\text { For inclusion purposes } \\
\text { Easier for all special ed. students to be in one } \\
\text { regular class } \\
\text { Placement in specific regular ed. classes is for } \\
\text { students' benefit }\end{array}$ \\
\hline
\end{tabular}




\section{Appendix L}

Table L1 (continued)

Emergent Themes In Order by Number of Teachers Responding to Each Theme

\begin{tabular}{|c|c|c|c|}
\hline Theme & $\begin{array}{c}\text { Number of } \\
\text { Teachers }\end{array}$ & $\begin{array}{l}\text { Grade } \\
\text { Level }\end{array}$ & Samples of Comments \\
\hline
\end{tabular}

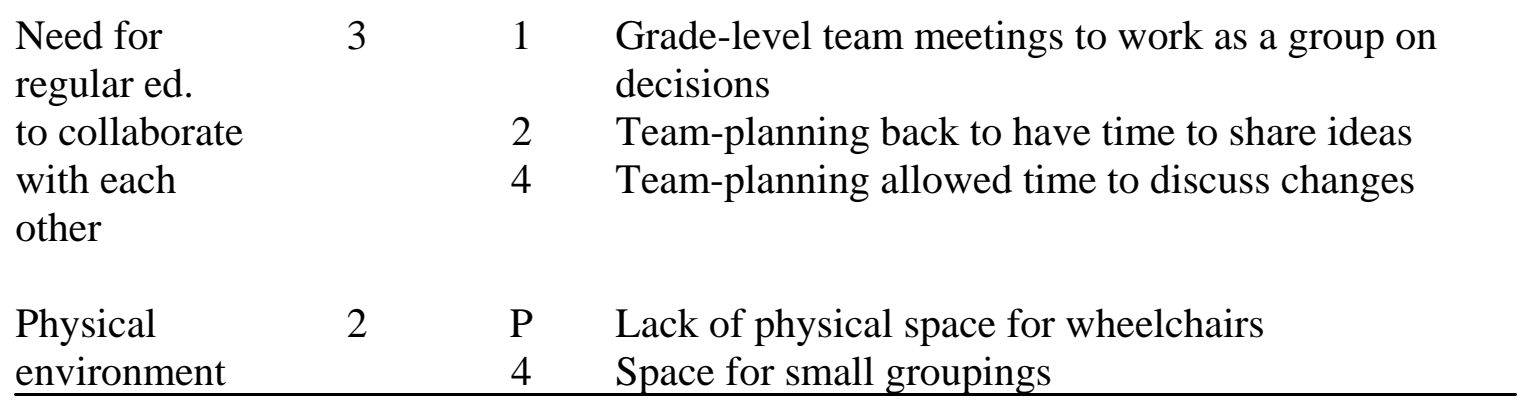


Appendix M

\section{WestVrginiaUniversity}

College of Human Resources and Education

April 29, 2004

\section{MEMORANDUM}

TO: $\quad$ Deborah Kuhns

FROM: $\quad$ Lynn Cartwright Interim Associate vean

RE: $\quad$ Human Resources \& Education H.S. \#2004-033

Title: "Shared Decision-Making and Its Impact on Inclusion for Special Needs Students"

Your Application for Exemption for the above-captioned research project has been reviewed under the Human Subjects Policies and has been approved. Attached is the original of your cover letter with the signed stamp of approval. This must accompany your survey or questionnaire.

This exemption will remain in effect on the condition that the research is carried out exactly as described in the application.

Best wishes for the success of your research.

cc: Deans Office

Student Advising and Records

Paul Chapman, Advisor

Olfice of the Dean 


\section{Appendix N}

\section{Vita}

\section{Deborah E. Kuhns}

I graduated with a B.S. degree in Speech and Hearing Therapy two years before the Individuals with Disabilities Education Act was signed into law. Since that time, I have been involved with special education in various capacities. I earned an M.A. in Learning Disabilities before Individualized Education Programs were implemented. Behavior Manifestations did not exist when I received an M.A. in Behavioral Disorders with a certificate in Autism. Neither was participation by students with disabilities in the general curriculum a concern at that time.

However, when I earned an M.A. in Educational leadership, SAT, Eligibility, and IEP meetings were multidisciplinary with more individuals involved. During the time that I worked toward certification in Mental Impairment, Prior Written Notices to inform parents of what transpired at meetings, which they did not attend concerning their child, were not being written. As the time has arrived for the reauthorization of IDEA, I have completed my Ed. D. in Educational Leadership. More accountability by educators is being required, while eligibility requirements for learning disabilities are changing.

Through my years and experiences as a Speech Therapist, Special Educator, and adjunct University Instructor, there has been a slow evolution toward shared decisionmaking. Although change is inevitable, shared decision-making as a style of leadership will hopefully remain to provide opportunities for collaboration that benefit special needs students. 